A Passion for Policy

Essays in Public Sector Reform 



\section{A Passion for Policy \\ Essays in Public Sector Reform}

Edited by John Wanna

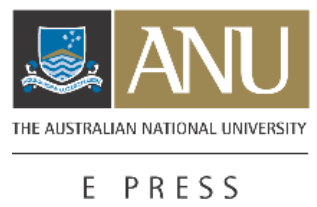




\section{ANU}

E PRESS
School the Australia and New Zealand

School of Government

Published by ANU E Press

The Australian National University

Canberra ACT 0200, Australia

Email: anuepress@anu.edu.au

This title is also available online at: http://epress.anu.edu.au/policy_citation.html

National Library of Australia

Cataloguing-in-Publication entry

Wanna, John.

A passion for policy: ANZOG lecture series 2005-2006.

ISBN 9781921313349 (pbk.).

ISBN 9781921313356 (web).

1. Policy sciences. 2. Political planning - Australia. I.

Australia and New Zealand School of Government. II. Title.

(Series : ANSOG monographs).

320.60994

All rights reserved. No part of this publication may be reproduced, stored in a retrieval system or transmitted in any form or by any means, electronic, mechanical, photocopying or otherwise, without the prior permission of the publisher.

Cover design by John Butcher

Printed by University Printing Services, ANU

Funding for this monograph series has been provided by the Australia and New Zealand School of Government Research Program.

This edition (C) 2007 ANU E Press 


\section{John Wanna, Series Editor}

Professor John Wanna is the Sir John Bunting Chair of Public Administration at the Research School of Social Sciences at The Australian National University. $\mathrm{He}$ is the director of research for the Australian and New Zealand School of Government (ANZSOG). He is also a joint appointment with the Department of Politics and Public Policy at Griffith University and a principal researcher with two research centres: the Governance and Public Policy Research Centre and the nationally-funded Key Centre in Ethics, Law, Justice and Governance at Griffith University. Professor Wanna has produced around 17 books including two national text books on policy and public management. He has produced a number of research-based studies on budgeting and financial management including: Budgetary Management and Control (1990); Managing Public Expenditure (2000), From Accounting to Accountability (2001) and, most recently, Controlling Public Expenditure (2003). He has just completed a study of state level leadership covering all the state and territory leaders - entitled Yes Premier: Labor leadership in Australia's states and territories - and has edited a book on Westminster Legacies in Asia and the Pacific - Westminster Legacies: Democracy and responsible government in Asia and the Pacific. He was a chief investigator in a major Australian Research Council funded study of the Future of Governance in Australia (1999-2001) involving Griffith and the ANU. His research interests include Australian and comparative politics, public expenditure and budgeting, and government-business relations. $\mathrm{He}$ also writes on Australian politics in newspapers such as The Australian, Courier-Mail and The Canberra Times and has been a regular state political commentator on $\mathrm{ABC}$ radio and TV. 



\section{Table of Contents}

Contributors $\quad$ ix

Foreword $\quad x i$

Acknowledgements xiii

Chapter 1. A Passion for Policy - Lynelle Briggs 1

Chapter 2. The Dangers of Complacency: The Case for Reforming Fiscal Policy in Australia — Bob McMullan $\quad 19$

Chapter 3. Beyond Conspicuous Compassion: Indigenous Australians Deserve More Than Good Intentions - Amanda Vanstone 39

Chapter 4. Shaping Opportunities, Creating Public Value: Government and Community Collaboration in the Australian Capital Territory Jon Stanhope

Chapter 5. Twenty-First Century Workforce Demographics and New Challenges for An Egalitarian Society - Sharman Stone

Chapter 6. Australia/New Zealand Public Servants: Mates or rivals? Mark Prebble

Chapter 7. Towards a New Era of Strategic Government - Geoff Gallop

Chapter 8. Recognising Public Value: The Challenge of Measuring Performance In Government — Mark Moore 



\section{Contributors}

Lynelle Briggs, Australian Public Service Commissioner

Professor Geoff Gallop, Graduate School of Government, University of Sydney

The Hon Bob McMullan MP, Shadow Minister for Federal/State Relations, International Development Assistance \& Deputy Manager of Opposition Business in the House

Professor Mark Moore, Director, Hauser Center for Nonprofit Organizations, John F. Kennedy School of Government, Harvard University

Dr Mark Prebble, State Services Commissioner, New Zealand

The Hon Jon Stanhope MLA, Chief Minister for the Australian Capital Territory The Hon Dr Sharman Stone MP, Minister for Workforce Participation

Senator Amanda Vanstone, former Minister for Immigration and Multicultural and Indigenous Affairs, Australian Ambassador to Italy 



\section{Foreword}

This is a special collection of papers, representing a range of views about diverse subjects by people whose opinions matter - not necessarily because they are 'right' or 'wrong', but because they are, for the most part, in the public eye and, most importantly, because they have the capacity to influence the shape and the reality of public policy.

With the exception of Professor Geoff Gallop and Professor Mark Moore, they are not practicing academics. Most, including Geoff Gallop, are either former or serving ministers of state. Two - Lynelle Briggs and Mark Prebble - are senior government officials with deep understandings of the historical and contemporary configurations of the public sectors in Australia and New Zealand, respectively.

All are vitally concerned with issues of policy development, practice, implementation and performance. Each has a story to tell, with insights that can only be drawn by those working at the 'sharp end' of policy. In slightly different ways, all are policy 'insiders', and this gives their views special resonance and relevance.

Jon Stanhope, Amanda Vanstone, Geoff Gallop, Sharman Stone and Bob McMullan may represent different sides of Australian politics, and they might each champion different views about matters of public policy, but they share the experience of shaping, implementing and defending policy decisions. They understand the 'realpolitik' of the policy process better than even the most avid academic commentator on Australian politics. Political realists they may be but, as key actors in the policy process, each has also brought fundamental ideals and values to bear in the formulation of policy.

Lynelle Briggs and Mark Prebble are, respectively, influential in their own right in the national public sectors of Australia and New Zealand. In a way, they are the 'torch bearers' for the traditional values of public service - values of impartiality, quality and timeliness. They also operate at the vanguard of emerging public service values and their leadership is essential in ensuring their respective public service cultures adapt positively and constructively to environmental change. They are both experienced professionals who work in a profoundly political 'industry' and, therefore, what they do is, in a sense, imbued with politics.

Mark Moore, as many will agree, is in a class of his own in such illustrious company. Mark has never been a politician, in the conventional sense of the word. Instead, he is an academic of considerable influence whose ideas have captured the attention and interest of politicians and bureaucrats in his native America and abroad. It is the force of his ideas - his reshaping of the traditional or orthodox narrative of public policy and public service - rather than the nature 


\begin{abstract}
A Passion for Policy
of his office, that wields influence. I believe the full extent of that influence has yet to be realised.

I trust that readers will be provoked, intrigued, challenged (and never bored) by this important collection of ideas. The ANZSOG Public Lecture series provides a unique and important opportunity for people of influence to share their thoughts and impressions in a public forum. This and future collections of ANZSOG public lectures will ensure that their thoughts will reach an even wider audience.
\end{abstract}

Professor John Wanna

Sir John Bunting Chair of Public Administration

ANZSOG, ANU 


\section{Acknowledgements}

The title of this monograph is taken from the public lecture presented by the Australian Public Service Commissioner, Ms Lynelle Briggs, in mid-2005. Her speech resonated with many other officials and other professionals and, over the next few months, her message was cited and repeated in various fora. Her words capture the flavour of these topical public lectures.

The Australia and New Zealand School of Government commenced an annual series of public lectures in February 2005. These were held in Canberra at the Academy of Science. The aim of the lecture series is to make serious intellectual contributions to the direction of public policy and public sector management. In commissioning speakers we intend to strengthen the dialogue between academics and practitioners especially in relation to forthcoming challenges and research agendas. The lectures provide distinguished speakers and opinion-shapers with the opportunity to provoke and stimulate their audiences and present a case for change, reform or renewal. All the lectures in this series were delivered with a strong sense of purpose and conviction. Because of this, the lectures are not only informative and persuasive but also stimulate ongoing debate and continuing dialogue.

In organising these lectures we wish to thank the Academy of Science and the Political Science Program at the Research School of Social Sciences, The Australian National University. The lecture series was organised by ANZSOG staff including Susan Hanson, Jenny Keene, Victoria Redfern, Mary Hapel, Shellaine Godbold, and John Butcher. Postgraduates in Political Science assisted with audio-visual equipment and promotion. The media and communications division at The Australian National University played an important role in promoting the events, as did The Canberra Times. Finally, I would like to thank the various staff who assisted the speakers and helped make the series a success.

Professor John Wanna

Sir John Bunting Chair of Public Administration

ANZSOG, ANU 



\section{Chapter 1 - A Passion for Policy}

\section{Lynelle Briggs, Australian Public Service Commissioner}

\section{Lecture presented 29 June 2005}

I am pleased to speak to you about the need to continue a passion for policy in the Australian Public Service. I assume that having made the time to be here today you share my concern for getting the best policy outcomes for Australia. I hope that at the conclusion of this lecture you will also share my enthusiasm for re-examining where the public service is positioned in the policy environment, and for working out where we need to be, and how to get there - and for re-igniting a passion that goes to the very heart of what we do.

What do I mean when I talk about a 'passion for policy'? For some of you it may seem an unlikely combination of words. You'll be surprised to know, then, that in 1887 Richard Bentley of London published Policy and Passion: a novel of Australian Life. Though dated, it comes close to describing the sense in which I use 'passion' today. 'There is [the author says] a quasi-intellectual passion which in some natures is hardly less potent than that aroused by wine or women.'

On the eve of a combat mission during WWII a young Gough Whitlam demonstrated such a passion in a letter to his wife, thousands of miles away. It was an impassioned argument in support of Curtin's post-war reconstruction and democratic rights referendum. The letter, Laurie Oakes, a parliamentary journalist, later observed, could easily have been addressed to 'the men and women of Australia'. Gough concluded the letter '[y]ou can hardly fail to see that the Commonwealth is better fitted to deal with such nationwide problems. And so to bed. Love, G.'

It is this sort of 'passion' that forms the essence of this lecture. It is an intellectual passion for new thinking, for challenging the status quo - a passion for resolving national problems, problems that are said to be unsolvable. It is a passion for working together, and for working differently.

The areas I want to cover in this lecture that go to make up this passion for new thinking, for resolving problems and for working together, are:

- making policy in a contestable public sector environment;

- the nature of the passion for policy development itself;

- growing the research and policy-making capability in the APS; and

- building whole-of-government policy. 


\section{Policy-making in a contestable public sector environment}

I start by tackling policy-making in a contestable public sector environment.

Once the source of almost all policy advice to the Commonwealth Government, the Australian Public Service now operates in a contestable environment. But I wonder whether most of us really understand the dynamics of that environment, and what its implications are for the Australian Public Service. The notion of a public service providing 'frank and fearless advice' is deeply embedded in our institutional psyche. Yet we stand alongside ministerial advisers, the media, lobbyists, think tanks and interest groups - who are neither supported nor constrained by our values; as providers of policy inputs to government, our virtual monopoly on policy is long gone.

The contestability of 'policy' is part of a more fundamental shift in the public sector environment, and I think it needs to be understood in this context.

As in the OECD, the public sector in Australia over the past 30 years has been continuously adjusting its 'fit' to a changing global society. To a society where economic, social and technological developments have given rise to new problems, new capacities and new relationships between citizens and governments - an environment in which an educated and empowered citizenry hold new and different views about what they expect from their social contract with government.

At the same time, governments have relinquished control of some of their key economic levers by, for example, floating their currencies, opening up their national economies and deregulating their financial systems. They now operate within the constraints of a global economy. Government policy is now delivered through a more devolved set of arrangements, including the privatisation of some areas of government business; a shift from direct service delivery to contracting out and regulation; and the creation of quasi-markets, where the government retains control of some aspects of the market including access, availability, quality, and sometimes even price. This is the policy delivery end of public policy.

At the other end, where policy advice is provided to government, there are at least an equally large number of players. Many are not contracted by or to government and offer their advice on behalf of non-government bodies. Nevertheless, according to author Celia Perkins, the large number of external sources of policy inputs available to government now points to an established market for policy advice. On this basis, she says, policy advice is naturally contestable.

For reasons I will elaborate on shortly, even if we in the bureaucracy could influence a move away from contestability (and I would argue we cannot), I do not believe there would be much reasoned support for it. We do, however, need 
to ask ourselves how we can make the most of our evolving circumstances some are inclined to view contestability as a threat, or worry that the position of the public service is being eroded. I view the situation differently - there are undoubted opportunities here for the public service to capitalise on all of these policy inputs so as to get the best possible policy outcomes - but I do think we need to mobilise our passion for policy - a passion that has always been there - in new ways and in new directions.

\section{A policy advice market}

So, if we accept that there is a policy market, who is in it? The Australian Public Service now stands alongside an extensive range of policy players -ministerial advisers, lobbyists, think tanks and other interest groups - all providers of policy inputs and advice to government. Some specific examples of policy institutes, or think tanks, that are in the field of contest include:

- The Melbourne Institute of Applied Economic and Social Research, which was established in 1962 and takes an interest in social and political issues. It aims to 'foster effective responses to economic and social issues through research that identifies alternative policy responses and quantifies their likely effects'.

- The Australia Institute, based in Canberra, which is a relative newcomer contributing to mainly social, economic and health matters. Its aim is to 'develop and conduct research and policy analysis and to participate forcefully in public debates'.

- The Australian Strategic Policy Institute, which is also based in Canberra, and is prominent in relation to defence issues. Its relationship to government is explicitly stated in its goals, which include providing what it calls 'fresh ideas for government'. The institute intends to be a source of new ideas and innovative solutions for government, both through its published work and through policy analyses specifically commissioned by the government.

- The Sydney-based Lowy Institute for International Policy describes itself as 'an independent, non-partisan, international policy think tank' and concerns itself with international policy. Its objective is to 'deepen the debate in Australia about international policy and to generate new ideas and dialogue on international developments'.

- The Institute of Public Affairs is focused on economic and political issues. It contributes to the policy debate around the environment, deregulation, workplace relations, energy, and governance. Its website declares that on the basis of its research it 'can recommend the best path for ... politicians, policy makers and businesses to take'.

All of these institutes are notionally independent. But in the case of the Australian Strategic Policy Institute and the Australian Institute of Family Studies, among 
others, they were established by the government for the express purpose of doing research and policy work that would inform the government's thinking on particular issues. Other think tanks that are 'independent' of government are nevertheless dependent on commissioned research, often from government, or on the donations of those who support the particular lines of argument that characterise the organisation - be they left wing, right wing or birds of some other feather. It is worth noting, too, that these organisations are often engaged in a 'debate' with one another - an ideological contest, if you like.

\section{NGOs and lobby groups}

Then there is the plethora of Non-Government Organisations (NGOs) and lobby groups that have a specific policy interest. Take for example the NGOs that operate within the policy environment of just one APS agency - the Australian Agency for International Development, or AusAid. There are almost 50 separate organisations in this sector including:

- the Australian Red Cross;

- Australians Caring for Refugees;

- International Needs Australia;

- Adventist Development and Relief Agency; and

- the International Women's Development Agency.

If we extrapolate from here, across all APS agencies and policy areas (and of course the number of NGOs would vary from area to area) we might begin to have a sense of just how many voices are clamouring to be heard by government and who bring their own particular passion for policy. In Barton alone, at the heart of government, there are dozens of NGOs and lobby groups:

- the National Farmers' Federation;

- the Australian Medical Association;

- the Salvation Army;

- the Australian Chamber of Commerce and Industry;

- the Australian Council of Trade Unions; and

- the Motor Traders' Association.

All of these peak lobbyists operate by gaining the attention of - and seeking to influence - Ministers and the bureaucracy. And they are heard. The inclusion of lobby groups in the recent Child Support Ministerial Taskforce reference group demonstrates a determination by the government to deal directly with lobby groups on this issue. The taskforce was chaired by Patrick Parkinson, a professor in the Faculty of Law at the University of Sydney and Chairperson of the Family Law Council. Members of the taskforce reference group included representatives of Unifam, Dads in Distress, the National Council of Single 
Mothers and their Children, the Sole Parents' Union of Australia, the Lone Fathers' Association of Australia, and the Early Childhood Association.

Michael Keating, a former head of the Department of Prime Minister and Cabinet suggests that governments are coy about their relationship with interest groups, because of perceptions of bias and allegations of a 'democratic deficit'. In practice, he says, governments consult closely with their preferred interest groups, but this is at the political level for major policy initiatives - the detail is worked out by the bureaucracy.

Over the last ten years, though, we have witnessed engagement between the public service and stakeholder groups at far earlier stages than ever before. Indeed, there is growing recognition that individual citizens and companies have a contribution to make and are also on the field of policy contest. There is now widespread use of market research techniques and other consultation mechanisms among Australian public service agencies. The extent to which agencies are consulting is revealed in the last State of the Service Report. This report found that 80 per cent of agencies consult with non-government organisations and 90 per cent consult with industry stakeholders when they are developing policy. They also consult with lots of other groups as well. An OECD policy brief argues that 'engaging citizens online raises legitimate expectations that public input will be used to inform policy-making'. The challenge, then, is to ensure that - having engaged an eager citizenry - the promise to listen does not become a hollow gesture, and that action or at least a reasoned response follows, wherever possible. Again, I think that this is an area where the Australian Public Service - drawing on its institutional resources - really does have an advantage.

\section{Ministerial advisers}

We should also not overlook the role of ministerial advisers. Their influence on policy development has drawn comment as far back as the 1970s. Liberal Senator, John Carrick, remarked then on the 'insidious' development whereby advisers - influential, faceless and largely unaccountable - 'prevent the department from giving its authentic and responsible view to the Minister'. As last year's State of the Service Report sets out in detail, the number of advisers has grown here as it has overseas. And the number may continue to grow as the demands for responsiveness - to the media and to the community - grow under the pressure of developments in information and communications technology.

The debate about whether ministers' advisors should have their own more formal accountability arrangements, through a mechanism similar to the APS values and Code of Conduct, is ongoing, and I do not want to go into that in this presentation. It is worth noting, though, that there is some recognition, at both academic and bureaucratic levels, that ministerial advisors should, by taking a 
role themselves in providing political advice, reduce the likelihood that public servants will be asked by their ministers to do things that are verging on the political.

I would argue that what we have to do in the APS, and do well, is make sure our relationships with ministers' advisors work in ways that are consistent with our values and productive to getting the best outcomes. We can not afford to be timid about it, and we need not be if we are clear about the constraints on the relationship and if we work within them - it is a practical application of our values framework.

The same applies to all the other players in the policy advising market, including parliamentary committees. The imperative for the APS, I think, is to focus on our important institutional role - to recognise how we can work together within the bureaucracy, and how we can get the best leverage off the important policy work that is being done beyond our institutional boundaries. We need to press home our competitive advantage.

As public servants, subordinate to statutory obligations, our fundamental advantage is our values, clearly laid out in the Public Service Act. We are a professional public service that provides disinterested, impartial and apolitical advice. By definition we have no barrow to push, no interest group to serve and no profit to make from the policy advice we provide. I am speaking in a broad sense. There are, of course, occasions when agencies have a clash of heads, when their passions or bureaucratic agendas collide. But, so long as we operate within the limits of our values, I think we have a secure position. We have an institutional memory that goes back to Federation and that can assist the government to keep history from repeating itself. We are uniquely placed to weigh up the advice that the government receives from other players, which, as Andrew Podger (the previous Public Service Commissioner) asserts, almost always reflects some sectoral interest or political view.

I would argue, too, that a particular advantage we have in the Australian Public Service, for policy work, and for every other aspect of our business, is our diversity. We have moved on from the equal employment opportunity focus of diversity - although that remains important - to a recognition that diversity is a tangible component of our organisational capability; that we should, so far as is possible, reflect the diversity of the community; and that diverse perspectives should inform our policy-making.

\section{The passion}

Some people would say that there is no place for passion in policy because a good public servant must remain impartial if they are to be responsive to the government of the day. I take issue with this. I believe there is any number of 
good reasons why public servants should be passionate about policy development.

We should be passionate about policy development because our work is critical to the national interest and impacts directly on Australians' lives and their quality of life - their employment, their health, how they pay their tax, their education, and the environment they live in. What we do impacts on the social and economic well being of the country and on our capacity to meet the challenging problems it faces.

We should be passionate about policy because it gives an intellectual buzz. To be good at policy work demands a mix of knowledge, systems thinking, analytical and conceptual abilities, relationship management and a sense of what is possible. It means having a real sense of the Machiavellian. It is a fascinating field to work in - challenging and complex - and because of that, it is incredibly rewarding.

The quality of policy advice can be variable - in terms of whether it is evidence-based; the time available; the facts and the options have been properly worked through; the views of various interested players considered; the impacts and consequences on different groups known and understood; and the costs understood. We are in competition for this market and, given our sporting traditions, we like to win. Passionate pursuit of policy development gives the public service the opportunity to show what it can do!

But I would go even further than that. I think it is of fundamental importance that public sector policy advisers have passion in their bellies - a passionate interest in what research is telling them; a passion for new ideas; a passion for pushing things along and for providing ministers a perspective on 'what's the right thing to do' at any particular point in time. It is this kind of 'sparkle and fire' that drives reform and what really makes a difference.

The reality of day to day government activity is quite different - it is conservative and reactionary - meaning change at the margin or change in response to public pressure. For the most part this is fine, but, in my view, longer-term reform agendas generally emerge only after some really passionate and persuasive arguments are persistently driven by quality public servants (and politicians) who really care.

These are the sorts of public servants I want to encourage - the ones who will run the extra mile; who have the courage of their convictions; who really care about their country and its directions; and who engage actively in the business of government. They are prepared to take the risk of serving challenging agendas up to ministers and pushing them because they matter to us all. More often than not, they will have a lot of public servants quietly supporting them in the backrooms of departments, who also recognise the need for change (and have 
done so for many frustratingly long years), but may not feel that they are in quite the same position to pursue it.

The crux of the issue is that you can be passionate without being partial - a good public servant learns how to manage the policy process well and learns how to take the knocks when the government takes a different direction. That is one of the things that makes our jobs harder and more challenging than most and why we are such a resilient bunch.

Being apolitical does not mean being in a vacuum or an automated cipher; being a colourless unengaged dispassionate entity. To be responsive and to serve the government of the day effectively means being engaged, investing your energy in and being enthusiastic for the policy process. Being passionate does not mean that you have to personally support policy directions in a political way. Nor does it mean that you have to be a zealot, with an uncompromising or partisan approach which treats all other views as heresy. It is about being passionate about the policy process and the ideas; exalting debate and proper change flowing from it; being totally professional and ensuring that the government gets the best possible advice. And it is about being passionate about our role in policy development in a strong democratic environment.

To be a passionate public servant can be risky. It can be dangerous to take a new or different stand and to pursue it passionately. That is why we need to always remember that we need to be responsive too and to keep a healthy distance from the issues at hand. To do that, we need to manage ourselves in a way that maintains a sound perspective on our roles and responsibilities and those of the government of the day to take the decisions. I would be surprised if most of us had not got this wrong at one time or another - we may have pushed too hard, or not let off when we should have, or not covered all our bases. It helps to have experience and an engaging personality and, in the absence of that, friends and bosses to keep us on track. We all learn through experience, but without some fire in our bellies we will not get very far, and nor will the country.

\section{Policy and whole of government working}

While I regard the contestability of policy as unambiguously positive for getting the best outcomes for Australia, it has also generated some issues that the Australian Public Service needs to address. If the public service is to realise its potential (and not just in relation to policy) there is a real imperative to unreservedly adopt whole of government working, beyond the rhetoric, and to make sure that we have the right people in the right jobs with the right skills.

A whole of government approach assumes the need to respond and adapt to the complex and networked environment of modern government that I described earlier - it is about how we remain relevant in a new and fundamentally different 
world. It is not a single instrument, for, say, collaboration on service delivery. Rather it is a cohering principle, necessary to maintain our sense of government as a consolidated entity, a single system that can be worked upon to deliver the outcomes expected by the government and the community.

The term itself is flavour of the month. The reality is that we have to move beyond the rhetoric and start doing it for real (this is being done well in some areas - the new Water Commission is really starting to make some headway with water policy across jurisdictions and boundaries). We need to develop an instinct in the public service for doing things collaboratively, while leveraging off the important work being done beyond our boundaries. The alternative is that we will become irrelevant. This is, or should be, part of our competitive advantage: our capacity to think across all the boundaries of all the portfolios and agencies that support government, and to draw on that unmatched resource of skills and experience.

The dilemma for the public sector is captured well, I think, in a recent book by William Eggers (2005) - Government 2.0: Using technology to improve education, cut red tape, reduce gridlock, and enhance democracy. Eggers argues, essentially, that the public sector is struggling with the shift from government in the industrial age (hierarchical and agency-cantered) to government in the information age (less-hierarchical and citizen-focused). Egger's book is written with reference to the U.S. experience, but some of it resonates here in Australia. Not everyone has cottoned-on to the speed at which things are moving - enabled by technology - and how responsive we need to be to government, to the community, and to each other as policy advisers.

In the past, the outcomes we are now looking to achieve from whole of government activity were mostly pursued through organisational restructuring and machinery of government changes. What is new is that today's whole of government approaches tend to look primarily to the development of organisational cultures, capabilities and relationships that support, model, understand and aspire to whole of government solutions.

The benefits to be had from whole of government working are no greater in any area than in policy development. There is potential here for the Australian Public Service to really press its advantage. We have an institutional framework that will allow us to work collaboratively within the public service, and beyond and we should be actively looking to do that.

A positive move in this direction was made with the issue of a joint communication from myself and all of the 18 portfolio secretaries, titled Working Together. It sets out what is expected of Australian Public Service employees working on whole of government initiatives. The communication emphasises the importance of working across organisational barriers to achieve policy and service delivery objectives. It also outlines some of the significant whole of 
government activity that is already being undertaken - especially at the Senior Executive level - but notes that Australian Public Service employees need to look beyond the immediate interests of their own organisation to the broader context. It goes on to provide practical guidance on ways to achieve the best results from our collective endeavours.

Within the public service we need to recognise that central and line agencies bring different perspectives and different resources to the task of policy development - line agencies are often the custodians of the evidence that should support policy for example, while central agencies may well have a better handle on what the government is looking to achieve from a policy development exercise. We should be looking for the synergies here, rather than, as is sometimes the case, engaging in a contest to determine which source of advice will prevail.

Line agencies are the custodians of the data, the day to day regulators, the people who know what will happen when very complex and sensitive systems are adjusted at critical points. Central agencies are information rich in a context sense: they know what the government wants at a strategic level across a range of portfolios and they have access to ministers and through ministers to money.

Because line and central agencies each bring particular skills and understanding to policy development, the quality or even extent of policy work will suffer when the creative balance between them is lost. There are any number of factors that can shake that balance, from the electoral cycle to Commonwealth-State relations to the personalities of ministers. It is our responsibility to make the relationship work.

\section{Building our capability for research and policy}

There is a related issue that I want to address as part of my argument - capability for doing really worthwhile research, evaluation and policy work that instils an intellectual passion for new thinking in our staff and in government, that challenges the status quo and that potentially resolves national problems.

For some time now I have been concerned that there has been an erosion of the capacity for sound research, evaluation and analysis in some areas of the APS . There are also concerns that the contribution of line agencies may be being marginalised as more and more policy issues are drawn into the centre. Some of our research and dedicated policy areas in line agencies have been cut back, and some of our best policy people are doing great work delivering big programs but are then unable to help young policy analysts and researchers learn the trade.

While this might be an unintended outcome of how we operate in a world subject to resource constraints and driven by the demands of day to day activities, programme management mantras and media management, it is not necessarily always the right long-term answer to those of us who see public service policy 
and research as the cherished core of longer-term government directions and of major new reforms.

I do not think these sorts of problems are insurmountable, but they do require some creative thinking - and a will - at the most senior levels to protect our policy and research base and a willingness in government to appreciate more fully what it can deliver.

I am not alone in my concerns. Academics, Fred Argy (1998), Ian McAuley (2001), David Adams (2002, 2004) and Stephen Bell (2004) suggest that the capacity for research and policy has been reduced in the public sector generally. Adams has pointed specifically to a loss of skills and corporate knowledge in the public service, including as a result of contracting out. McAuley, referring specifically to the public service here in Canberra, says that the 'assets of specialisation, continuity and experience have been lost'. Argy, in a more extreme scenario, sees a future where 'departments will become short term in their focus and that serious policy related research and advice will be left to lobby groups, private consultants and think tanks ...' Bell sees that future as having arrived. There has been, he says, 'an influx of inexpert, relatively policy-ignorant managers versed in the generic corporate techniques of strategic, financial and human resource management'.

In terms of managers being 'versed in the generic techniques of strategic, financial and human resource management', I can assure you all that my secretary and agency head colleagues and I would not have it any other way! They are fundamental skills for the sustainability and viability of the modern public service, and I am sure that the Australian public see it that way too. They know that if the business side of operations do not run smoothly, the core objectives and priorities of any organisation will not be delivered well.

I think it is important that we bring a bit more perspective to the policy and research debate. This country has just come through 25 years of probably the greatest policy reform effort in its history or in comparison with similar periods in other countries - we had a lot to do and we have done it. The economy has opened up, our social policies provide good support, our tax system has been reformed, and labour market reforms continue. Free trade agreements are starting to materialise, water research and policy has begun to emerge along with other environmental policy issues, and micro economic reforms continue with energy and transport infrastructure White Papers being implemented. The challenge for us today is to continue the reform process and to identify the next steps for the longer term positioning of our country.

To do that well we need to strengthen our capacity for research, analysis, evaluation and policy formulation. Thankfully, we are not starting from scratch - overall I think we have good foundations for research and policy - and in 
some areas there is excellent work being done. Examples I would cite to illustrate this point are:

- the Productivity Commission's strong research capacity into economic and social issues;

- the work of the Australian Bureau of Agricultural Resource Economics and the Bureau of Transport and Regional Economics;

- the research and analytical capacity of the Australian National Audit Office;

- the Economic Analytical Unit located within the Department of Foreign Affairs and Trade, which publishes analyses of economic and trade issues of interest to Australia;

- the research capacity in the area of social issues by the Department of Family and Community Services, and its range of accessible publications on the issues it is investigating and the results of those investigations; and

- and the Evaluation Group at the Australian Public Service Commission with its specific evaluation and research capacity centred around the Australian Public Service Employment Database and the annual State of the Service Report.

I should also add that the Australian Public Service bears responsibility for the maintenance of any number of data bases and repositories of evidence necessary to underpin good policy.

In the UK there are also concerns about research capacity in the public sector, and they are investing in activities aimed at improving that capacity. The Centre for Management and Policy Studies within the UK Cabinet Office is promoting evidence-based policy-making through strategies such as:

- information 'knowledge pools';

- the training of officials in evidence interpretation use and application;

- a central website that provides access to the 'knowledge pools' and the training, as well as the research programs of government departments; and

- facilitating academic research placements in the Civil Service.

An online resource, set up by the Cabinet Office Government Social Policy Research Unit - called the 'policy hub' is promoted as 'the first port of call for all concerned with policy making'. It aims to promote strategic thinking and improve policy making and delivery across government. Its links, according to the site, provide tailored access to resources and activities from the UK and abroad which help formulate, develop and evaluate policy more efficiently and effectively.

Why was the policy hub developed? A 2002 report of the Better Regulation Taskforce, entitled Local Delivery of Central Government, recommended that the policy hub be developed as the key gateway for promoting best practice, guidance and case studies to policy makers. It promised a new approach to policy 
making that would be evidence based, cross cutting and innovative. The policy hub is not just about the public sector though; it recognises that there are many external inputs into government policy making. It aims to provide a platform for promoting the highest standards of research and evaluation. It highlights the conclusions of high-profile projects and includes a guide to policy evaluation and analysis (the Magenta Book) that aims to help 'intelligent customers' and 'intelligent providers' determine what constitutes high quality work in the field on policy evaluation and analysis.

Another systematic attempt to promote evidence-based policy and to improve research and policy-making capabilities is the 'Campbell Collaboration' - it asks the threshold questions: what helps? what harms? based on what evidence? The Campbell Collaboration, or C2 as it is known, was formally established at a meeting at the University of Pennsylvania in 2000. Like the policy hub, it is an online resource, and contains systematic reviews of research evidence prepared and maintained by contributors to the $\mathrm{C} 2$ Coordinating Groups.

Coordinating groups are responsible for helping to identify topics for systematic review, for providing reviewers with advice on planning and executing reviews, and for making reviews accessible. The $\mathrm{C} 2$ Crime and Justice Coordinating Group is hosted by the Australian Institute of Criminology. The group comprises an international network of individuals that prepare, update and disseminate systematic reviews of high quality research conducted worldwide, on reducing crime and delinquency or to improve justice.

I think it is worth going through the nine key principles on which the work of $\mathrm{C} 2$ is based. These are:

1. Collaboration, by internally and externally fostering good communications, open decision-making and teamwork;

2. Building on the enthusiasm of individuals, by involving and supporting people of different skills and backgrounds;

3. Avoiding unnecessary duplication, by good management and co-ordination to ensure economy of the effort;

4. Minimizing bias, through a variety of approaches such as abiding by high standards of scientific evidence, ensuring broad participation, and avoiding conflicts of interest;

5. Keeping up to date, by a commitment to ensure that Campbell Reviews are maintained through identification and incorporation of new evidence;

6. Striving for relevance, by promoting the assessment of policies and practices using outcomes that matter to people;

7. Promoting access, by wide dissemination of the outputs of the Collaboration, taking advantage of strategic alliances and by promoting appropriate prices, content and media to meet the needs of users worldwide; 
8. Ensuring quality, by being open and responsive to criticism, applying advances in methodology and developing systems for quality improvement; and

9. Continuity, by ensuring that responsibility for reviews, editorial processes and key functions is maintained and renewed.

They are a good set of principles. $\mathrm{C} 2$ is an interesting initiative, as is the policy hub.

In New Zealand, the social policy agencies are getting together to work on longer term policy directions.

I wonder whether these might be the sorts of systematic approaches to bringing research together for use in policy-making that we need to consider here in Australia.

In addition to strengthening our capacity for research and analysis in the APS, there is, in my view, a need to sharpen the pointy end of the policy process to really develop the policy advising function. Michael Keating says that through the 1970s and early 1980s both the Labor and Liberal parties felt their intentions were being frustrated - or even deliberately obstructed - by an unresponsive public service, that thought it knew best. This was, he says, the impetus for governments to look for policy advice elsewhere.

There cannot be much doubt that we have moved on from there - some would say we have now moved too far - but I think we need to ask whether it is enough to be responsive as it is commonly understood - to respond readily - or whether we need to be more strategic about it. I would suggest the latter.

But what do I mean by strategic in this context? What I am getting at is captured well in the Commission's APS Values and Code of Conduct in Practice: a guide to official conduct for APS employees and Agency Heads. Responsive employees, it says:

- are knowledgeable about the government's stated policies;

- are sensitive to the intent and direction of policy;

- take a whole-of-government view;

- are well informed about the issues involved;

- draw on professional knowledge and expertise and are alert to best practice;

- consult relevant stakeholders and understand their different perspectives;

- provide practical and realistic options and assess their costs, benefits and consequences;

- convey advice clearly and succinctly; and

- carry out decisions and implement programs promptly, conscientiously, efficiently and effectively. 
It continues to say that responsive policy advice is frank, honest, comprehensive, accurate and timely. It is well argued, creative, anticipates issues, and demonstrates an appreciation of the underlying intent of government policy. It is forthright and direct, and does not withhold or gloss over important known facts or 'bad news'. It demands a close and cooperative relationship with ministers and their employees and it is an iterative process. In total, it is a big ask for public servants.

Research for the upcoming Management Advisory Committee report on Managing and Sustaining the APS Workforce, paying particular attention to graduate recruitment and career development shows that graduate programme entrants and entrants at the APS 3-4 level are progressing to the ELl level within about 7 years. This is not a very long apprenticeship for developing the sometimes sophisticated skills and instincts needed for policy advising. It requires really good judgement and broad shoulders - to handle the disappointment when your advice is rejected and to know the sorts of questions to ask to understand why; to know when the time for persuasion and influencing is past, and when it is time to move on; and to know when to resurrect a policy whose time has come.

\section{Dependent Spouse Rebate}

I cut my teeth as a policy advisor on successive governments' families and income support policies in the 1980s and 1990s.

The overhaul at that time of the tax/transfer system for families in Australia, and in particular the removal of the Dependent Spouse Rebate - which I had a hand in - is an example of the sort of complicated and interacting sets of policies that we have to deal with, that demand the sort of sophisticated skills I have outlined - and where a good policy had to wait.

The Dependent Spouse Rebate was introduced in 1936 and was predominantly received by husbands through the tax system. It was consistent with the dominant social expectation that the male was the only breadwinner and head of the household.

However, by the 1970s, social change and particularly the acceptance - at least rhetorically - of notions of gender equity, together with rising concerns about family poverty, generated support in the bureaucracy and in areas of the community for change to the tax/transfer system for families.

In 1975, the Commission into Poverty recommended, among other things, that the Commonwealth government abolish regressive tax deductions to alleviate poverty in large families. Transfer payments through the social security system were viewed as a better means of mitigating poverty. The Whitlam government made some changes to tax relief for families, but the rebates remained in place. 
In 1976 the Fraser government abolished the dependent children rebate and used the savings to increase transfer payments for families, which were renamed Family Allowance. The Dependent Spouse Rebate survived.

In 1986 the Social Security Review recommended wide ranging changes, including that family payments should be paid to the principal carer, usually the mother, and that transfer payments rather than tax measures were the more effective means of achieving this.

Despite strong support for this policy approach it was not until January 1993 that all children's payments in the social security system were made to the principal carer. This increased payments to about 200,000 women in welfare dependent families. For those of us officials in Social Security at the time this was regarded as a really significant reform, and long overdue.

The Dependent Spouse Rebate, paid through the tax system, was really contrary to what was happening with income security transfer payments more broadly. Yet it survived, despite contrary policy advice. We continued to put it onto the table though, and in September 1994 the Home Child Care Allowance replaced the Dependent Spouse Rebate for families with children. It acknowledged, at last, that women were not liabilities of their husbands and that work in the home and as carers had direct economic value.

The point I want to make here is that policy exists in a specific context - it is dependent on a whole range of factors - competing priorities, fiscal constraints, the electoral cycle, presentational issues, even the strength of your Minister, and timing. It is complicated.

The GST, a policy we are now probably more familiar with, illustrates the point too. Keating could not make it happen. And, after John Hewson took it to the electorate and lost the unlosable election, most of us probably thought we had heard the last of the GST. But, clearly, the policy advice from the bureaucracy and Prime Minister Howard's political will for a consumption tax remained. It was a policy that, it would seem, needed a few outings before the electorate were comfortable with it - the timing needed to be right.

Finally there is also an onus on those of us who are senior leaders in the Australian Public Service to make sure our employees have the capabilities they need to carry out good policy advising - good policy outcomes, do, after all, depend on it. What this demands is a really focussed strategy for developing specific capabilities in this area. An initiative worth exploring is partnerships between agencies to attract, develop and retain staff. A partnership of the social policy agencies, for example, could collaborate to attract, develop and retain staff. They could provide opportunities for staff to develop breadth and depth of experience by offering career pathways where staff move on a planned basis 
across say FACS, Health, Centrelink and the HIC. With each move, staff would gain experience in all facets of social policy, including policy advising.

The upcoming Management Advisory Committee report on Managing and Sustaining the APS Workforce, paying particular attention to graduate recruitment and career development, which I referred to earlier, will include other suggestions for developing our capabilities - not just for research and policy, but for all areas of our business. I think we need to canvass all the options, because if we do not get it right we really have to ask ourselves whether we are doing the job we are here for.

\section{Conclusion}

So to conclude, my main arguments in this lecture are:

- firstly, the APS operates in a contestable policy environment, and it is imperative that we use our advantages - our breadth, our institutional memory and our history of work in the public interest - and that we use them to get the best policy outcomes we possibly can for the Australian community;

- secondly, the best way we can do that is to really get on board with whole of government working, and to leverage off the good research and other work that is being done within and without the APS;

- thirdly, our capabilities are critical to the whole enterprise. We need to have the right people with the right skills in the right jobs; but

- most importantly, we need to have some passion to really make it fly.

I hope that I have managed in this presentation to persuade you of the need for new thinking about our approach to policy development and advice in the Australian Public Service - that, indeed, we need to reignite a passion for policy. The position of the APS in relation to policy is secure only as long as it maintains a reputation for impartiality, quality, integrity, evidence-based policy and for working in the national interest - in short, for being a professional public service. I hope this service will endeavour to foster that passion - for good public policy and for great policy outcomes for the Australian people.

\section{References}

Adams, David (2004). 'Usable Knowledge in Public Policy'. Australian Journal of Public Administration 63 (1), 29-42.

Adams, D. and Hess, M. (2002). 'Knowing and Skilling in Contemporary Public Administration'. Australian Journal of Public Administration 61(4), 68-79 (cited in Bell 2004:24).

Argy, Fred (1998). Australia at the Crossroads, Allen \& Unwin, Sydney (cited in Bell 2004:24). 
Australian Public Service Commission (2005). State of the Service Report 2004-05. Commonwealth of Australia. http://www.apsc.gov.au/stateoftheservice/ 0405/report.pdf

Bell, Stephen (2004) 'Appropriate' Policy Knowledge, and Institutional and Governance Implications'. Australian Journal of Public Administration 63 (1), 22-28.

Better Regulation Taskforce (2002). Local Delivery of Central Government. http://www.brc.gov.uk/downloads/pdf/localdelivery.pdf

Eggers, William (2005). Government 2.0: Using technology to improve education, cut red tape, reduce gridlock and enhance democracy. Rowman \& Littlefield Publishers.

Management Advisory Committee (2005). Managing and Sustaining the APS Workforce: Paying Particular Attention To Graduate Recruitment And Career Development. Commonwealth of Australia. http://www.apsc.gov.au/ mac/apsworkforce.pdf

Management Advisory Committee (2005). Working together: Principles and practices to guide the Australian Public Service. Australian Public Service Commission. http://www.apsc.gov.au/mac/workingguide.htm

McAuley, Ian (2001). 'Dumbing Down in Canberra: A guide to the public service reform industry'. Dissent, Summer, 32-8. (cited in Bell 2004:24). 


\section{Chapter 2 - The Dangers of Complacency: The Case for Reforming Fiscal Policy in Australia}

\section{Bob McMullan MP}

\section{Lecture presented 27 April 2005}

Australia entered the $20^{\text {th }}$ century as arguably the richest country in the world. However, during the century we slowly fell through the rankings. This was not primarily because we went backwards, but rather that we failed to keep pace with our competitors. We face a similar challenge as we enter the $21^{\text {st }}$ century. We do not enter this century as the richest country in the world, but we are one of the fastest-growing developed economies. However, there are signs that the same factors which led to our decline last century are re-emerging. Therefore, it is timely to examine what caused our genteel decline and the factors which underpinned our improved performance over the last 20 years so that we may apply those lessons to our $21^{\text {st }}$ century challenges.

A brief examination of the statistical evidence illustrates the extent and significance of Australia's underperformance during the $20^{\text {th }}$ century. Consideration of this illustrates the potential consequences should a similar loss of momentum continue through the early $21^{\text {st }}$ century.

Paul Ormerod, in Butterfly Economics, cites Australia as one of those at the bottom of the league table of Western economies in terms of growth performance during the $20^{\text {th }}$ century. He estimates we were one of only three which grew at less than 1.5 percent on average over the period. Ormerod also cites Australia in the early part of the $20^{\text {th }}$ century as one of the few countries to achieve higher per capita GDP than the US during this period. And yet we had fallen to 76 per cent of US per capita GDP in the early 1970s; to 70 per cent by 1990 and had recovered only to the 1970s level by 2002 (OECD Economic Survey of Australia, February 2005:30). Put simply, this means the average Australian is thousands of dollars per year worse off than they should have been. It also means we as a nation have fewer resources to apply to the social and national challenges we face today.

America's economic performance has been strong and steady. While the average increase in real per capita income in the US over the century to 1997 appears modest - slightly below 2 per cent - the cumulative effect has been dramatic as the graph in Figure 1 illustrates: 
Figure 1 - Real per capita income in US dollars 1870-1997

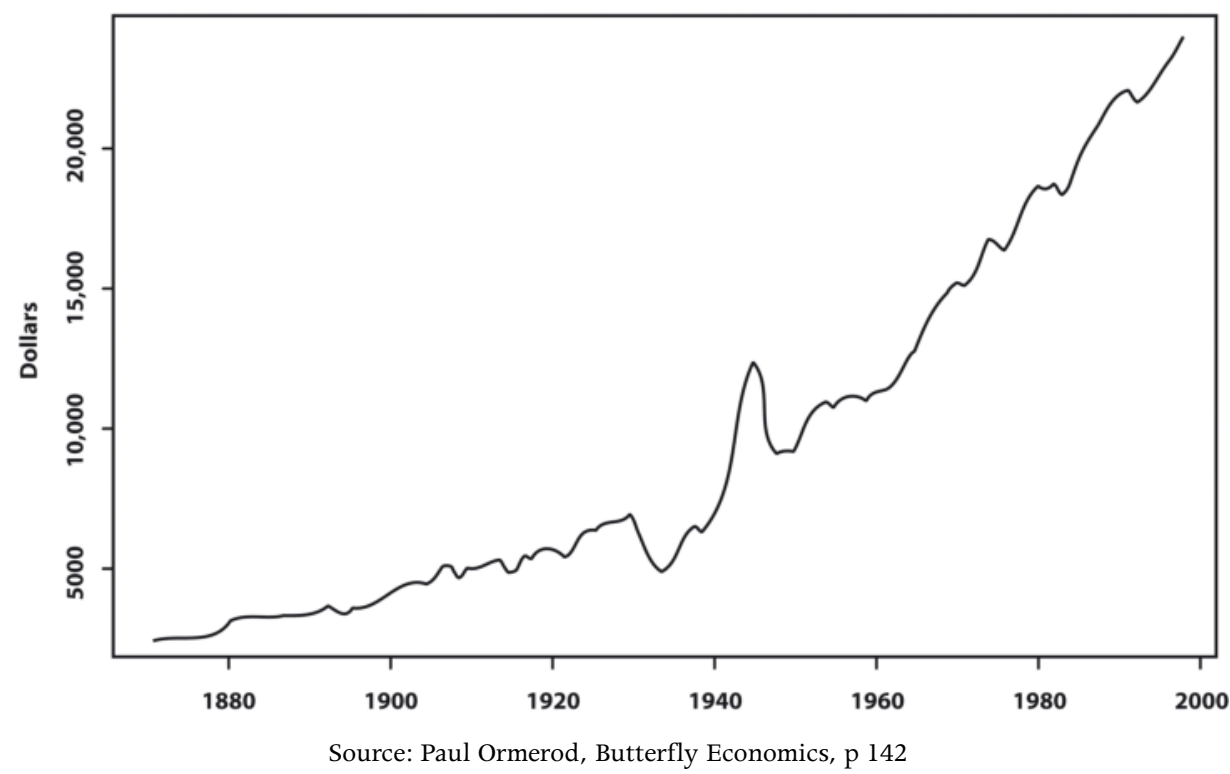

The comparative rate of growth between Australia and the US, as shown in Figure 2 below, graph based on data for the USA and Australia illustrates the compounding impact of the gap between our respective performances over the previous century.

Figure 2 - Australia and United States GDP Growth per Capita 1900-2000

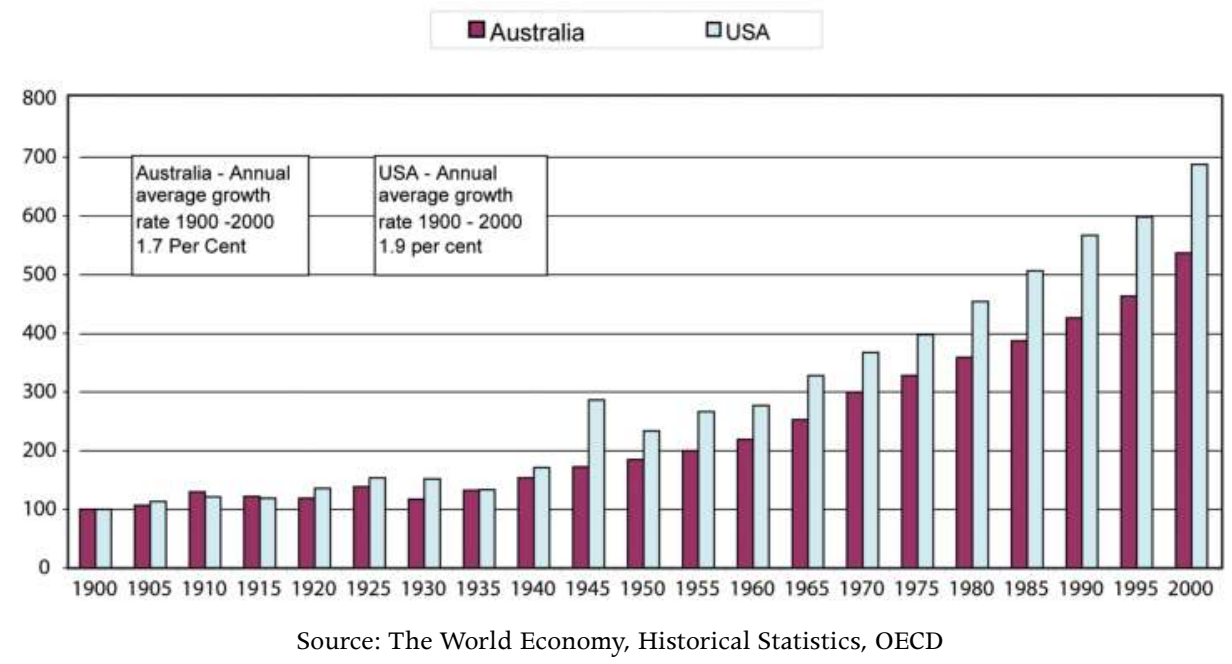

The implications of this long-term analysis are reinforced by Tiffen and Gittins in their excellent book, How Australia Compares. This provides a number of tables which throw an interesting light on Australia's economic performance 
over the last century. They quote work by Angus Maddison which estimates world economic growth over the last century. Table 1 below refers to income per capita over the period 1870 to 1998 :

\section{Table 1}

\begin{tabular}{|c|c|c|c|c|c|}
\hline \multicolumn{6}{|c|}{ Income per capita, 1870-1998 } \\
\hline & \multicolumn{5}{|c|}{ Per capita income in 000s of 1990 international dollars } \\
\hline & 1870 & 1913 & 1950 & 1973 & 1998 \\
\hline United States & 2.4 & 5.3 & 9.6 & 16.7 & 27.3 \\
\hline Norway & 1.4 & 2.5 & 5.4 & 11.2 & 23.7 \\
\hline Denmark & 2.0 & 3.9 & 6.9 & 14.0 & 22.1 \\
\hline Switzerland & 2.2 & 4.3 & 9.1 & 18.2 & 21.4 \\
\hline Canada & 1.7 & 4.4 & 7.4 & 13.8 & 20.6 \\
\hline Japan & 0.7 & 1.4 & 1.9 & 11.4 & 20.4 \\
\hline Australia & 3.6 & 5.7 & 7.5 & 12.8 & 20.4 \\
\hline Netherlands & 2.8 & 4.0 & 6.0 & 13.1 & 20.2 \\
\hline France & 1.9 & 3.5 & 5.3 & 13.1 & 19.6 \\
\hline Belgium & 2.7 & 4.2 & 5.6 & 12.2 & 19.4 \\
\hline Austria & 1.9 & 3.5 & 3.7 & 11.2 & 18.9 \\
\hline United Kingdom & 3.2 & 4.9 & 6.9 & 12.0 & 18.7 \\
\hline Sweden & 1.7 & 3.1 & 6.7 & 13.5 & 18.7 \\
\hline Finland & 1.1 & 2.1 & 4.3 & 11.1 & 18.3 \\
\hline Ireland & - & - & 3.4 & 6.9 & 18.2 \\
\hline Germany & 1.8 & 3.6 & 3.9 & 12 & 17.8 \\
\hline Italy & 1.5 & 2.6 & 3.5 & 10.6 & 17.8 \\
\hline New Zealand & 2.7 & 5.2 & 8.5 & 12.5 & 14.8 \\
\hline Mean & 2.1 & 3.8 & 5.9 & 12.6 & 19.9 \\
\hline
\end{tabular}

Source: Rodney Tiffen \& Ross Gittins, How Australia Compares: 42

In 1870 and 1913 Australia was at the top of the table for per capita income. However, by 1950 we had dropped to fourth and by 1973 we were no better than eighth. The period from 1973 to 1998 has seen us improve to sixth.

The comparative figures on the fastest growing economies (Table 2 below) provide a dramatic demonstration of Australia's poor relative performance in the early part of the $20^{\text {th }}$ century. Of the 17 countries measured, from 1822 to 1870 Australia was clearly the fastest growing economy in the world, yet from 1870 to 1913 Australia had fallen to $14^{\text {th }}$ position. In the period 1913 to 1950 we fell further to be the $15^{\text {th }}$ fastest growing economy. Significantly, the only countries with lower growth rates than Australia were Austria and Germany, which were reaping the consequences of the First World War. 
Table 2

\begin{tabular}{|c|c|c|c|c|c|}
\hline \multicolumn{6}{|c|}{ Economic growth, $1820-1998$ Average per capita growth rates, $\%$} \\
\hline & $1820-70$ & $1870-1913$ & $1913-50$ & $1950-73$ & $1973-98$ \\
\hline Ireland & - & - & - & 3.04 & 3.97 \\
\hline Norway & 0.52 & 1.3 & 2.13 & 3.19 & 3.02 \\
\hline Japan & 0.19 & 1.48 & 0.89 & 8.05 & 2.34 \\
\hline Austria & 0.85 & 1.45 & 0.18 & 4.94 & 2.1 \\
\hline Italy & 0.59 & 1.26 & 0.85 & 4.95 & 2.07 \\
\hline Finland & 0.76 & 1.44 & 1.91 & 4.25 & 2.03 \\
\hline United States & 1.34 & 1.82 & 1.61 & 2.45 & 1.99 \\
\hline Belgium & 1.44 & 1.05 & 0.7 & 3.55 & 1.89 \\
\hline Australia & 3.99 & 1.05 & 0.73 & 2.34 & 1.89 \\
\hline Denmark & 0.91 & 1.57 & 1.56 & 3.08 & 1.86 \\
\hline United Kingdom & 1.26 & 1.01 & 0.92 & 2.44 & 1.79 \\
\hline Netherlands & 0.83 & 0.9 & 1.07 & 3.45 & 1.76 \\
\hline France & 0.85 & 1.45 & 1.12 & 4.05 & 1.61 \\
\hline Germany & 1.09 & 1.63 & 0.17 & 5.02 & 1.6 \\
\hline Canada & 1.29 & 2.27 & 1.4 & 2.74 & 1.6 \\
\hline Sweden & 0.66 & 1.46 & 2.12 & 3.07 & 1.31 \\
\hline New Zealand & 3.9 & 1.51 & 1.35 & 1.72 & 0.67 \\
\hline Switzerland & 1.09 & 1.55 & 2.06 & 3.08 & 0.64 \\
\hline Mean & 1.27 & 1.42 & 1.22 & 3.63 & 1.9 \\
\hline
\end{tabular}

Source: Rodney Tiffen \& Ross Gittins, How Australia Compares: 44

However, the most telling part of the table is for the period 1950 to 1973, often paradoxically referred to as the 'golden years'. In this period, while Australia, like all other Western countries, was experiencing strong economic growth, our relative economic performance was dreadful. We fell to $17^{\text {th }}$ out of 18 and grew at less than two thirds the average rate of other developed countries. During the final period referred to by Tiffen and Gittins, from 1973 to 1998, Australia improved to eighth in the global economic race.

Table 3 below demonstrates the comparative trade performance of developed countries. Australia, like all the other developed countries, with the possible exception of Japan, has increased its trade intensity over the last 30 years. However our trade performance has been consistently poor. During the 1970s our net trade performance was about the middle of the field and better than average. However, during the 1980s and 1990s we crashed to almost the bottom of the list and remained there. It is impossible to see how Australia can succeed in the medium term without an improvement in this area. 


\section{Table 3}

\begin{tabular}{lrrrr}
\hline & Trade balance as \% of GDP, $1970-99$ & & \\
& & & & \\
Ireland & $1970-73$ & $1974-79$ & $1980-89$ & $1990-99$ \\
Norway & -7.4 & -11.3 & -2.5 & 9.9 \\
Netherlands & 0.6 & -2.7 & 4.1 & 6.3 \\
Finland & 0.2 & 1 & 3 & 5.1 \\
Denmark & -1.1 & -0.9 & 0.4 & 5 \\
Sweden & -1.5 & -2.8 & 1 & 4.8 \\
Switzerland & 1.4 & -0.5 & 1.5 & 4.6 \\
Belgium & -1.2 & 1.4 & -0.2 & 3.6 \\
Italy & 2.3 & -0.8 & 0.3 & 3.5 \\
Japan & -0.1 & -0.2 & -0.5 & 2.5 \\
New Zealand & 1.6 & 0.4 & 1.9 & 1.6 \\
Canada & 0.2 & -4 & -1 & 1.6 \\
France & 1.6 & -0.3 & 1.8 & 1.3 \\
Germany & 0.1 & -0.7 & -1.4 & 1.3 \\
Austria & 1.9 & 2.2 & 2.6 & 0.9 \\
Australia & 0.6 & -0.8 & 0.2 & -0.2 \\
United Kingdom & 0.9 & -0.5 & -2.2 & -0.9 \\
United States & -0.1 & -0.9 & -0.2 & -1 \\
& 0.1 & -0.4 & -1.8 & -1.2 \\
Mean & & & & \\
\hline Surc: Rod & 0 & -1.2 & 0.4 & 2.7 \\
\hline
\end{tabular}

Source: Rodney Tiffen \& Ross Gittins, How Australia Compares: 50

One aspect of our performance to which economists would give great weight in relation to overall current account problems is the relative net saving performance. Australia's performance is very poor over the period from 1970 to 1999. Absolute saving performance has fallen from 12.4 per cent of GDP to 2.2 per cent, and we have fallen decisively to last place on the global savings list. It is important to remember that this net savings effort is something to which government can contribute directly through its own budgetary efforts.

This is where the figures are somewhat surprising. While Australia's overall budget balance has improved significantly in recent years we have merely kept pace with the average performance of other countries. As the following table (Table 4) shows, Australia's performance in the budget balance has not improved since the small but significant relative improvement during the Hawke government. However, putting aside minor variations we have been in the middle of the field for the last 30 years. 
Table 4

Budget balance Mean budget surplus/deficit as \% of GDP during period of each government

\begin{tabular}{lrrrrrr} 
& McMahon & Whitlam & Fraser & Hawke & Keating & Howard \\
& $1970-72$ & $1973-75$ & $1976-82$ & $1983-91$ & $1992-95$ & $1996-2002$ \\
17-country mean & 0.4 & -1 & -3.2 & -2.9 & -4.7 & 0.1 \\
Australia & -0.3 & -2.4 & -3.8 & -3.1 & -4.5 & -0.1 \\
Australia's rank & 11 & 12 & 12 & 9 & 9 & 9 \\
Highest country & Sweden & Finland & Finland & Norway & Norway & Norway \\
Value & 4.7 & 5.1 & 4.6 & 4.5 & 0.2 & 9.2 \\
Lowest country & Italy & Italy & Ireland & Italy & Sweden & Japan \\
Value & -5.4 & -8.6 & -9.8 & -10.9 & -9.6 & -5.8 \\
\hline
\end{tabular}

Table 5 best illustrates the poor economic performance of the past and the risks of the present.

Table 5

\begin{tabular}{lrrrrrr}
\hline \multicolumn{7}{c}{ Economic growth Mean per capita GDP growth rates (\% per annum) during each government } \\
& McMahon & Whitlam & Fraser & Hawke & Keating & Howard \\
& $1971-72$ & $1973-75$ & $1976-82$ & $1983-91$ & $1992-95$ & $1996-2000$ \\
18-country mean & 3.2 & 2 & 1.9 & 2.2 & 1.6 & 2.8 \\
Australia & 1.6 & 1.7 & 1.1 & 1.9 & 3.1 & 3 \\
Australia's rank & 17 & 12 & 14 & 12 & 3 & 5 \\
Highest growth & Japan & Norway & Norway & Japan & Ireland & Ireland \\
Value & 5.2 & 3.8 & 3.2 & 3.7 & 4.8 & 8.8 \\
Lowest growth & Sweden & Switzerland New Zealand New Zealand & Switzerland & Japan \\
Value & 1.1 & -1 & 0.2 & 0.1 & -0.8 & 1.1 \\
\hline
\end{tabular}

Source: Rodney Tiffen \& Ross Gittins, How Australia Compares: 92

Table 5 shows average per capita Gross Domestic Product (GDP) growth rates during the period of each recent Australian government. It demonstrates the very poor performance up to the 1980s and a significant improvement in later years. However, the period 1996 to 2000 does show the first signs of slippage. This is neither the place nor the time to enter contemporary controversy about the reasons for our recent economic improvement being at risk. Issues like skills, infrastructure and research and development are matters for robust debate in the day-to-day political contest.

My concern here is for the longer term. I attribute much of our relative decline during the early and mid $20^{\text {th }}$ century to an arrogant complacency that our resource endowments would guarantee us our place in the world without us having to make the hard decisions others might have to face. Indeed, Donald Horne captured this sentiment in his celebrated phrase 'The Lucky Country'. It took much debate and difficult reforms in the 1980s and 1990s to turn this around. The signs of such complacency are beginning to emerge again. Therefore I wish to concentrate in this presentation today on the issues relating to failings in the intellectual and administrative infrastructure which underpin the national economic debate. 
The experience of previous decades shows that the quality of economic analysis and debate in any one period is a significant factor in creating the preconditions for strong economic growth in the future. The history of reform in Australia, which bore fruit in the 1980s and 1990s, has its origin in the quality of the economic debate and analysis in earlier years. This claim is supported by the Organisation for Economic Co-operation and Development (OECD 2004: 8) in its most recent report, OECD Economic Surveys Australia 2004, which states, 'The Australian economy is still benefiting from the program of widespread and deep reforms that started in the 1980s'. Further it said, 'Australia became a model for other OECD countries ... (due to) ....the tenacity and thoroughness with which deep structural reforms were proposed, discussed, legislated, implemented and followed-up' (2004: 11). But also, and importantly for my argument here, 'The pace of reform has recently not been as strong as it could have been.' (2004: 11).

Much of the quality of that economic debate to which the OECD refers was enhanced by the independent (and sometimes fiercely independent) analysis by the Productivity Commission and its predecessors. John Warhurst, in Jobs or Dogma, outlines the history of the Tariff Board and its successor, the Industries Assistance Commission (IAC), and their struggle to change economic policy and debate in this country. He describes the quality of their contribution as, 'the advice given to the Government on the economic costs and benefits was recognised as one of the highest calibre which could reasonably be expected from the Australian economics profession. Therefore that advice ... was by and large supported by members of the profession in academia, government and the media.' (1982: 5).

He also recognised the importance of their activism: 'the IAC as an active participant pressing its own views both formally and informally' (1982: 3) and their long term perspective and educational function: 'The IAC always remained optimistic that short-term pressures on government policy making could be lessened ... by the provision of greater information about the future. It believed that ignorance of the future made governments vulnerable to ad hoc decisions.' (1982: 3). In support he quotes a 1978 IAC staff paper: 'if the community at large has no awareness of the problems, it will be less prepared to bear the short-term costs of possible solutions.' (1982: 232).

There is no more significant indication of the power and significance of the debates generated by these agencies than Gough Whitlam's famous phrase: 'I am a Rattigan man'. (Warhurst 1982: 3) With this phrase Whitlam was both confirming his commitment to lower tariffs and acknowledging the lead role which the Tariff Board and its then Chairman had played in that debate. Over the next 30 years the Industries Assistance Commission, the Industries Commission and the Productivity Commission have played a major advocacy 
and educative role which has helped the overall economic reform process significantly.

The key question today is: Is the commitment to reform faltering?

It has been significant that, we have started to see commentary on the way in which the Productivity Commission is being sidelined in important debates. Ross Garnaut in a recent article in the Australian Financial Review, 23 March 2005, called for 'a return to independent, authoritative and transparent analysis of trade policy options as a basis for public education and discussion.' Similarly, Ross Gittins in the Sydney Morning Herald last month, in commenting on the government's proposed inquiry into infrastructure said: 'When the Government is sidelining its independent inquiry agency it is a sign they do not want good economic policy getting in the way of expedient politics.' ${ }^{\prime}$

It is therefore intriguing and encouraging to see the Productivity Commission challenging the Howard government's approach to economic reform. As Alan Wood, in the Australian of 15 April 2005 made clear, 'the Productivity Commission's final report on National Competition Policy makes plain ... success will depend on co-operative federalism.' Wood concluded that the Prime Minister has rejected the Productivity Commission's advice on the need to co-operate with the states because it does not suit his new aggressive centralist agenda. The key issue here is not whether the Prime Minister, the Productivity Commission or Alan Wood will prove to be correct. What this incident illustrates is the valuable role of authoritative and independent commentary and analysis in the ongoing task of building the case for genuine economic reform.

As an indicator of the role of informed debate in building the basis for such reforms, the Productivity Commission pointed to some of the lessons to be learnt from National Competition Policy including:

- 'That such an ambitious program received support from all governments can be attributed to much pre-existing evidence of the potential gains from reform, to broad agreement on the means of achieving those gains and to effective political leadership.'

- 'Independent and transparent review and assessment processes are critical to secure good outcomes, especially on contentious issues; prevent backsliding; and promote public understanding of the justification for reform.'

- 'In any reform program, the potential adjustment and distributional implications should be considered at the outset, with decisions about transitional assistance guided by appropriate principles. $^{2}$

The argument for independent analysis and advice to government across a range of issues has been gathering momentum. My colleague, Lindsay Tanner, has called for the creation of a national infrastructure commission. He said, 'Australia 
has been well served by bodies like the Grants Commission, Australian Competition and Consumer Commission, Reserve Bank, Australian Bureau of Statistics and the Productivity Commission. The role of such expert, non-partisan bodies in economic policy is steadily increasing. Although in many cases, the ultimate decisions properly remain in the hands of elected governments, such bodies play a vital filtering role and provide benchmarks against which the actions and promises of governments can be measured.' (Renewing Australia's Infrastructure, Speech to Australian Council for Infrastructure Development, 21 March 2005). I believe that it is time that we created an independent agency to play this role so that we might enhance the quality of debate in Australia about fiscal policy

Wanna, Kelly and Forster in their book, Managing Public Expenditure in Australia, described accountable budgetary processes as 'a key mechanism of stable democratic societies' (200: 1). With the increasing focus on the state and appropriateness of fiscal policy, I would argue we need the public to be able to make informed judgements. The importance of budgets to a society is that budgets 'have long quantified the possibilities open to government' (Wanna et al 12). Therefore, knowledge about the true state of the budget allows people to express their views about the choices government is contemplating or about the choices presented at election time.

Managing Public Expenditure in Australia is an excellent analysis of how our spending priorities are decided. It is alarming that there is nothing comparable on how much we should spend in the first place. This book also highlights the basis of the allegations made concerning John Howard's cover-up of his $\$ 9$ billion budget deficit before the 1983 election and the equivalent allegations by conservative politicians concerning a similar accusation against the Keating government before the 1996 election.

It is argued that these allegations served as the basis for the Howard government's decision to introduce a Charter of Budget Honesty (1998). This legislation has many virtues. Together with the previous history of budgetary reforms, in particular with regard to the forward estimates, it has provided a reasonable basis for examination of some aspects of current fiscal policy. However a number of problems remain which need to be addressed.

It is widely recognised that the out-year numbers in the forward estimates are unrealistic. That is, future expenditure is understated so that surpluses appear larger. This creates a significant distortion in the analysis of election commitments by governments and oppositions. The Charter of Budget Honesty also has serious shortcomings in so far as it relates to the section concerning election costings.

In fact, the Charter of Budget Honesty, in so far as it relates to the costing of election promises, is as rigged as the Florida voting system. Each appears to have all the trappings of fairness but in practice each is seriously skewed in favour 
of the incumbent. It sounds like something from a George Orwell novel when you suggest that something with as innocent a title as the Charter of Budget Honesty is actually a rigged system designed to favour its founders. But there is no doubt. After three futile attempts to operate under the rules of this Charter it is clear that it is deliberately and demonstrably unfair. This not an accidental by-product of the system or a flaw in its implementation. It is a conscious and deliberate design feature of the system.

The fundamental issue is that the government has access to the bureaucracy in the lead-up to the campaign. Therefore they can have all their policy proposals tested and costed as options for cabinet consideration in advance of the election. This enables an interactive, iterative approach in which options are tested, assessed, modified and determined in a gradual, evolutionary way. The government party can then conveniently retain these options for release during the election.

By contrast, the opposition has a one-off shot with access only to the publicly available information. Three examples from the most recent election should serve to establish the case. Medicare Gold had been costed rigorously with the assistance of health economists, social and economic modelling specialists and actuaries. The departments of Treasury and Finance found no fault with their work. However, in costing the policy the departments used unpublished casemix data. This was never available to the opposition. There was no capacity for the opposition to have access to this data before the policy was publicly announced and its costings released. Had a party in government been seeking to introduce such a policy they would have been able to access this data before their policy was released: an open and shut case of bias in the rules of the game.

Similarly, in the case of the sale of Telstra, the departments were in a position to assist any incumbent government with the task of costing the sale by virtue of the fact that they had available to them confidential dividend information supplied by Telstra. This information was not available to the opposition. What all this makes clear is that although both government and opposition go through the same processes after the election is called, the pre-election circumstances are such that the inevitable outcome is that the government parties are at a massive advantage.

A powerful contemporary example of the shortcomings of the Charter of Budget Honesty as it relates to election costings is the recent events surrounding the government's Medicare safety net. There are two aspects of the problem. One is minor, although of contemporary political relevance, concerning the government's state of knowledge. The other aspect is the failure of the current system to deal with the fundamental flaws in the safety net proposal which are unaffected by the threshold at which it cuts in. First, the timetable. The Howard government knew at the time of the 2004 Budget that the costs for the Medicare 
safety net were blowing out - they provided an extra \$240 million to fill the gap. By June the Health Minister knew that the anticipated annual take-up on which the costing assessment was based had been reached in just three months.

By September, the Pre Election Fiscal Outlook (PEFO) disclosed, under the guise of parameter changes, that the shortcomings in the scheme had led to an approximately 100 per cent increase in the cost of the safety net due to, amongst other things, higher out of pocket costs. This was an inevitable consequence of the perverse incentives built into the system as originally designed. It was only marginally affected by the threshold changes required by the Senate.

It was not until 27 September, just 12 days before the election, that the costings by Finance of Labor's pledge to abolish the safety net revealed the full extent of the blow-out. This revealed that the cost of the scheme had reached $\$ 1.3$ billion over four years. It is inconceivable that the government was not aware of the extent of the blow-out. The Department of Finance would not observe such a phenomenon and fail to advise their minister or the Department of Health. And yet despite the transparency claimed for the Charter of Budget Honesty process, none of it would have been revealed without the coincidence of Labor's pledge to abolish the scheme. Those monitoring the process in the public interest need to be more independent and given an explicit responsibility to make such dangers public as soon as possible.

This logically leads us to the second aspect of the problems of the safety net. Experience has shown what should have been obvious from the start:

- The scheme created perverse incentives which were likely to increase the overall cost of the provision of health services, not reduce it; and

- It was also inevitable, and has proved to be the case, that the greatest benefits of the scheme would flow to the already well-off. The statistics for September 2004 show that the benefits are heavily skewed to high income electorates.

The data published by the Minister for Health shows that of the top 20 constituencies in terms of benefits received from the safety net, 15 also feature in the top 20 electorates by income. The top four, and six of the top seven, are on the North Shore of Sydney. This is a massive subsidy to the North Shore of Sydney from the Western suburbs and regional Australia. For example, the Education Minister Brendon Nelson's seat of Bradfield had received almost \$1 million while the remote seat of Lingiari in the Northern Territory with an approximately 30 per cent Indigenous population had received only $\$ 20,000-$ a ratio of more than 40:1 in favour of the already well-off.

What the political process needs is a process which is more likely to expose these fundamental flaws rather than cover them up.

Ross Gittins, in the Sydney Morning Herald, outlined the fundamental unfairness of this system in an article written soon after the 2004 election. The first, and 
initially unexpected, handicap for current and future oppositions lies in the timing and impact of the pre-election fiscal outlook. Gittins says of this:

In the good old days, once this year's budget (or, occasionally, the mid-year review) was on the table, the parties knew how much they had to play with and could safely get on with deciding and announcing their major policies.

Not any more. Thanks to the advent of the PEFO, the Opposition cannot be certain how much it has to spend until 10 days into a (usually) five-week campaign. (The Treasurer has the advantage of being able to seek continuous informal indications from his underlings.) ...

So here we have the advent of the PEFO acting to damage rather than enhance the democratic process. Labor - and all subsequent oppositions - will have to find a way of releasing its policies in broad terms early, then firming up the specifics during the campaign.

On the central issue of the imbalance of advice Gittins summarises the situation as follows:

Finally we come to the farcical operation of the provision for Treasury and Finance to cost the two parties' promises during the campaign. It is a farce because it is so heavily weighted against the Opposition - any opposition.

The trouble is, the bureaucrats are the servants of the Government for almost 35 months out of every 36. Only during the election campaign's 'caretaker period' are they given their independence and permitted to treat both sides equally.

So the Government gets all the access it wants to the bureaucrats' expertise until just the last few weeks. And in the run-up to each election, it peppers them with hundreds of requests for the costing of hypothetical policies.

What's more, the Government's pre-election contact with the bureaucrats is an 'iterative' (trial-and-error) process: how much would it cost if we decided to do A? If you wanted to do A it would cost $\mathrm{X}$, but if you did Al, which isn't very different, it would cost only Y. Oh, really. Thanks for the tip.

Trouble is, the bureaucrats aren't permitted to give such helpful advice to the Opposition - not during the term, nor during the caretaker period. The Opposition just submits its policy costings and waits for the bureaucrats' public pronouncement. Any working papers or background information the Opposition supplies to the bureaucrats must be made public - and thus perused by their political opponents. 
You see now just how unbalanced the process is. The Government is largely feeding back to the bureaucrats their own costings, whereas the Opposition runs a high risk of slipping up somehow and being monstered by the Treasurer. ${ }^{3}$

None of this should lead to a conclusion that the process of rigorous costing of election policies is illegitimate. It is simply the case that the existing rules and processes are inherently unfair. In my experience the officials from Treasury and Finance do an honest and thorough job within the rules as they stand. But nothing they can do overcomes the fact that the process is rigged against the opposition, whichever party that may be from time to time.

We also need to repair some gaping holes in the fiscal policy debate. While both major parties claim they believe in balancing the budget over the economic cycle neither has been prepared to recognise the logical outcome of this position. This has led to the absurd position where leaders of both parties have committed to potentially counter-productive pro-cyclical measures.

For example, the Prime Minister, John Howard in 2003 put forward what was a superficially attractive proposition: 'our principle is that if you have paid off your debt ... and you have a surplus, you have no right to keep more than the surplus you need. And we therefore take the view that when ... you've met your priority areas of spending like defence and health and so forth, you should then give what is over back to the people who own it - that is the Australian taxpayers'. 4

However Simes, in analysing this proposition, pointed out its fundamental absurdity as a policy prescription:

The logic of this approach to policy is that tax cuts will be provided at times when revenues are buoyant - that is, in economic booms - and the Budget will be tightened when weaker economic conditions hurt revenues - precisely the opposite of good policy. ${ }^{5}$

However, this is a problem which has had bipartisan dimensions.

After the recent elections, and therefore outside the pressure of an election period, the previous Leader of the Opposition said in a speech in Parliament, 'we will not run budget deficits' without any qualification to recognise that economic circumstances will certainly change over the next five years. ${ }^{6}$

Now, these two gentlemen are not stupid or economically illiterate. So, why do they propose what they must know could be counterproductive? It is because in public life in Australia today it is not acceptable to mention the dreaded ' $\mathrm{D}$ ' word, deficit!

Everybody knows, and simple arithmetic makes clear, that balancing the budget over the economic cycle means being prepared to run deficits when the economy 
is running at below average levels of activity. It also means that merely being in surplus may not be sufficient during times of very strong growth. What is needed is something like the structural deficit analysis undertaken by Access Economics and the OECD. Access Economics defines the structural budget cash balance as one which 'separates cyclical (factors) from long term fundamentals ... that is, it estimates where the Budget would be if the economy were running at trend levels of activity.' In effect, it is the measure which allows us to check whether we are meeting our target of balancing the budget over the economic cycle.

For example, their latest Budget Monitor concludes:

... both 2004-05 and 2005-06 are expected to see the most notable deterioration in the structural integrity of the Budget since, well, the last election. By the latter year the structural Budget may have returned to deficit, the victim of overly enthusiastic policy decisions in the six months from April to October $2004 .^{7}$

They also compare the structural balance with the Intergenerational Report as follows:

Remember that 'the structural Budget balance' abstracts from the bump and grind of the economic cycle. The Intergenerational Report (IGR) did that too. And remember that 'the structural Budget balance' is estimated assuming current policies are maintained - again, exactly as the IGR did. Therefore the IGR results (and the 40 year average they imply - a Federal primary deficit of 1.4 per cent of GDP) are effectively a measure of the long run structural Budget balance. The IGR itself therefore said that, judged on a 40 year benchmark (rather than the 4 year benchmark used in the Access Economics analysis here), today's Budget policies imply an average long term structural Budget deficit of 1.4 per cent of GDP, or over $\$ 11$ billion a year in today's money. ${ }^{8}$

The OECD also produces a structural balance assessment of the Australian budget as well as those of other member countries. While the two are not strictly comparable due to minor methodological differences and because the OECD works on a calendar year basis while Access uses a financial year basis, they produce sufficiently similar assessments to give confidence in the accuracy of the work.

The Access Economics Budget Monitor makes a significant contribution to such intelligent discussion of fiscal policy and the budget as there is at the moment in Australia. If it were to be reinforced by a higher profile agency which might work with Access to enhance the Monitor generally, and the structural balance analysis in particular, it would make an even greater contribution to public knowledge of national fiscal policy. 
The fundamental proposition about balancing the budget also has its critics. Economist Fred Argy proposes that we should run a small deficit over the cycle. Argy contends: 'that governments should balance revenue against recurrent expenditures ... over the economic cycle ... However, at present their fiscal targets go well beyond that ... (their) target requires that revenue be used to finance capital expenditure as well as recurrent expenditure over the long term This is fiscal conservatism gone mad (Fred Argy, Where To From Here?, p 155). Conversely, Ric Simes has argued that we should run a small surplus over the cycle. ${ }^{9}$

An accurate and informed debate about all these issues is a very important part of a healthy democracy. Therefore, I believe a new institutional framework to facilitate and inform fiscal policy debate in Australia is necessary.

There are essentially two precedents that we could follow. In the United States, clear, formal bureaucratic structures are enhanced by the Congressional Budget Office and the Council of Economic Advisers. It is hard to see how the Congressional Budget Office model could be made to work in the Westminster system. The Parliamentary Research Service already does an outstanding job and I do not believe that the Congressional Budget Office model is the way forward.

There is considerable merit in adding to our economic policy infrastructure a council of economic advisers. With the strength of independent economic analysis and think tanks and private financial institutions as well as the universities we have a very useful and powerful tool of old economic advice to the government. I have had the opportunity to discuss the concept of an Australian Council of Economic Advisers with people with knowledge of the US model such as Professor McKibbin here at the ANU. Any Australian council would be similar to but different from the US model. There are many business, academic and institutional economists who would willingly provide their services to advise the Prime Minister, or the Treasurer, about a broad range of important economic issues.

The days when the information, the technology and the resources were exclusively available to government to analyse such issues are long gone. In fact, bank economists with access to up-to-date data on lending, deposit and financial transaction are better placed to advise on some issues than public sector economists. Regular reports, analysis and commentary from such a council would improve the overall quality of economic debate while also broadening the base of economic advice to the government of the day.

However, I regard this as a much broader initiative than merely dealing with the questions of fiscal policy to which I am referring to her. The more interesting precedent is the British Institute of Fiscal Studies, an independent body which comments on and promotes research and informed discussion of fiscal matters. 
Some examples of its ongoing work which are relevant to the 2005 UK general election are:

- monthly bulletins analysing the Government's public finance figures;

- analysis of 2005 budget and spending review options;

- examination of the evolution of the level of taxation as a share of national income;

- briefing notes on long-term trends in British taxation and spending;

- assessment of the distributional impact of policies;

- ongoing analysis of trends in inequality;

- analysis of the impact of the three parties' higher education funding policies; and

- detailed assessment of the Conservative Party's proposal to increase support for pensioner saving.

Ric Simes outlined his views of the case for an Australian equivalent of the Institute of Fiscal Studies in the following terms:

The involvement of the ABS can help to enhance the integrity of the basic data. This is a starting point. However, a greater challenge is to sustain a high level of public debate on public policy issues to promote better decisions. Australia has managed to stimulate such debate on specific issues at different times. For example, the tariff reform and labour market policies have benefited from the extensive research and policy efforts both within the public sector (e.g. the Productivity Commission and its precursors) and the universities.

On the other hand, the level of debate over macroeconomic policy issues more generally has varied over time. A large proportion of Australia's better macroeconomists are housed within the Reserve Bank, but much of the serious debate on monetary policy stays within the building. It would be healthier all round if a means could be found to strengthen the research capability on monetary policy outside of the Reserve Bank thereby enabling a more robust public debate.

Similarly, the level of public debate on fiscal policy would benefit greatly from more consistent high-level research and review. This would provide invaluable input in what at times is a quite superficial reporting on these matters. In turn, Government decision-making would be improved.

A modest amount of strategic funding would allow Government to establish an independent centre - with a proposed title of the Institute for Fiscal Affairs (IFA) - and with a brief to monitor and analyse policy. The location of the Institute could be determined via a tender. University departments and private consulting firms with existing expertise in related areas may be attracted to bid for the project' ${ }^{10}$ 
I believe this is a compelling case. A potential work program for an Institute of Fiscal Studies could include:

- costing and analysis of government and opposition policies;

- regular analysis of the implications of government monthly financial statements;

- analysis of state government budgets and opposition proposals (if states join the scheme);

- $\quad$ similar work on New Zealand if New Zealand joins the scheme;

- further development of the structural analysis of the budget balance

- a review of the Charter of Budget Honesty;

- monitoring the performance of fiscal policy against the government's fiscal rules and principles;

- conducting research into policies related to intergenerational matters; and

- promoting public debate on fiscal policy.

The key question remaining is: how should such an institute be funded to enable it to operate strongly while remaining independent? The following models recommend themselves:

a. a model based on the Australian Strategic Policy Institute - that is, a budget funded model as a free standing institute gaining its reputation for quality and independence from the standing of the original director and subsequently from the rigour and relevance of the output;

b. an exclusively private sector funding model similar to the various think tanks in the United States;

c. a government funded body with an independent board;

d. a government funded body with a charter of legislative independence;

e. an independent body funded as a result of a government tender for independent services of this kind;

f. a body similar to one of those listed above, owned by more than one government, for example, one that all is also funded by one or more state governments, and possibly also by the New Zealand government; and,

g. a specialist sub-part of the Productivity Commission.

It seems to me that the best outcome is likely to be achieved by a combination of e. (an independent body) and f. (a body that is similar to those above and owned by more than one government).

The advantages of a transparently independent body to perform functions of the type outlined here are its real and apparent neutrality and the freedom it obtains from public service constraints. If some or all of the states and New Zealand were interested in participating this would add the benefit that no one income source could 'own' the institute. 
Such an institute could also contribute to Geoff Mulgan's outline of one of the issues for governments to consider in rebuilding trust. He said, 'Other issues for government include independent performance information and more accessibility. In an information-intensive environment where the public is full of experts, good trustworthy government operates in open ways that make use of society's intelligence. $^{\prime 11}$

Through such a process it is likely that an independent consortium such as a university combining with an independent economic assessment firm might well win the tender for a period of three to five years at a cost of not much more than $\$ 1$ million per year to the taxpayers. Of course, it will be obvious to some that this model bears some similarities to the Australian and New Zealand School of Government structure, but then again, imitation is the sincerest form of flattery. If such an independent agency were to be established it could also take over the election costing functions currently performed by Treasury and Finance under the Charter of Budget Honesty Act.

The essential thesis I am putting forward is this: Australia's economic performance needs re-invigoration. Such a process has many aspects. My emphasis tonight is on the need to establish the basis for an enhanced and informed debate about economic policy generally and fiscal policy in particular. This is vital to ensure that as we proceed through the $21^{\text {st }}$ century we do so on the basis of a fiscal policy targeted to our long-term economic needs, which optimises the utilisation of taxpayers' funds and which enables a fair and informed assessment of alternative proposals put forward during the course of our democratic dialogue, particularly at election time.

An independent Institute of Fiscal Studies based in Australia or Australia and New Zealand would make a significant contribution to this and enhance our chances of avoiding the complacency and relative failure of the first decades of the 20th century. We cannot afford that complacency now.

\section{Bibliography}

Access Economics (2004) Budget Monitor, October.

Argy, Fred (2003) Where To From Here?, Australia, Allen \& Unwin.

Baehler, Karen; Callister, Paul; Gregory, Bob; Hawke, Gary; Ladley, Andrew; Ryan, Bill; Scott, Claudia; Stephens, Bob; Walker, Ann; Wolf, Amanda (2005) 'Surveying Research on New Zealand Government: What Next?', ANZSOG Research Survey, Australian Journal of Public Administration, March.

Garnaut, Ross (2005) 'Blend trade talks into bigger picture', Australian Financial Review, 23 March.

Gittins, Ross (2005) Sydney Morning Herald, 21 March. 
Gittins, Ross (2004) 'Charter of Budget Honesty distorts election campaigns', Sydney Morning Herald, 18 October.

Holden, John (2004) Capturing Cultural Value, Demos.

Horne, Donald (1964) The Lucky Country, Penguin.

Kay, John (2004) The Truth about Markets, Penguin

Latham, Mark (2004) Hansard, 17 November.

Mitchell, Alan (2005) 'Transparency pays its way', Australian Financial Review, 23 March.

Mulgan, Geoff (2004) Mulgan Comments on Trust, ANZSOG News, Spring.

Organisation for Economic Cooperation and Development (2005) OECD Economic Surveys 2004 Australia, February.

Ormerod, Paul (1997) Butterfly Economics, New York, Pantheon Books.

Productivity Commission (2005) Review of NCP Reforms.

Simes, Ric (2003) Fiscal Policy Rules in Australia, Chifley Research Centre, September.

Tanner, Lindsay (2005) 'Renewing Australia's Infrastructure', Speech to Australian Council for Infrastructure Development, 21 March.

Tiffen, Rodney \& Gittins, Ross (2004) How Australia Compares, Cambridge University Press.

Wanna, John, Kelly, Joanne and John Forster (2000) Managing Public Expenditure in Australia, St Leonards, Allen \& Unwin.

Warhurst, John (1982) Jobs or Dogma, St Lucia, University of Queensland Press. Wood, Alan (2005) Australian, 15 April.

\section{ENDNOTES}

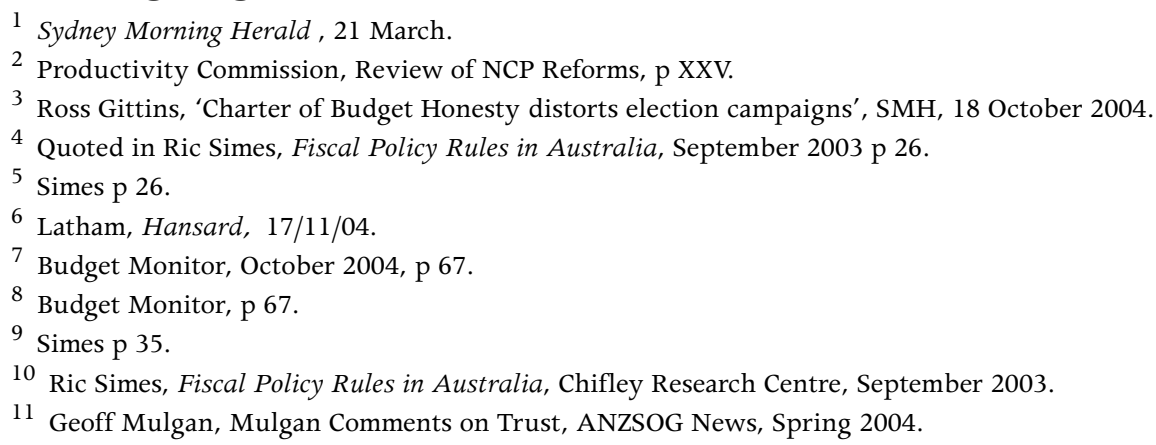





\section{Chapter 3 - Beyond Conspicuous Compassion: Indigenous Australians Deserve More Than Good Intentions}

\section{Senator Amanda Vanstone, Minister for Immigration and Multicultural and Indigenous Affairs}

\section{Lecture presented 7 December 2005}

I acknowledge the traditional owners of the land on which we're meeting today. I acknowledge the richness of the culture that prospered here in the past and also the strength of the culture that continues to enrich Australians in the $21^{\text {st }}$ century. However I must also acknowledge the frustration of looking at the last 30 years of Indigenous policy in this country and not seeing results anywhere near good enough to show for it. Life for too many of our first Australians continues to be unhealthy, unhappy, violent and short.

\section{A time for change}

Surely we can all agree on one thing. For First Australians, this can not be as good as it gets, it cannot be the best we can do. We can, and we must, do better.

For the Australian government, states and territories, the public service around Australia, the private sector, the community generally and First Australians themselves, things have to change. The goodwill at different levels of government and across party lines is such as I have never seen before.

We have an extraordinary opportunity for change. To grasp that opportunity we must be prepared to tell it like it is and we cannot accept lower standards for First Australians than we do for other Australians. This rare opportunity has to be seized. We have to be sure footed. We need to face reality. Indeed, a reality check is nearly always more effective and much, much fairer than half-baked promises.

As they do with other Australians, all governments have to accept their proper responsibilities for First Australians. Government departments have to deliver. The private sector needs opportunities to play a part. Equally, Indigenous people have to accept responsibility and play their part.

\section{More than good intentions}

Good intentions are all very well but will not be good enough on their own. We need to be prepared to make the tough decisions. We must back Indigenous 
Australians in their aspirations and in building their future. The time for thinking that we know what's best for Indigenous Australians has passed.

The environment will be challenging for those who are comfortable indulging in what has been called 'conspicuous compassion' - a culture of ostentatious caring which is about feeling good, not doing good. Caring but not making change condemns Aboriginal people to some sort of cultural museum where they should expect less than others. Some people find conspicuous compassion quite therapeutic - for themselves. These are the people who still feel uncomfortable with mutual obligation and fret about what is needed to tackle welfare dependency - who would rather see another generation of Aboriginal Australians marginalised than confront the debilitating effects of passive acceptance of handouts.

If we are going to change things we have to be able to call a spade a spade. I see more willingness from people like Sue Gordon, Warren Mundine and Noel Pearson to confront these realities than from possibly well-meaning but out-of-touch commentators. In my experience Aboriginal people have no problem with the notion of mutual obligation or shared responsibilities. These principles draw very much from longstanding aspects of Aboriginal culture - in central Australia, for example, the Ngaanyatjatjara (nundarra) people have long used the words Ngapartji Ngapartji to describe what we would call mutual obligation.

In the name of self-determination, it seems that Aboriginal and Torres Strait Islander Commission (ATSIC) did little more than set up Indigenous people for failure. The hands-off approach of governments - at all levels - helped institutionalise mismanagement, corruption and exploitation. It allowed self interest and the unscrupulous to undermine attempts to make things better.

\section{Standards}

It is time to start treating Indigenous Australians like every other citizen. They can no longer be denied the opportunities that other Australians expect. They need to be given every opportunity to share in the rich experience of Australian life.

We must overcome the sense that ordinary Australian aspirations are out of reach for Indigenous Australians. Things like: healthy, happy kids; a good day's pay for a good day's work; and, aspirations for a better life. Expectations can and must be lifted. The idea of Indigenous people as passive recipients of whatever governments provide has to be rejected once and for all.

For too long we have accepted a different standard for Indigenous people. The understandable abhorrence of the injustices of the past has led in some ways to a reluctance to be critical and to respond firmly when we should have. A fear of doing more harm led us to doing very little. Why have we tolerated more neglect for children in remote Aboriginal communities? Why do we tolerate 
inadequate school attendance? Why do we accept less in terms of educational standards? By doing so we condemn Indigenous kids to a life with less opportunity than as Australians, as First Australians, they are entitled to.

\section{Responsibilities}

There is no way to avoid it - different standards have short-changed Indigenous people. We must not accept poorer levels of service or poorer outcomes for Indigenous people. This is why the Australian Government decided last year, to end the practice of separate policy development and program delivery for Indigenous people.

The programs previously administered separately by ATSIC are now being administered by mainstream departments which now clearly carry the responsibility for providing services to all Australians. They cannot pass the buck on these issues.

At the same time we are requiring them to work together to solve problems that cross many areas of responsibility. No one should underestimate the difficulty of pulling together this kind of whole-of-government approach. The 'stovepipes' of government policy and programs have grown up over many decades and cannot be undone overnight. This reform task is the other side of shared responsibility - governments taking responsibility for their bit. Shared responsibility means Indigenous Australians taking responsibility in their own communities; but it also means governments delivering on their responsibilities.

That said, I am proud of how far we have come over the last 12 months. We have successfully negotiated 121 Shared Responsibility Agreements with 98 communities. Some of these agreements may seem modest to outsiders, but as the expression of the aspirations of these communities and the desire to improve the lives of their children, we are starting to see some hopeful signs.

Our Indigenous Coordination Centres (ICC) which are located all around the country - from Kalgoorlie to Nhulunbuy, Roma to Ceduna, Tamworth to Melbourne - are meant to lead this process from the ground up. These ICCs are made up of teams of people from different departments. We have put the people together and the task now is to get them working together and to respond directly to the needs of local people. In some places such as NSW they are also co-located with state government staff.

In Canberra there is an unprecedented commitment to driving real change in the way governments do business. The relevant Ministers meet together regularly as do the Secretaries. None of this is easy, bureaucracies have a history of failing Aboriginal people. But we are going to keep pushing ahead, we are determined that the service the Australian government provides will be less complex, more flexible and make a real difference. 
It is pleasing to see that some states and territories are making important moves in the same direction. While I appreciate the growing level of cooperation from the states and territories, nonetheless we will occasionally have disagreements. Some will not agree with my view that all the states and territories should be much more transparent in accounting for what they do with and for Indigenous Australians. For example, it might interest you to know that $\$ 1.1$ billion of Goods and Services Tax (GST) revenues flowing to states is diverted to those jurisdictions with higher proportions of remote Aboriginal populations such as Queensland, Western Australia and the Northern Territory. There is little transparency in what happens to this money and how much of it finds its way to Indigenous people.

I am keen to ensure that all money allocated to improve outcomes for indigenous people is actually reaching them where they live - and not bloating bureaucracies, both government and non-government, or being used for other things. I am also sure the states such as NSW and Victoria with lower proportions of Indigenous people and which therefore subsidise the other states and the northern territory are as interested as I am in ensuring that it is being used for the purposes intended. If this money is being invested wisely we should be able to look forward to the day when the relative disadvantage has diminished and redistribution on this scale will not be needed.

Governments do not always have the solutions. It is very heartening to see the private sector's growing role in Indigenous affairs. Forward-thinking mining companies have long seen the value of a constructive engagement with Indigenous people. It is inspiring to see major banks, retailers and others in the corporate sector really engaging with Indigenous Australia and getting results that governments would not achieve. I could tell you about some of them but I am a bit worried about promoting one bank or retailer over another. There are potentially many more creative ideas within the private sector that could respond to some of the issues facing Indigenous people.

\section{Land}

Aboriginal land provides an excellent example of different standards being simply accepted without question. In the Northern Territory 45 per cent of land is Aboriginal land. However as I have said before, being land rich but dirt poor is not good enough. There is no romance in communal poverty. It crushes individual motivation and condemns all too passive acceptance of more of the same. Something has to change and it will.

The government's commitment to protect the right of communal ownership of Aboriginal land is rock solid. It will be preserved for future generations. Within that framework we have started a new and productive debate about how Aboriginal people can draw economic benefits from their land. Recent 
announcements in conjunction with the Northern Territory are the first steps in helping Aboriginal people to own their own homes and to develop businesses in townships, just as we non-Indigenous people have always been able to do.

The current arrangements actually leave many Aboriginal people without control over their lives. This is because traditional owners are but a subset of people who live on Aboriginal lands. The historical displacement of Aboriginal people has left many Aboriginal residents of communities on Aboriginal land which is not their own country and therefore they have no traditional power and no real security of tenure. They live effectively in a feudal system at the pleasure of the traditional owners, which unfortunately sometimes involves arbitrary decisions that pass out largesse to favoured family and friends.

While acknowledging the justice of the land rights decisions, I think there is an underlying injustice here that needs remedying. Our proposals to streamline leasehold arrangements, where traditional owners agree, and to provide incentives to purchase homes will go some way to improve this situation. When implemented, they will provide incentive for the development of businesses to service Aboriginal towns and the people in them. Importantly, they will also give people the chance to effectively own their own home.

The National Indigenous Council in this area has done some tremendous work. The general reception to our recent announcements on land rights and native title has been refreshingly constructive. I am all for a robust debate on the merits of different approaches. But at last it seems that maybe we are slowly moving away from some of the old entrenched ideological positions in Indigenous affairs and towards a more business-like appraisal of the benefits for Indigenous people. This can only be for the better.

\section{Townships and homelands}

Giving people a chance to own their own home is an important step towards having the same standards. We also need to look at treating Indigenous communities as what they are - small towns.

If we called the larger Aboriginal communities towns instead of communities, it might help put the difference in perspective. You might be confronted with questions like:

- Why doesn't the Council look after things like water, rubbish and sewerage in this town?

- Why do kids in this town not go to school?

- Why do the authorities not seem to care?

- Why can you not buy your own house in this town?

- Why do people not pay rent for their houses? 
These are ordinary questions about ordinary things that do not happen in these places because they are dealt with differently. We want that to end.

Why should essential services in these towns be provided by annual grants from the Commonwealth and not through the same sort of arrangements that work in hundreds of other little towns around Australia?

People in communities should not have to be burdened with responsibilities for town infrastructure which most of us in this room would struggle to manage. Community councils should be able to concentrate on tackling local issues and building capacity and hope in the future. Then they should not be worrying about next year's power contract. Indigenous community structures are fragile enough without being ground down by being landed with responsibilities for delivering services that are rightfully the responsibility of governments.

Some jurisdictions are moving in the right direction. In the Northern Territory, for example, we are working quite closely with the Territory government to establish Regional Authorities that essentially extend local government arrangements to remote Indigenous people. In other words, normalisation and delivery of government services.

This normalisation relates to the major townships. However we need to think about the large numbers of very small settlements or homelands. There are around 1,000 communities with less than 100 people, and of those, more than 80 per cent have less than 50 people. Despite the higher rate of population growth of Aboriginal people, it is unlikely that many of these homelands will grow to become viable towns. We have started talking to the Northern Territory and other governments about these issues.

They raise some important issues for the future such as:

- How viable are they?

- While some are doing OK and helping with drug rehabilitation and maintenance of culture, others may be risky environments, particularly for women and children

- What level of amenity can be expected to be provided to small settlements in some cases hundreds of kilometres from each other?

All Australians living in remote areas of the country have less access to services and support than those in more populated areas. There is an acceptance of a level of self-dependence. Perhaps we need to explicitly draw a line on the level of service that can be provided to homeland settlements.

We need a wider debate about this. Listening to Indigenous Australians does not mean blindly accepting, for example, that services - such as education, health and housing - can be delivered at equal levels and equally well in 
townships and the homelands for the same people. We have to be realistic and we have to be honest.

\section{Education}

Education is another area where for too long different standards have been delivered and different standards have been accepted. And guess what we have ended up with - different standards again for First Australians. In many of our remote schools different standards are expected of Indigenous children. We use excuses like cultural difference to explain to ourselves why they cannot learn. Does this mean we are saying they are somehow less intelligent? If you expect less and then you give less, you get less.

Second-rate education offering the preservation of Indigenous culture as its objective does not provide a basic education that Indigenous Australians should be able to expect.

Everywhere in the world, hope for the future starts with education. Parents not sending their children to school is a powerful statement of their loss of faith in a better future. The longer it takes us to tackle this, the more children are missing opportunities to truly determine their own future.

States and territories must take action to get kids to school and retain their interest. They must recruit bright and effective teachers who will relish the challenges and rewards of making a difference, like in Cherbourg. States should start publishing attendance rates in communities. Unless we face reality, we cannot hope to build a better future. Some of our innovative approaches such as the 'no school, no pool' initiative are starting to pay off. We need more new ideas.

\section{Conclusion}

For kids, education is everything. But we cannot hope to give that to them if their communities are not safe, their housing is inadequate and their health is lousy. As I said before we have never had opportunities for change like those that are before us today. We do not want to look back in 10 years time and say that we wished we had taken the chance when the opportunity was there for the taking.

We will waste that opportunity if we are not prepared to tell it like it is. We have got to be courageous and deliver results. Good intentions are not good enough. Indigenous Australians must be able to expect the same range of opportunities as other Australians. No more cultural museums that might make some people feel good and leave Indigenous Australians without a viable future. Continuing cultural identity does not require poverty or isolation from mainstream Australian society. 
We are talking fundamental change, changing the way governments relate to Indigenous Australians. Making sure they deliver to their Indigenous citizens as they do to all other citizens.

As long as 100 years ago, Theodore Roosevelt, in a very elegant political speech entitled 'A Strenuous Life' highlighted the point that worthy goals are not easily achieved. The changes we need to make will certainly not be easy but, as Roosevelt pointed out, a strenuous life is a life worth living. 


\title{
Chapter 4 - Shaping Opportunities, Creating Public Value: Government and Community Collaboration in the Australian Capital Territory
}

\author{
Jon Stanhope MLA, Chief Minister for the Australian Capital \\ Territory
}

\section{Lecture presented 31 August 2005}

I begin today with a cautionary tale. The substance of it will no doubt be familiar to this audience, even if the detail is not. It is a reminder of the work that still needs to be done before there is any consensus - even a broad one - about what community consultation and collaboration involves, and what it means.

A little over a week ago, the deadline passed for submissions to a discussion paper the ACT government issued earlier in the year on the subject of formally recognising same-sex relationships. As often happens with these things, there was a flood of last-minute submissions - probably two-thirds of the 300 or so submissions came in during the week before the cut-off. While it looks like this late rush may have significantly evened out the scales, the majority of the early-bird submissions were clearly opposed to formal recognition of same-sex union. The government had expected that imbalance, had made no secret of the fact, and I made no secret of it either when I faced the local television news cameras on the day submissions closed.

I thought the questions put to me by one television journalist that day were instructive. First, I was asked whether, if the majority of the submissions were opposed to same-sex union, I would abandon the pursuit of formal recognition. In other words, would I be guided by the will of the people. The second question was equally enlightening. I was asked whether, since the number of people who would be affected by any outcome - in other words, the gay and lesbian community - was quite small, the whole exercise was a waste of time, energy and resources.

I think you can probably anticipate my answers. On the first issue I pointed out that this had not been a referendum, nor even an opinion poll. On the second, I wondered aloud whether it would be considered a waste of time and resources to address the basic rights of any other small minority — say, Indigenous people. 
The journalist's first question betrayed a common misapprehension about public opinion and community consultation, and was a reminder of the corruption, in this age of talk-back radio and instantaneous, SMS reality-television voting, of statistical concepts that once had a clear scientific meaning.

The second question betrayed a misapprehension about the meaning of democracy. Together, the two questions went to the substance of tonight's topic - to what extent do consultative governments risk allowing their priorities to be dictated by the barometer of shifting public opinion over an election cycle? And, as a corollary, to what extent must the creation of opportunity and the delivery of true equity for minorities be driven by government, even in the absence of a groundswell of public desire? In short, how can governments collaborate with the community to create things of value without abrogating their responsibility to make decisions about the best allocation of resources?

Here in Canberra, in the early years of the 21st century, we are privileged to live in an age and in a place of great opportunity. Vast communications, financial and distribution networks link our immediate world to those of our near and distant neighbours as never before. Our cultural, intellectual, economic and social horizons have never been broader, nor so easily within our reach. But the opportunities created have not been distributed evenly. Some groups and some individuals have been excluded or denied participation. In some ways, our capacity to control and predict our own environment has diminished, as events half a city or half a world away have come to affect our lives more directly and more swiftly.

The days have passed when the town hall, the church or the local factory was the forum for the common civic experience of most people. And yet, there is still some sense in which many of us yearn for those simpler structures, those shared narratives of who we are. Witness the continuing popularity of clubs the aggregate membership of clubs in the ACT is about 420,000, larger than the total population. Witness too the warmth with which people respond to opportunities to come together in celebration or commemoration. When the ACT government inaugurated the Canberra Gold awards this year, to recognise those who had given more than 50 years of their lives to this city, it was staggered to receive a thousand nominations.

ACT governments have within their reach a great resource, in the form of the combined talents and skills of the community they serve. They ought to make better use of that resource. It would be a poor, naïve or overly confident government that believed it had the answers to everything, that it was the repository of every good idea, that it had its finger simultaneously on the pulse of every part of society.

Inclusion, consultation, collaboration are vital if for no other reason that governments cannot hope to consistently deliver public value merely by 
consulting their own feelings or their own consciences. Of course, this conversation with the community, in its most blunt and basic manifestation, occurs periodically in parliamentary democracies in the form of elections - a pretty clear message of how well a government is seen to have used its mandate to promote the common good.

Here in the ACT we do pretty well when it comes to this particular form of consultation. Our Hare-Clarke voting system is arguably the most democratic in use anywhere in the country. At last year's territory election, voter turnout was the highest on record and the informal vote - one important measure of disenfranchisement - was just 2.7 per cent, compared with a national average of around 5 per cent.

But an election is a form of conversation - a form of consultation - that has certain limitations. The most obvious is that elections are infrequent. Another is that they deliver a judgment, but no reasons. Another, even in a nation with compulsory voting, is that they exclude too many members of the community - everyone under 18 for a start, along with others who have been, for whatever reason, voluntarily or involuntarily, alienated from the democratic process.

The ACT government came to office knowing for certain that such pockets of alienated, excluded individuals existed. We could see their shadows flit across the life of this affluent, educated society. Our ambition was to see the shapes that cast those shadows, to put names to them, to give them a voice.

Such an ambition does not always meet with the approval of those who already dominate the spotlight and who already have the loudest voices. When I travelled to Junee earlier this year to ask some of the ACT prisoners incarcerated there what they would most like to see in the prison we are building here in the territory, there was a predictable chorus of outrage from those who believe that prisoners should be neither seen nor heard - that, in effect, they have no rights, and no insights to offer.

As it turned out, the big concerns of the inmates to whom I spoke were not the quality of the meals or the comfort of the mattresses or the television reception. The single biggest concern - the single biggest fear - of these big, tough, prison-hardened men, was what awaited them on the outside, on the day their sentence ended and they walked free. And let me assure you, most of them will walk free, sooner or later. The question is whether we, as a community, intend to give them a fighting chance to set their feet on a path that will not lead straight back inside.

I believe that when we talk about governments creating opportunity, we can not just mean opportunities for intellectual stimulation for our smart students, opportunities to break into export markets for our brightest entrepreneurs, opportunities for our finest and most talented sportsmen. We must also mean 
opportunity for those students who struggle in class. We must mean the opportunity for a charity clothing shop to create a pleasant working environment for its volunteers, with no expectation that it will ever be listed in the Forbes 500. We must mean the opportunity for every child to participate in sport knowing that no gold medal will result, and with no greater outcomes intended than fun, participation, and good health.

You can not create those opportunities without engaging. You can not do it without listening. You cannot know what the charity shop needs to make the life of its volunteers more comfortable until you ask. You can not know what struggling students require unless you consult their teachers. You cannot know what sport will be popular with youngsters unless you put the question.

One of the most humbling and instructive moments in the life of any ACT Chief Minister is the fortnightly Chief Minister Talkback segment on the local ABC radio station, $6662 \mathrm{CN}$. It doe not really matter what issue of great political moment has been in the news over the course of the week or how many censure motions have been passed or what fiery debate has accompanied the passage of what contentious Bill. You can be confident that most callers will still want to talk about the need for a stop sign at their local intersection, or a tree branch obscuring a street sign, or the parched state of their local oval.

Part of this focus can be traced to our hybrid form of government here in the ACT, which amalgamates municipal and state functions. Here in the ACT the Minister for Health will, as likely as not, also be the Minister for school ovals. The Attorney General will, in all likelihood, also be the Minister responsible for overhanging branches.

There are downsides and upsides to this administrative model. One downside is the tendency for critics to dismiss the Assembly as a 'jumped-up town council' and to howl down any attempt by MLAs to voice an opinion on anything that strays beyond the purely parochial. It is disappointing that, a decade and a half after self-government, there are still those - some of them MLAs - who belittle the Assembly and argue that the focus of its members must always, and entirely, be on the potholes and the stop signs, and never on the more philosophical questions of what kind of society we wish to be. I believe that in the best of all worlds even local councils, even ordinary citizens, ought to be involved in that sort of discussion.

One of the big advantages of our hybrid status is that Canberrans enjoy an ease of access to ministers and a familiarity with the machinations of government that is quite unusual. Any Canberran knows they can speak to me directly just by dialling the ABC every second Friday morning, or by heading out to one of the government's frequent community Cabinet meetings. 
This unique administrative structure gives the ACT the opportunity to create avenues for collaboration and participation that are not easily available to other jurisdictions. Here in the ACT the government that educates your child is the same as the government that empties your bins. It has seen you at your best and your worst, and has been seen by you in the same way.

But while opportunities for closer interaction and collaboration exist, the question remains what shape these mechanisms should take, and to what end should all that mass of collected opinion and those lists of suggestions be put.

Alexis de Tocqueville spoke of 'intermediary' associations between the state and the individual, in which feelings and opinions were recruited, the heart was enlarged, and the human mind was developed by the reciprocal influence of citizens upon one another. Such associations need not always be formal, nor long-lasting, though sometimes they must be. They can range from ad hoc public meetings to opinion polls to formally appointed task forces with a narrow focus, or advisory bodies with a broader but still thematic purview.

The more formal these consultations become, the more they are open to manipulation. It is relatively difficult to control or direct a one-off public meeting on a matter that has aroused community passion. But it is easy enough for a government to stack a board or a consultative committee and then to claim that its findings - with which the government just happens to agree - are legitimate since they have been independently arrived at.

There are also significant risks in uncontrolled, or unmediated, consultation. A government that is scrupulous in its consultation, yet which routinely ignores the results of that process, brings consultation into disrepute as swiftly as one that stacks its committees.

This is not academic. It goes right to the core of consultation. What can be expected from a consultation? What do those who are consulted expect themselves? Must the opinions garnered be acted upon, if the process is to have any standing? Is it worth the effort, the anxiety and the inevitable misunderstandings and misinformation?

And make no mistake, it can involve anxiety. Consider the example of the government's recent consultation over a proposal to close Ginninderra District High School and build a \$43 million pre-school-to-Year-10 government school campus in West Belconnen. Before the government could consult, it needed something to consult about. The minister could not just go to the community with a blank sheet and then, six months down the track, bring to Cabinet a notebook full of uncosted ideas.

So the government developed a comprehensive proposal and then went to the community. Instantly, we were accused of presenting the community with a fait accompli, and of having no real intention to consult at all. 
Some weeks into the consultation period we announced that some of the alternative proposals suggested by residents would be tested by a consultant. Suddenly, we were accused by critics of backing down. 'Government backflip on school', crowed the media, which just days before had been berating the government for its so-called pretence at consultation. I doubt the absurdity or the inconsistency of the criticism has been much relished by those with the greatest interest in reaching a workable solution - the parents and students of West Belconnen.

So, is it worth it? Is consultation worth it? In the end, the answer must be yes - even in West Belconnen. Yes, the value derived from consultation outweighs the ambiguity and the cost.

The ACT government is philosophically committed to drawing the community deeper into the conversation about what kind of society we want to be, and how we go about creating that society.

That is why we have gone to the effort of producing a Community Engagement Manual that guides agencies through the process. At an international conference on engaging communities held in Brisbane recently, delegates voted the manual the most valuable document they took home from the whole conference.

It is why we have worked to improve the gender balance on government appointed boards. If the opinion of the boards did not matter, their make-up would not matter much either. Their opinions do matter, but the Government believes those opinions ought to be more representative of the community. In our first term of government we managed to achieve an overall gender balance on all government-appointed boards.

As I said, consultation can take many forms. When the ACT government was consulting the community on the issue of a bill of rights, we commissioned a deliberative poll - the first regional one to be held in this country - to draw out the issues and to measure whether fully informing a community about the pros and cons of a controversial issue might cause public opinion to shift.

As I am sure you know, the idea of a deliberative poll is to draw together a representative sample of the community and expose it to the full range of arguments for and against a proposition, allowing it to ask whatever questions it likes, to probe as deeply as it wishes, to really wrestle with the issues.

As you probably also know, Australia's first deliberative poll, held in the last days before the republic referendum, generated a measurable shift in opinion among participants.

A measurable shift was recorded by the $\mathrm{ACT}^{\prime}$ 's deliberative poll on a bill of rights, too. At the outset of the process, opinion was weighted 60-40 against a bill. By the end of the period the balance was 60-40 in favour. 
Sadly, deliberative polling is a pretty costly and disruptive way of gauging informed community sentiment. It will only ever be one of an array of mechanisms in the armoury of a consultative government. Others are needed. The challenge is to know which mechanisms are suited to which circumstances. Another challenge is to ensure that the terms, definitions and underlying assumptions each party brings to a consultation are roughly equivalent.

The Italian political theorist Danilo Zolo believes that finding such a common language is almost impossible. He argues that the meaning of an event experienced in one social environment - a religious experience, for example cannot even be properly translated into terms that can be understood in a different environment - a sports club, for instance, or an office, or a nuclear research laboratory. I suspect this might be overstating the case. I think people are more socially and intellectually flexible than he allows. But his point is taken and it is a reminder that effective consultation is more complex than simply insisting that the conversation be conducted in plain English.

One thing that would ideally be settled at the outset of any consultation is just what a government hopes to achieve from the process. What does it seek? If it is public good, how do we define, measure, or even detect, the creation of 'public good'? How do we measure whether the creation of that public good has flowed from consultation, or from some other source?

A fairly traditional view of governance is that it is the job of governments to exercise authority in pursuit of the common good or public interest. This authority is manifested in the laws, regulations, policies, programmes and services with which a government surrounds itself, and through which it pursues its aims. This authority can also be manifested, though perhaps more obliquely, in attempts by governments to articulate a vision that will influence the tenor and mood of the times. The Canberra Plan, the current ACT government's social, spatial and economic blueprint for Canberra, is a vision of this sort.

At the most prosaic level, 'public value' can be described as those public goods and services that are 'valued by the public'.

Governments generate public value by producing or organising the production of public goods. These go beyond tangible things such as services and security. They include such nebulous goods as public trust, tolerance and civic participation.

But must a public value be consciously valued by the public in order to be deemed valuable? How do we know what the community values; and how do we balance conflicting or unrealistic community desires? Might not the very act of routinely consulting the community escalate community expectations or encourage unreasonable demands? Consultation is a risky business. 
But risk, well-managed, is a stimulus to innovation and invention. And the more practised in consultation a community becomes, the better able it is to see that creating public value, creating opportunity, is not necessarily cost-neutral that it can involve sacrifice and trade-offs. The more accustomed the public becomes to consultation, the more it comes to understand that public value exacts an opportunity cost.

And there is another potential advantage to be gained from consultation. The community is likely to put a greater value on a public good that it has had a direct hand in fashioning, a public good towards which it feels a sense of ownership. Making the community a joint architect in the creation of public value means that the community has a vested interest in its success or survival. Such a community is likely to not just involve itself in the planning phase, but to remain engaged, to involve itself in the delivery and administration of the public good it has helped create. Neighbourhood Watch, a collaboration between police and the community, is one obvious example of this vested interest at work.

Over the past three decades or so there have been fundamental shifts in the way we think about and undertake public administration.

The guiding principle of early thinking about public administration was 'efficiency'. And this remains an important principle, even today. But much has changed since Sir Phillip Whistler Street defined public administration in 1935 as 'the management of men and materials in the accomplishment of the purposes of the State'. We still strive for the most effective management of personnel and resources, but few of us would argue that the goal of administration should any longer be baldly described as the 'purposes of state'.

Since World War II, our political and administrative systems have been deeply transformed by social change and communication technologies. The vocabulary of public administration has been complicated by the arrival of managerialism, economic rationalism and, contractualism. The practicalities of administration have been altered by a new belief that the user must pay and by a trend towards decentralisation that has seen the rise of school-based management, the demise of the Australian Government Printing Service and the privatisation of the Commonwealth Employment Service.

As the structures of administration have altered, sometimes beyond recognition, so have the community's expectations of what it should and is capable of delivering. Somewhat paradoxically, these elevated expectations have coincided with a growing sense among some commentators over the past decade or so that our democratic institutions - parliaments, political parties, bureaucracies, legal systems, media, and other civil organisations - have become fatigued and incapable of interesting and involving citizens and the broader community in public life. 
Personally, I believe the doom-merchants are probably looking nostalgically back to a golden age of global civic engagement that did not really exist. This is dangerous because it mystifies the past as a civic or social 'utopia' in which all members of the community participated fully in public life. Such mythologising conveniently overlooks the long periods of even relative recent history during which large numbers of individuals were not only formally disenfranchised but effectively excluded from full social engagement in a host of ways - not least women.

The very idea that the community is now 'disengaged' from public institutions implies that 'engagement' is not just the preferred, but the normal state of affairs, from which we have carelessly allowed our institutions to drift.

What is unquestionable is that people now engage, with each other and with government, in quite different ways. Communication technologies have had a massive impact. Information that in the past could only be gained by attending a public meeting or a political rally can now be gleaned from television or the Internet. As newspaper circulations decline, the chat room and the blog continue their march towards the domination of public conversation.

E-government is transforming the capacity of governments to reach into people's lives, inform them, elicit their opinions and encourage their participation. At a purely functional level, e-government means that a growing number of services and a growing mass of government information is available 24 hours a day, seven days a week. Reports, fact sheets and discussion papers can be downloaded by anyone with Internet access. And the interaction can be two-way. When the ACT government wanted to test public reactions to proposed new off-leash dog areas recently, it solicited online comments. Arguably, there are more avenues and easier avenues for public participation in civic life than ever before.

It is true, sadly, that there is a greater than ever cynicism about politics and politicians - particularly about election promises - but it cannot be assumed that this is synonymous with political disengagement. Nor can it be assumed that it signals some crisis of trust.

Building some workable degree of community trust in government is one of the enduring challenges of government and it is a challenge that is not made any easier by the competitive, adversarial nature of politics, in which parties actively seek to undermine community trust in each other.

At its most dangerous and counterproductive, this sport can, of course, undermine public trust in institutions beyond the elected government. To give just one example, gratuitous criticism of the police, aimed at wounding a government, can instead wound public confidence in community safety and security. Thankfully, in my experience, the public tends to be just as cynical about those seeking to do the undermining as it is about those being putatively 
undermined. Moreover, I believe that electorates are willing to respond to governments that reach out to the community, governments that take an inclusive approach, governments that prove that they want to know what the community thinks - not just the 5 per cent or so of the community that decide elections.

I believe that for all the talk about a disengaged electorate, there is ample evidence that many people want to be engaged, want to have a say, and are looking to play an active role in shaping the life of their neighbourhood, school, town centre, and city. They are prepared to listen, but they also want to be listened to, to have their local expertise and intimate local knowledge valued and incorporated into policy-making and program delivery. Our community is quick to embrace opportunities to contribute, when they are offered. We encounter no difficulties in drawing together diverse gatherings for special groups like the Dragway Advisory Committee, which gives space and voice not only to motor-sport proponents, but to local residents anxious about the possible impact on their local amenity.

The challenge for government is not really to motivate the community, but to better harness their already considerable motivation. In his book The Wisdom of Crowds, James Surowiecki observes that politics is ultimately about the impact of government on the everyday lives of citizens. And he wonders why anyone would imagine that the way to do politics well would be to distance yourself as far as possible from the everyday lives of citizens. Mind you, I have never quite understood either why anyone who had not enjoyed a long and close association with community life would desire a political career, which seems to be a logical extension of community activism and involvement, rather than a vocation in its own right.

As I said earlier, I believe that the administrative structure of the ACT, combining municipal and state functions, lends itself in quite exciting ways to closer community collaboration and involvement - and not just within discrete portfolio areas. One of the ACT government's ambitions has been to take a more holistic approach to government. That is why we have woven together our economic, social and spatial ambitions under the single banner of The Canberra Plan. It is why we established the Community Inclusion Board, which can range across the policy spectrum in its quest for strategies to combat disengagement and social exclusion, rather than focusing solely on education, or economic disadvantage, or disability. It is why, a year ago, we introduced the country's first bill of rights, The Human Rights Act, to ensure that every government agency brings to its dealings with the people a consciousness of the human-rights implications of its actions.

The ACT is home to a vast number of vocal and vigorous not-for-profit community organisations and consumer advocacy groups. Because a large number of us have worked at one time or another in government, most of these groups 
have individuals in their ranks who are well and truly conversant with government processes and who know quite well how to get the ear of government or, failing that, how to get under the skin of government. Of course, we must always be cautious in assuming that these groups truly represent the sections of society for which they claim to speak, and on whose behalf they claim to advocate. We must always take care to go beyond the usual suspects in seeking opinions or forming partnerships. In reality, in a city of lobby groups, the silenced, excluded sections of society may still be inadequately represented.

No government can be aware of the minutia of the challenges that confront sections of the community, down to the level of the individual or the family. We cannot know, unless we are told, that making a modest investment in the soundproofing of the entrance to The Street Theatre Studio, for example, will stop noise spilling in from the café. We cannot know, unless we happen upon the truth, or someone tells us, that basic structural repairs to the Stephen King Memorial Centre will transform the venue for the Vietnam Veterans who meet there.

What governments can do, and what the ACT government seeks to do, is to create channels that ensure that such minutia of feed into our decision-making processes. We do this through initiatives such as the Renew Community Infrastructure and Facilities Program - which provides small but meaningful grants that help revive ageing community infrastructure, and the Community Grants Program. These programs are a recognition that the creation of public value comes in many forms and guises. Community initiatives sometimes need only the smallest injection of public funds - micro-funds, if you like - to flourish. But that potential will remain latent unless the community knows that support is available or if it feels intimidated by government structures.

Success requires more than political will. It requires a commitment to community engagement to imbue every agency that acts in the name of government. The community engagement manual is a crucial resource in this respect, guiding officials and steering them through some of the reefs and rocks that confront the unwary or the inexperienced. These include the unintended creation of bottlenecks, the risk of creating barriers to participation without the consultative mechanisms themselves, the danger of mistaking unrepresentative for representative views and of polarising or alienating sectors of the community. I cannot pretend that the ACT government is always exemplary in its attempts to involve the community in creating its own civic destiny. But I do know that we strive to engage as fully as we can.

I could cite many examples of collaborative work we have undertaken, but will highlight just one partnership set up under the Community Inclusion Fund, because it encapsulates many of the themes I have discussed in this lecture. 
On advice from the Community Inclusion Board, the government is providing $\$ 116,000$ over three years to the Majura Women's Group in Downer, in partnership with ACT Mental Health, to take its 'Mums at Home in the Community' program further afield, into Tuggeranong. For a number of years, this self-run community group has encouraged women with young children to come together for a couple of hours each week, to talk about their experiences and learn new skills. Each year the women set themselves challenging projects. Last year they completed a fantastic mosaic for the Queen Elizabeth II Family Centre. This year, with the help of an artist in residence, they're designing and making two felt wall hangings for the mothers' rooms in the Mental Health Unit at Calvary Public Hospital. By combining on-site childcare, which gives the women some time to themselves, and project-based activities, the women have developed a model for dealing with some of the characteristic problems and risks that can confront mothers at home - including social isolation, low self-esteem and post-natal depression.

While it is too early to say whether the model has successfully been transplanted to the southside, the project shows the real public value, the real public good, that can flow from genuine partnerships between government and the community, born out of the community's own instinctive awareness of where the gaps exist, and what might fill those gaps.

It was Woodrow Wilson who described the networks, organisations and associations that make up the social fabric as 'self-originated, self-constituted, self-confident, self-sustaining, veritable communities'. Sometimes. But sometimes, in our complex world, the community alone is not equal to the challenge. Sometimes, self-sufficiency needs to be supplemented. In truth, neither the community nor government holds all the answers. But in combination, there is little that cannot be achieved.

As Chief Minister I am often thankful for our hybrid administrative structure here in the territory. I truly believe that it is a gift to government, an unparalleled opportunity to reach deep into the community, to engage with the community, to make the kinds of small inroads and forge the small partnerships that have large and lasting legacies. 


\section{Chapter 5 - Twenty-First Century Workforce Demographics and New Challenges for An Egalitarian Society}

\section{Dr Sharman Stone MP, Minister for Workforce Participation}

\section{Lecture presented 30 August 2006}

Let me begin right up front by acknowledging the traditional owners of this part of this country. I think it is a very important protocol now to establish and recognise the traditional owners. One of the things I was very pleased to do was to represent the Government on the Council for Aboriginal Reconciliation for three years because my earliest writings were about Australian race relations.

I have to say that I cannot be more pleased with the Ministry I have, Workforce Participation, because all of my working life and all the time I have spent in Universities has been working to try and overcome disadvantage. For example, I have worked in prisons with, in particular, Aboriginal prisoners and I have worked in very small communities as a community development officer, in the days when we had the Australian Assistance Plan in the 1970's. I will never forget when I walked in to this job interview on the first day after my university graduation and they said, 'your job will be to empower the people'. For me that was just what I felt it was all about - I wanted to empower people.

We are at a time in Australia where we facing a number of important challenges and where we need to respond with real changes. I hope that tonight we can have a conversation and have questions and statements from the floor so I can hear your views. I promise I will not talk forever. Clearly no Government has got all the answers. Reform is an evolutionary process and what better place to have this conversation than in a university, like this.

Let me begin by saying how I define egalitarian society. This is where individual status is achieved, not ascribed at birth, and where there is no institutional support for creating or perpetuating a stratified society. We have such a society in Australia and we're proud of it. We are a society that aims to give everyone a fair go. This is not to say of course, that it is not much harder for some than others to reach their full potential. It depends a great deal on your birth and your family's circumstances. For example, it is much harder to achieve in Australia if there is no breadwinner in the family and where there hasn't been one in several generations of the family. It is much harder to achieve your full potential if your family is not English speaking or not literate. It is much easier 
to have access to good educational facilities if you are born into a better off family than if you are born into one that is disadvantaged.

It is my job as Minister of Workforce Participation to help disadvantaged Australians to achieve their potential, to help the long term unemployed and the disadvantaged from being condemned to depression, social isolation, stigma, exclusion or discrimination. Society measures individuals by what they do in the form of paid employment.

Bruce Headey, from the Melbourne Institute, has done a lot of work on the impact of joblessness. He found that while joblessness was a transitory phenomenon for many households, there were significant numbers of households which were persistently jobless.

Indeed, in any given year, around 16 per cent of working age households are jobless in Australia. Nearly 10 per cent of these experience persistent joblessness for three years or more. Single parents are twelve times more likely, and people with a disability six times more likely, than the rest of the community to be persistently jobless. We have about 600000 children growing up in households where no member of the family is in employment. Joblessness often couples with poverty, financial stress, depression and poor physical and mental health. Joblessness also causes a twofold increase in the chance of marital break up and halves the chance of ever partnering or re-partnering.

It goes without saying that our welfare system needs to be comprehensive and generous enough to provide an adequate living for those without their own means of support because of, for example, old age or because they are too sick or disabled or have parental responsibilities without a supporting partner. Obviously in a society like ours it is fundamental that we have a safety net and that we help those who are not able to support themselves. However, over the last few decades, our welfare system in Australia has slipped out of alignment with expectations and community practices. Some elements of the welfare system have created disincentives for people to move from welfare dependency and into paid employment.

To put this in context, Australia has enjoyed over a decade of economic growth. With the Government's reforms since 1996, we are living in an economic climate of low inflation and low interest rates. The unemployment rate is at 30 year lows and we have experienced nearly 17 per cent growth in real wages. More than 10 million Australians are now in work, 7 million of them in full time work. Over 1.9 million jobs have been created since 1996 and long term unemployment has fallen from 197,000 in March 1996 down to 95,000 now - about a 52 per cent decrease. It is fantastic, indeed it is!

However, there are also around 2.5 million people of working age in Australia that are receiving working age welfare payments. Of those, about 500,000 of are 
officially unemployed, receiving the Newstart payment and required to look for work. The other two million people are receiving pensions, and are not required to look for work, made up of about 700,000 people receiving the disability support pension and around 600,000 receiving parenting payments, the large majority of whom are single women. Amazingly, despite the fact that we have not had a huge number of workplace accidents or a shocking deterioration of health standards in Australia, the number of disability support pension recipients has grown by over 60 per cent in the last 11 years such that the cost to the taxpayer of disability support pension payments is now around eight billion dollars per annum.

Now, of course, besides the concern I hope I have expressed to you about the personal impact of unemployment on the individual, unemployment is not a benign experience. Long term unemployment poses real risks of social isolation for families, particularly where it becomes intergenerational. One challenge that we face is that many jobs are not advertised.

I was in Ballarat yesterday and I found that 70 per cent of employers have a preference for word of mouth as a means of employing people. Something like 60 per cent of job vacancies in Ballarat are not advertised. If you do not have any member of your family in your household that is in work, then you are outside the loop for hearing of or knowing where many of the jobs are. You do not hear about the new maternity leave vacancy because your mother and grandmother are not in work. You do not hear about the new apprenticeship vacancy that has come up at your uncle's place of work. Employer's preference for word of mouth, and not advertising their job vacancies, makes it extraordinarily difficult for our unemployed to get a job, particularly where they do not have a network, such as through members of their family, that can speak on their behalf and help them find work. One product of these circumstances is intergenerational unemployment. Work ethic is a learned behaviour just as parenting is. If you are not aware of what it takes, what you have to do, how to present in a job interview and what is expected of you at work, it becomes very challenging for you to succeed in a job without assistance. It is very difficult for children to learn appropriate work ethic when they are living in a jobless family and this substantially increases their chances of being unemployed themselves.

While we are concerned about the impact on individuals and families of unemployment, we are also concerned with the declining ratio of those in work compared to receiving working age welfare. The balance between tax payers and dependent welfare claimants has shifted from the 1960's, when three per cent working age population was on welfare, to around 17 per cent today. In the 1960's there were 22 tax payers supporting one person on welfare. Today, this ratio has collapsed to five tax payers for every one welfare dependent person. 
If this trend continues, we will be down to two to one in a decade. Based on current trends, we cannot sustain this level of welfare spending.

A further challenge we are facing is Australia's ageing population. The baby boomers, and I am just on the cusp of a baby boomer generation, are reaching retirement age. Our natural population increase has not kept up with the baby booming numbers and we do not have a substantial number of new births pushing up behind the baby boomers. This is a problem afflicting many countries. In Japan, UK, USA and New Zealand, we are all asking, 'How are we going to fix this problem and sustain our economy?'

We obviously need sufficient human capital to maintain our economic strength and keep our business sector growing. We have had recent surveys done by the Reserve Bank, and an ageing workforce consistently rates as a first or second order issue for large sized enterprises. Some people keep talking about the 'skills' shortage. However, the point is that it is not just at the skilled end, it is our entire labour force. We have shortages in the trades and in the tertiary qualified highly skilled end of the market. We have a huge shortage in the health sector and also in engineering, particularly mining. But we also have a significant shortage in entry level positions particularly in the retail, manufacturing, hospitality, tourism and agriculture sectors. So a lot of businesses are constrained in their further growth because they cannot get workers.

The Department of Employment and Workplace Relations (DEWR), my department, recently asked Monash University to do some analysis on the workforce for us. We had the Intergenerational Report, that Peter Costello launched, which gave us a longer term look at these issues, but the Monash Research, entitled Workforce Tomorrow, had a five year forward look the trends in our workforce. It projects a 195,000 person workforce short fall in the next five years across all sectors. Just as significantly in numbers in the retail, manufacturing, hospitality, tourism, agribusiness and in areas of trades and other specialties.

So what are doing about all of this? We have three policy drivers for how we tackle our current situation. In 1996, when we were elected, we had the Commonwealth Employment Service, a public sector operated service. When we came to office, we felt that it was not good enough nor performing well enough so we immediately began to look at better ways of assisting the unemployed into work. First thing that was introduced was Work for the Dole in 1997. People were very concerned about this. They said, 'That's shocking, using the dole to stigmatise and label people and what's this mutual obligation business?' In fact, our Work for the Dole program has been extraordinarily successful. 42 per cent of our participants in the programme, after six months, are either in work or are directed into employment related training. 
In 1998 we also introduced the Job Network program, and this was a revolution, a very bold move. It was all about providing Australian Government Employment Services, through a contracted out model, in a competitive environment where providers are paid on outcomes, for putting the unemployed into jobs. A ratings process, called Star Ratings, are used to track the progress of providers so when a new tender round comes through we have a way of rewarding the better providers.

It had been extraordinarily successful. In the last six months, Job Network Providers have placed more people in jobs than the last six years of the Commonwealth Employment Service (CES). I am not saying that it is as good as it can be, but it is evolving and I am certainly working very hard to ensure that administration and bureaucracy is at a minimum and that we remove any perversities in the incentive structure from the Job Network program in order to have people placed into jobs as soon as possible.

Job Network is just one part of it, there is also the Disability Employment Network, Vocational Rehabilitation Program and the Personal Support Program, which helps those who are jobless but also homeless and who may face other barriers such as drug and alcohol dependency or mental illness. We also have a youth programme, Job Placement Employment and Training (JPET). There are nine separate programmes in Australia, a constellation if you like.

These programmes form the structure through which we are delivering Welfare to Work but let me outline the policy basis behind this structure. As I said to you, we have this incredible trajectory of increasing disability support pensions. We also have significant underemployment, compared to the Organisation for Economic Cooperation and Development (OECD), of our parents on pensions. We are still amongst the lowest in the OECD countries in terms of the employment rates of people receiving disability benefits and there are sixteen other countries that perform better than us. We have the third highest rate of jobless families in the OECD.

We do not have a very good record compared to other OECD countries, which is why we are doing things differently now. On the 1 July 2006, we implemented our Welfare to Work reforms. If you were a parent on Parenting Payment, single or partnered, in the past you were allowed to stay on that payment until your youngest turned 16. This caused problems because by that stage, women in particular, their skills were rusty as they have been out of the workforce for a long time. By the time the youngest was 16, a lot of parents felt that there was not much hope at all of re-entering the workforce.

So now since 1 July, when your youngest reaches six, you will go to Centrelink who will sign you to a Job Network or Disability Employment Network provider and we will give you every support to upgrade your skills. You can, for example, go and get a nursing qualification or teaching or whatever you like and you will 
continue on the pension until your youngest is 8 . But if you have not got a job by then, you will be transferred you onto an unemployment payment, Newstart.

We believe that in the current environment, if you are really trying you will be employed within those two years. We are making sure that there isn't a problem with your childcare and we have put conditions around what is a suitable job. For example, parents will only be required to accept the job if it is appropriate, if there is access to affordable childcare, it is not more than an hour away from where you are living and that you clear at least $\$ 25$ a week more than the pension or allowance you were on. That is, on the minimum wage, being $\$ 12.75$ per hour, if you are working the minimum 15 hours a week, you are still $\$ 4500$ better off a year working than if you stay on the pension. And of course that is just the monetary advantage. When we survey people, they tell us all the time, particularly parents, 'It is not the income, I want to work and I want to get back and build my own independence, rebuild my networks and get back in touch with where I was'. So our parents are going to be substantially better off than before.

With Disability Support Pensioners (DSP), most of our people on DSP are mature age men with skilled backgrounds but who have muscular skeletal problems which put them on to DSP. In the past to get on DSP you went to your Doctor and then took a medical certificate to Centrelink, who granted you the DSP. In other words, if you couldn't work part time, we parked you on DSP until you reached Old Age Pension age. This is very bad for people, particularly for those with depression, anxiety and/or phobias. We know through extensive Australian research that the best thing you can do for people with a mental illness is help them back in to the workplace, a supportive workplace.

This has all now changed. Of course the people on DSP before 1 July are 'Grandfathered' and their situation doesn't change. But from 1 July 2006, if you present with a medical certificate you will be then referred to a Job Capacity Assessment with work specialists and rehabilitation specialists and they will assess how many hours you can work. If you can work in a job at least fifteen hours a week, then you will receive Newstart not DSP, and we will very actively help you be upskilled, supported back into the workplace and we will work with employers to ensure they understand your condition. We will give you every opportunity to work. For example, we can provide workplace modification grants, which can be used to put in a ramp, change your lighting and change your software. We have also implemented a Supported Wage System. If you are assessed as being only 60 per cent productive because of your impairment, through the Supported Wage System, the Government conducts a special assessment process and the employer will not be required to pay more than 60 per cent of the award wage. 
I mentioned to you the preferred employment process in Australia is word of mouth. We want people to think outside the square and take the risk of employing people they may not know. Our industrial relations reforms have made this much easier, particularly with the removal of unfair dismissal laws. They have also made it much easier to have a part time job or work at home.

We believe through these changes that we are giving our 2.5 million Australians of working age on welfare a better chance. We are not prepared to sit back in our society and say, 'Well let's hope that somehow they get themselves a job.' We know that unemployment can be intergenerational. We know that unemployment leads to stress and pressure on families and individuals. We know we have an ageing population and that we have to do something about increasing our workforce participation in Australia. Finally we have that issue of the declining ratio of welfare dependent working age persons to tax payers and we have to think very seriously how we redress the decline.

So I will leave it there. I have not talked much about our Indigenous Australians, who as many of you know have a much harder time with intergenerational unemployment and higher unemployment rates than others. We have to get rid of the idea of sit down money in remote communities where there is work. We are also looking closely at our humanitarian refugees that also experience higher rates of unemployment. I have a special focus on how we are going to support them in to work, particularly by improving the teaching of English to these groups.

Let me finally say to you that we are an egalitarian society and across our great nation there a lot of people who are not reaching their full potential. As Minister of Workforce Participation, my aim is to make sure that our Government is able to do more and to do better for people who deserve better. 



\title{
Chapter 6 - Australia/New Zealand Public Servants: Mates or rivals?
}

\author{
Dr Mark Prebble, State Services Commissioner, New Zealand
}

\section{Lecture presented 26 October 2005}

I am going to talk tonight about public service matters, and the relationship between Australian and New Zealand Public Servants. This is because I am a life long bureaucrat, and my mind tends to turn to public service type issues.

For example, last month when hurricane Katrina was battering the state of Louisiana in America and we all watched the story unfold, my mind turned to public service related questions. I wondered how well prepared we would be to meet such a problem. I wondered whether our City Councils would cope with such devastation, and whether our Police would stay on the beat. I hope that our liaison between the central and local governments would be more robust than that between the New Orleans Council, the Louisiana State Government and the American Federal Administration.

The media, perhaps reflecting the wider interests of their readers, did not focus very closely on such matters. Instead, they looked at people and their lives. In particular, as I imagine may have happened here in Australia, we heard stories about New Zealanders who were caught up in the disaster. Besides some Kiwis it included a few residents, some backpackers and some older tourists.

During aftermath of the event, one of the most widely reported stories in the media was related to a young New Zealander who was rescued from the chaos at the New Orleans Convention Centre by an Australian media crew.

Notably, some of the most widely reported stories in the New Zealand media were related to travellers and citizens from other countries being assisted by both American and International media crews. In particular, the assistance provided to New Zealanders by the Australian media was seen in New Zealand as a very friendly act between good friends, which it was.

But my public service mind turned to the question of whether this level of friendship, or mateship, could be expected to prevail between the public services of our two countries, Australia and New Zealand. Can we naturally expect that we will help each other out in all circumstances and always immediately understand each other's needs? Does that degree of friendship exist between Australian and New Zealand public servants, what is the 'proper' relationship 
between us and what is needed to ensure that the best and most effective relationship is maintained?

I want to discuss the relationship between the public services first in the context of the relationship between New Zealanders and Australians in general. I will move on to look at the interests and drivers that particularly affect the relationship between public servants. I will then conclude with some thoughts about processes and initiatives that we could each pursue in order to strengthen effective relationships.

Turning first to the contextual essence within which our public services interact is a close relationship between the people of two nations. I do not intend to attempt to sum up that relationship. That is the business of politicians. I certainly do not intend to review the mystery of our 'identity'. That belongs to academics and artists. And I will not even attempt a more analytical summing up of our national interests and programmes. That is for diplomats. I am a mere public official, and I want to focus on the way in which our two respective officialdoms interact.

The picture is overwhelmingly positive in that New Zealanders and Australians move freely between our two countries and mix together in many contexts. Statistics from the last few years show that nearly half a million New Zealanders live in Australia, and fractionally over one tenth of that number of Australians live in New Zealand. This means that over two per cent of the Australian population is made up of people described as New Zealanders, and over one per cent of the New Zealand population are Australians.

It is not a matter of migration: there are also very large numbers of short term movements, facilitated by the free movements of people across the Tasman. There have been special arrangements between our respective governments for travel since the 1920s and these were formalised by the Trans Tasman Travel Arrangement in 1973. The effect is substantial. Trans Tasman tourism accounts for approximately half of total arrivals and departures in New Zealand every year. That is, Aussies coming to ski at Queenstown and Kiwis going to sit on the beach at Surfers. It is Aussies coming to see a green country and Kiwis coming to see a red country. It is Aussies and Kiwis going to visit friends. This is an example of the friendship between our two peoples.

Evidence of this is found in the recent Cosby-Textor 'mood of the nation' poll which was conducted in August 2005 in Australia. It surveyed some 500 Australians. They were asked to assess various nationalities on a range of characteristics. When asked which nationalities were likeable, New Zealanders scored the highest, with 90 per cent of those surveyed rating New Zealanders as likeable. 88 per cent scored New Zealanders highly for our shared values, and 79 per cent identified New Zealanders as honest and trustworthy. In all these respects, New Zealand scored higher than any other nation. 
In another poll this year, conducted by the Lowy Institute, Australians were assessed on their positive regard for various countries. Understandably, the most positive assessments went to countries with which Australians have longstanding, deep and stable relationships. Europe had an 85 per cent positive rating and the UK was 86 per cent. New Zealand scored highest with a rating of 94 per cent.

Clearly such ratings must fluctuate, depending on events for the day. For example, feelings ran strong after the collapse of Ansett Airways Australia, and because of Air New Zealand's involvement New Zealand did not receive positive stories in the media. Similarly, whenever we in New Zealand are impertinent enough to win some sporting event it can lead to strong feelings at the pub. But there are strong aspects of our history which will tend to underpin the relationship between our two nations as formative parts of our history are shared.

We share our British colonial experience, our commitment to democracy and our tradition of the Common Law. There are strong economic ties, especially in banking, and the Closer Economic Relations Agreement has provided bi-lateral free trade in goods and services between our two countries since 1990.

Our troops, police and diplomats have stood together in many contexts, especially around the Asia Pacific region. For example, in the Regional Assistance Mission to the Solomon Islands, Australian and New Zealand support was critical in facilitating the cease fire. Neutral venues for negotiation between the parties were provided on HMAS Tobruk and Newcastle, and also HMNZS Te Kaha. Since July 2003 the Australian-led regional assistance mission has worked jointly to restore security and effective operation of Government, with a major commitment from New Zealand. We are currently providing a \$20 million per annum aid programme, around a $\$ 7$ million police support programme with about 35 police officers, and support from our Defence Force.

Earlier this century, Australia and New Zealand worked actively together in East Timor, where New Zealand had a battalion with armoured vehicles and helicopter support. For three years that group worked alongside Australia to bring security to East Timor.

As we look forward, our defence forces plan co-operatively together. In practical terms, this has meant New Zealand purchasing equipment the same as or compatible with Australia. For example, in 2004 New Zealand signed a contract between the New Zealand Government and the Australian ship builder Tenix, to build seven new ships for the New Zealand Navy. The New Zealand Government has also announced its intention to purchase NH90 helicopters, and as the Australian Government has also selected the NH90, this ensures significant co-operative benefits for both nations. Then there is sport, which does not just extend to people as we share common interests in horse and harness racing and bloodstock. 
The picture is almost complete, except for language, where, in Winston Churchill's famous statement about Britain and America, we are two nations divided by common language. Though hardly anyone else around the world can tell the difference, Kiwis and Aussies can usually identify each other by our accents straight away. And if you are not sure, all you have to do is suggest a meal of fish and chips to sort out the identity problem. And all Aussies and Kiwis quickly learn the importance of never counting items together, or if they do, we should never count to the number beyond five, because inevitably it leads to serious social confusion.

So, if language is the only significant difficulty in the context between us, surely it must be automatic that our two public services can always operate as one. It must be possible for us to circulate between each other's offices and jobs. After all, there are currently four Australians occupying positions as head of New Zealand public service departments and one of them has recently adopted New Zealand citizenship.

As I move from the broad context to consider relationships between our public servants, it is not hard to find examples when things have not been as happy as one would hope between two close friends.

So what is it about public servants? Are we just naturally unreasonable? Are we uniquely selected from the argumentative people of our two societies? of course, that is not so. The reason for continued difficulties arising must come from the jobs we do and the interests that we represent. So, are there interests that drive us apart and propel us into different positions?

Clearly there are differences. At the most basic level, we may be close, but there are differences in our locations. We are both surrounded by water, but Australia is very close to the nations of your immediate north, and those nations have significantly different cultures to the common Trans Tasman culture. Additionally, a New Zealander must fly the Tasman before we arrive at another country, and that country is Australia.

There are differences in endowment. Australia has a vast land, mostly dry. New Zealand has a small land which was memorably described by a former Prime Minister as 'pluvial'. As a result, though we both have significant agricultural interests, the importance in New Zealand of pastoral and horticultural trade is much more relatively significant than it is for Australia.

There are also some differences in world view. New Zealand's adherence to a nuclear free policy has contributed to a difference in our foreign policies. We both stand for and defend freedom and democracy around the world, but Australia's alliance with the United States is stronger than New Zealand's connection. 
But none of these differences are determinative. I suggest the difference is much simpler and more basic. The essential difference is that Australia and New Zealand are two separate sovereign nations. We will each decide our own future. And as those decisions are made it falls to public servants to give effect to those decisions and to give effect to whatever differences that might arise between our two nations.

It is obvious that it would be public servants who feel the difference most acutely, because it is public servants who give effect to and live by the respective sovereign decisions of our two governments.

In this respect we should remember that the basic characteristic of sovereignty is that there is no lawful means for one sovereign nation to impose its will on another.

As you know, states within a federation can resort to processes to resolve differences. This might involve the law, or changes of government through the ballot box. Separate sovereign nations, however, must rely on persuasion, and the effectiveness of cool and rational persuasion is always undermined if there is some emotional overlay or tension. In my experience, there can be plenty of tension. And some of that is generated specifically by doubts about each other's attitudes to sovereignty.

There are, for example, many New Zealand officials who believe they know Australian officials who cannot accept that New Zealand is a separate sovereign nation and not a state of Australia. And what is more, not only do those New Zealand officials believe this is the attitude of those Australian officials, but it may be true that the Australian and New Zealand people are of the same belief. Conversely, I have come across Australian officials who believe that New Zealand officials are so precious about New Zealand's sovereignty and so suspicious of Australian actions, that there is no point in attempting to do business with us. Once again, it may well be that there are New Zealand officials who do in fact hold such defensive views as are imputed to them by those Australian officials.

All this is a rather convoluted way of saying that sovereignty is the point. The fact that we are sovereign nations, whose writ does not run in each other's nation, means that if we are to conduct business, we must do so diplomatically. Oddly enough, diplomacy is not necessarily made easy when there are very strong and warm people to people relationships. On the contrary, it is the very fact that our two populations get on so well together that creates extraordinarily high expectations in the quality of the relationship between public servants. When we cannot meet and maintain that high quality relationship, then our disappointment leads us into a potential for mutual frustration and recrimination and this leads to disappointment when there is a loss of trust between very close friends that may lead to real bitterness. 
The message is that it is up to us as public officials to maintain the highest level of professionalism in our relationships so that misunderstandings are avoided and opportunities for co-operation are pursued. And this brings me to the third area of my speech which is my menu for a Trans Tasman official's relationship. I believe that, in a context of a warm people to people relationship, divided by the imperatives of sovereignty, it falls to Australian and New Zealand public servants to maintain a strong and effective professional relationship. In doing so, we have the benefit of some great modelling by our political leaders. The relationship which Australia and New Zealand have is better developed and more extensive than that between any other countries.

Our two Prime Ministers meet annually and consult frequently. For a number of years the Foreign Ministers have met twice yearly to discuss the overall relationship and foreign policy co-operation. Our Trade Ministers and Defence Ministers have met annually for some years and our Finance Ministers have started to meet annually.

New Zealand Ministers are invited to participate in many Ministerial Council Meetings in Australia on domestic policy agendas. This means that our political leaders have many connections which can be drawn on when necessary.

As well as these political connections, the private sector is taking a lead. In the last couple of years the Australia New Zealand Leadership Forum has brought together major figures from both sides of the Tasman for a couple of days of in-depth informal discussion. This is already improving understanding in both countries and stronger networks are developing.

So, with that lead from political leaders and the private sector, my question tonight, is 'what can we do to make sure that New Zealand and Australian officials have connections and institutional frameworks which will work to minimise misunderstanding and assist resolution of difficulties?' I have a suggested recipe with three ingredients.

The first ingredient is that, when we have two groups of public servants who must sometimes work together across the differences of sovereignty, it is valuable to build networks, especially by learning together. That is why the Australia and New Zealand School of Government is a fortunate and timely opportunity to build networks.

In each of the last three years New Zealand has sent 20 students to join 100 Australian students in the Executive Masters in Public Administration Course. We have sent 15 senior officials to join some 65 Australian senior officials in the Executive Fellows Programme. And next February, I expect to send half a dozen New Zealand Chief Executives to participate in the first ANZSOG Chief Executives Forum, among 30 participants all told. 
All of these events are developing highly trained people with shared experience and new networks. We, in Wellington, are already seeing the benefits as more of our staff understand aspects of the Australian system and know more people to contact in times of difficulty. Building networks always helps when building diplomacy.

The second ingredient is to build shared experience through co-operation. This is not new. New Zealand and Australian officials have worked together in many contexts. In defence and security, we have stood together in many battles since Gallipoli. In diplomacy, our diplomats very often work together in the United Nations and in trade. For example, we are both currently negotiating a Closer Economic Partnership with the 10 member states of Association of South East Asian Nations (ASEAN) to facilitate trade flows between Australasia and South East Asia. We have also acted jointly in the past, for example, in a complaint to the World Trade Organisation (WTO) against the US lamb safeguard mechanism.

But even more importantly, we increasingly see co-operation between New Zealand and Australian agencies on joint issues. For example, we now have very close co-operation on passenger processing arrangements. When people check in on flights between Australia and New Zealand, information is exchanged in real time about the passengers and their documentation. Any necessary measures can then be taken before the plane leaves either New Zealand or Australia. This requires very close co-operation between officials of both countries, supported by compatible information technology systems and close sharing of information. That requires constant maintenance of relationships so we can each take our own sovereign decisions.

There are other examples involving the development of joint accounting standards, harmonisation of business law and related areas. Taken together this amounts to a significant agenda to achieve a joint ideal of a single economic market.

The third ingredient, where sovereign nations must respect the fact that we cannot require the other to accept our will, is to devise means by which we can agree to make joint decisions. The evolution of joint agencies, such as Food Standards Australia New Zealand is an example of this.

The most exciting example of this is the proposed Australia New Zealand Joint Therapeutic Products Agency. This has been some years in the making, and was agreed between our two governments a couple of years ago. In the period since, officials have been working to design the details of the joint agency. The process has not been easy. It turns out that there are significant detailed differences between our countries. For example, the Commonwealth Authorities and Companies Act contain different provisions from our Crown Entities Act. These differences include the extent to which we rely on formal and informal sanctions against appointees to public bodies. That has not previously mattered as we 
relied on harmonisation of rules, but if, through a joint institution, we are to make joint rules, then we need joint authority.

The work of designing the joint institution is difficult, but is well worthwhile, because we both stand to make gains in economies of scale. And a joint institution which draws its authority equally from the governments of its two member nations will maintain our two sovereign interests, while allowing public servants to work together. If we can get this right, we may have devised a new and robust way for the public servants of both countries to work together to meet our mutual interests.

So, that's my menu. First, we build networks and learning through ANZSOG. Second, we co-operate on as many issues as possible. And third, we devise institutional structures which respect our sovereignty and allow us to work together for the common good.

We need all three of these ingredients, and possibly more, because we are mates, but at the same time, we can be rivals. As loyal servants of our respective sovereign governments we can serve our nations and work well together for the mutual good. 


\title{
Chapter 7 - Towards a New Era of Strategic Government
}

\section{Professor Geoff Gallop, Graduate School of Government, University of Sydney}

\section{Lecture presented 25 October 2006}

\begin{abstract}
For the last two decades of the twentieth-century New Public Management dominated political theory and practice. It involved the incorporation of the market model into the public sector itself and the re-orientation of and reduction in the role of the State in the economy. Departments became agencies, statutory authorities were corporatised and many privatised. Public servants became public sector managers responsible for delivering on agreed performance targets in their agencies, most notably efficiency targets. The level playing field replaced state intervention as markets rather than governments determined resource allocation.
\end{abstract}

In recent years, however, we have seen a new tendency emerge - Strategic Government. It involves the outlining of a vision, the setting of objectives and targets in consultation with the public, the development of strategies to achieve the objectives, and the formation of collaborative arrangements within government and between the government and private and community sectors to carry out these strategies. It is often linked to a new concern for and belief in the sustainability principle and its triple bottom line of economic, social and environmental objectives.

Strategic Management has emerged from the contradictions within New Public Management - between efficiency and effectiveness and between individual choice and public provision. Democratic pressure has not just pushed for a more holistic resolution of these contradictions but also for new powers and interventions to deal with complex problems associated with poverty and social exclusion, to tackle the new policy agendas in health, education, community safety and welfare, and to respond to the threats posed by terrorism and global warming.

Increased relationship complexity associated with Strategic Government requires new capabilities for public servants and moving beyond the simplicities associated with the 'Let the Managers Manage' depiction of public accountability and ministerial responsibility. 
Threats to institutional autonomy and individual freedom, created by aspects of Strategic Government, require an increased concern for/and institutionalisation of the principle of subsidiarity and new human rights protections in our laws, as has been done in the ACT and Victoria.

\section{Introduction}

I am delighted to be contributing to the Australian and New Zealand School of Government's ANU Lecture Program.

The creation of ANZSOG and indeed the Graduate School of Government at the University of Sydney where I teach is an indication that public administration is returning to its rightful place as an essential element in the study of government and politics.

Politics is not just about theory and policy it is also about administration and implementation. Systems have to be administered and policies implemented.

The way this has been, could be and ought to be done is a matter that warrants serious theoretical and practical investigation.

The study of public administration has broadened its horizons as governments have come to expect their heads of department not just to administer but to manage change and create value. This has paved the way for new terminology, in this case 'public management'.

For those who practise public management the emergence of Graduate Schools of Government has been timely. They have complemented the wonderful work of our institutes of public administration and the innovative thinking associated with our schools of public policy today. To be involved in the public sector is to be at the cutting edge of some of the most creative thinking associated with political and social inquiry. If you want a demonstration of this, look up the website of the Strategy Unit in the UK Cabinet office. ${ }^{1}$

We are interested in systems and outcomes, processes and outputs, and strategies and operations.

The long-standing debate about ends and means has been given new meaning as we explore the relationships involved more intensively.

That public servants themselves have been given the opportunity to reflect on these matters through their participation in graduate programs augurs well for the future.

Of course I come to these discussions after 20 years as an elected representative in a State Parliament, three years of which were as a minister and five years as a premier. 
Public servants were always there - informing and advising, helping and counselling, worrying and warning, planning and arranging, and occasionally (and I emphasise occasionally), scheming and obstructing.

Without them the system simply couldn't work. They are part of an equation that involves both the political and the administrative arms of government. Neither can be properly understood without the other. It is all about relationships. As indeed is politics in general: government and people, public and private, commonwealth and state, state and local, executive, legislature and judiciary, cabinet and caucus, etc.

Many factors can influence the way these relationships develop from straightforward events to longer-term tendencies associated with social, economic, environmental or technological changes. I say 'influence' because in the end politicians have to interpret and respond to these events and tendencies. The way they do - and how successful they are - is a major factor in determining the type of public management we have.

When we reflect on this we should always remind ourselves of the words of John Maynard Keynes:

The ideas of economists and political philosophers, both when they are right and when they are wrong, are more powerful than is commonly understood. Indeed the world is ruled by little else. Practical men, who believe themselves to be quite exempt from any intellectual influence, are usually the slaves of some defunct economist. Madmen in authority, who hear voices in the air, are distilling their frenzy from some academic scribbler of a few years back. ${ }^{2}$

\section{New Public Management}

Tonight I want to reflect on the changes that have occurred over those 20 years. For a large part of that time there was a governing paradigm which we now call the New Public Management. For a couple of years in Carmen Lawrence's government I was it - Minister Assisting the Treasurer and Minister for Microeconomic Reform. I recall representing the Premier at one of the crucial meetings that established the national competition reform agenda for the 1990's.

This was also the time when I had my first of many debates with my media advisers about how to describe and advocate.

I had been on talkback radio and was asked: 'What do you mean by microeconomic reform?'

True to my early education in economics I replied: 'The use of competition to guarantee an efficient allocation of resources throughout society.' 
When I came out of the studio I knew I was in the bad books. My media adviser put it bluntly: 'The punters would not have the remotest idea of what you meant. Economic theory is one thing, clarity and simplicity another.'

'Okay,' I responded, 'how would this go: Making sure the production of goods and services follows consumer demand, and only the best and most efficient in the private and public sectors survive.'

'That's worse,' he said. 'Not only is it too long, it doesn't speak to the day-to-day needs of the punters.'

Feeling challenged but not beaten I made another attempt: 'Reducing waste and increasing productivity in both the public and private sectors.'

Sensing a breakthrough was close, my word doctor urged me to go further: 'You're getting closer, but I am still not clear on what it means for the family budget.'

'Lower taxes and lower prices!' I exclaimed in a Eureka moment.

'Now you're talking the language of the people', he concluded, smiling in the knowledge that mediaspeak had recorded another win in the real culture wars.

What governments took on board were not just new methodologies but a new way of thinking about the role of the public sector itself.

Let me try to define these changes by referring to some of the terminology that was used.

The public service became the public sector as the emphasis shifted from the advisory to the service delivery functions of government.

Senior public servants became public sector managers whose accountability to the government of the day was clearly demonstrated in Public Sector Management Acts that had replaced the long-standing Public Service Acts.

Ministerial responsibility was effectively re-interpreted within the broader context of public sector management generally. Public servants were given more independence and therefore more responsibility. It was a case of 'letting the managers manage.'

Services to the government of the day and to the community became outputs whose efficiency and effectiveness could be measured.

Concepts like benchmarking, comparability, contestability, choice and competition became part of the public sector vocabulary as did the level playing field'.

Citizens and subjects became customers and clients. Government departments became agencies. A range of statutory authorities became government trading enterprises (or GTE's). 
Corporatisation and privatisation became public sector policy options for GTE's and corporate-style management was introduced for departments. In some jurisdictions a range of government agencies were transformed into self-governing trusts.

The changes that resulted have been comprehensive and far-reaching in their impact.

Many GTE's have been disaggregated, corporatised and made subject to competition. Many too have been privatised by both commonwealth and state governments.

New independent regulators have replaced ministers as arbitrators of price and access to infrastructure.

Performance management and external auditing are now fully institutionalised as is accrual accounting.

The strict separation of public and private has been broken down by de-regulation, outsourcing and a range of public-private partnerships across a range of activities.

Contract management, previously the preserve of the infrastructure arms of government, has become central to the work of many public sector agencies. Jeff Kennett's Victoria was actually described as 'The Contract State'. ${ }^{3}$

Given that these were policies that undermined established patterns of power and influence their acceptance and implementation required strength of purpose. Increasingly governments came to seek advice from outside the traditional channels. Consultants were engaged not just as advisers, but to assist in implementation. The size, status and power of Departments of Prime Minister and Cabinet and Premier and Cabinet increased significantly. Top-down change was deemed necessary if public services were to be liberated from the straitjacket of bureaucracy and citizens from limitations placed on their ability to choose.

By the end of the century the reach of this new form of politics and public management had spread into what had been the Soviet Empire and was exerting influence in Japan, Korea, India and China. In as much as globalisation had its theory this was it - a new terminology and a new political economy and public administration for a new era. It descended into pure hubris with the declaration that history had come to an end. ${ }^{4}$

But, of course, history did not come to an end. As Hegel observed of the relationship between knowledge and events: 'the Owl of Minerva only takes flight at dusk, after the changes have occurred. We only know of the full implications of a major change at the very point that something new is taking shape' ${ }^{5}$ 


\section{Strategic government}

In my view we are seeing something new emerge in the public domain. It is a form of public management that is a response not just to terrorism and global warming but also to the contradictions that exist within the practice of New Public Management. This new form of Strategic Government has become the paradigm of choice for governments representing the traditions of both left and right but it suits the instincts of the former more than the latter, particularly when linked to a commitment to the principles of sustainability associated with the economic, social and environmental triple bottom line.

But this is to move ahead of myself. Some definition and description is required. If we turn to political terminology again, subtle but important shifts can be discerned.

Concepts like 'strategic planning', 'joined-up government', 'collaboration', 'partnerships', 'sustainability', 'progress indicators' have been superimposed onto those associated with the New Public Management.

The idea of comprehensive social change is back on the agenda. However, rather than just defining this change in terms of the values and institutions said to be fundamental to human welfare, governments are increasingly describing change with reference to economic, social, environmental and governance indicators, such as levels of employment, standards of health and education, biodiversity, air quality and degrees of citizenship. The argument is simple: if there is such a thing as 'the good society' then surely it will display these features.

In some cases - most notably in Tasmania under the leadership of the late Jim Bacon - the community has been consulted about these objectives and what would measure their achievement. This has given renewed currency to the concepts of 'citizenship' and 'political engagement' ${ }^{6}$

What is also encouraging about the development is its problem solving approach to public policy and administration. Achieving targets requires focus, co-operation across government, and collaboration with the community. It is all about results rather than just inputs and outputs and the results being referred to are 'whole-of-society' results.

Public management is being localised ('place management') and personalised ('case management') as it is recognised that both locational and individual factors are at work in issues like poverty and social exclusion. It is not just a case of taking services to people but of involving people themselves in problem-solving and capacity-building. People are seen, then, not just as citizens and subjects, customers and clients, but as 'co-producers' in the new rights and responsibilities mix of modern politics. 
Nor are these ideas only relevant to areas like welfare and health we also see them at work in transport, crime prevention, water and energy policy. The view that 'the personal is the political' is now established wisdom in respect of meaningful social change and the conservation of scarce resources.

All in all what we see is a more comprehensive definition of the objectives of public policy and management, the setting of society-wide targets, the involvement of the people in the setting of these targets and the implementation of policy, and more co-operation and co-ordination across government and with the private sector and community.

None of this represents a radical overturning of the changes of the last decades of the twentieth-century. Rather, it is a response to the contradictions created by that new contract/managerial state and a recognition of its limitations in the face of new issues and challenges.

\section{Efficiency or effectiveness?}

There was always a tension at the heart of New Public Management practice. Whilst it spoke of the three Es of public administration - economy, efficiency and effectiveness - the position and importance of the last objective effectiveness - was always somewhat problematical. Here we can see the tension between public and private values fully exposed. Was the aim of the exercise to lift the productivity of the public sector or was it to create public value? Was it to serve the interests of citizens as taxpayers or the interests of citizens as clients, customers, or residents? Was it about public good or private choice?

In this battle of ideas and interests 'efficiency' was a winner. It was straightforward - the number of inputs required for a product or service. It was associated with an economic theory of resource allocation via markets. Different jurisdictions could be compared and benchmarks established.

Public sector agencies could be compared with their private sector equivalents and put to the test through outsourcing. Governments saw themselves as corporations looking to maximise the efficiency of their operations in the interests of their owners - the taxpayers.

In many cases this led governments - both federal and state - to conclude that some of their operations should be restructured and sold off to the private sector. In this respect, Australia was no different from many other jurisdiction.

This is not to say that New Public Management did not produce some very innovative and useful methodologies for determining public sector effectiveness, including citizens' charters, the use of consultation techniques, satisfaction surveys and, of course, room for direct choice by the individual. The problem was that the whole notion of effectiveness was framed narrowly around the 
work of the agencies themselves and not on the overall performance of the public sector and the society it served.

Of course some government agencies are like businesses and governments need to be businesslike but governments are not businesses. The sum total of individual interests expressed through the market can never produce the public interest except via the logic of utopia. Considerations related to the long-term as well as the short-term, minorities as well as majorities, social relationships as well as efficiency and environmental amenity as well as economic well-being all need to be taken into account.

For centre-left parties the concept of sustainability became a powerful organizing principle and methodology for policy analysis. Economic strength, social relationships and environmental amenity all became important. Rather than see government as organised to deliver each separately, it was redefined to become a means by which each was tackled together in the search for balanced and therefore sustainable outcomes. Indeed to treat them separately ignored the obvious tensions that existed between them.

Even conservatives came to see the narrowness of the market morality and New Public Management agenda. This was reflected in their rediscovery of 'values' related to family, community and nation. The State had a role to play to protect and promote these values in the market-place of modern ideas.

Strategic planning in government has brought all of these issues to the surface for proper investigation and resolution. Indeed I would argue that a new sense of purpose has been injected into public sector politics and management as common purposes are clarified and tests of and strategies for achievement are developed in consultation with the public.

What is different about this version of planning is that it is not just about command and control. Issues related to individual motivation and community endeavour as seen as just as important as legislation, regulation and public provision. Consider, for example the deeper understanding we now have of the complexities of tackling social exclusion, poverty and long-term unemployment. These complexities - and those related to the search for the triple-bottom line generally - are brought to the surface not as 'determining structures' but as 'problems to be tackled'.

New Public Management was always going to have some difficulty with complex issues such as poverty, long-term unemployment and social exclusion. Its vision of functionally separate and independently managed units of government delivering standardised services to customers or clients worked well for the 'average' citizen. When it came to the differences associated with a multicultural society, the history associated with indigenous disadvantage, the psychology 
associated with poverty and the culture associated with long-term unemployment, it was bereft of solutions.

Thus commenced a range of initiatives in the way public services are delivered such as partnerships with community and business, localised and individualised management and co-production. These initiatives were designed to fill in the gaps between the silos and re-establish the all-important enabling functions of government.

\section{Citizens or consumers?}

The truth is there is a range of contradictions in respect of the way we participate in society - as voters or consumers. In the former we decide as members of a community deliberating on the range and limits of collective provision. In the latter we make decisions for ourselves and our families: which gas company? Which school? What form of health insurance?

There is a tension here that was not fully appreciated as the move to market solutions took hold. The point of public policy was defined as liberating the individual from the straightjacket of collective discipline except in the most basic areas of government provision such as national security, community safety and commercial regulation. Just as the adherents of this approach to government were uncomfortable in the face of politics with all its complexity, confusion, and compromise, so too were the public uncomfortable with the limitations the market model placed on the meaning of public purpose and participation.

By the early years of the twenty-first century both major parties in Australia were being urged by their supporters to ask harder questions about these matters, particularly privatisation. Even the open investment policies of the nation were put to the test when Shell made its unsuccessful bid to takeover Woodside Petroleum.

As a wider range of policies re-emerged as matters for public debate a level of choice returned with the Australian Labor Party (ALP) generally opposed to privatisation (if not to competition) and the Liberal Party generally but not always in favour of privatisation. The role played by State Labor Governments in facilitating this broader debate about 'ends' and 'means' was particularly important.

It has been the State Governments who have pioneered a strategic approach to government in Australia. All of the States have a strategic plan or are, in the case of New South Wales, in the process of developing one: Victoria's Growing Victoria Together, Queensland's Smart State Strategy, Western Australia's Better Planning: Better Services and State Sustainability Strategy, South Australia's Strategic Plan, Tasmania's Tasmania Together 2020, and New South Wales' A New Direction for the Future. 
They all involve developing major themes for government, priority setting around sustainability-type objectives, the setting of targets or strategic outcomes, the involvement of the people and the monitoring of performance. Under the umbrella of such planning some major structural changes have been implemented and new means of public engagement introduced not just around particular policy issues like water, but also through Regional Cabinets and Regional Parliaments. $^{7}$

\section{A new policy agenda}

The move to strategic planning, joined up government and public-private collaboration was not just a response to the contradictions of New Public Management. Yes it did provide for more legitimacy in an age of distrust. Yes it did provide for a sense of purpose within government. Yes it did provide for a more sophisticated debate about the ends and means of contemporary government. Yes it did allow for a more pragmatic mix of public and private endeavour. It did represent the working through of a series of problems that had developed with the implementation of New Public Management.

However, what is as important as these factors is the emergence of new issues on the political agenda that require strong and more strategic government.

In the first place there have been important changes in priority for the big three areas of state government service provision - health, education and community safety. In health it has become clear that policy needs to move beyond the treatment of illness to the prevention of illness. In education the community requires a range of outcomes to be realised as well as the teaching of a particular curriculum. In matters relating to policing there has been recognition of the need not just to fight crime but also to deal with the causes of crime.

At the federal level there has also been a recognition of the need to move beyond income support in welfare to capacity-building and personal responsibility. Issues seen as welfare issues have become employment and training issues just as those traditionally seen as economic (such as human capital) have become personal, social and cultural issues as well.

Traditional models of service delivery - the provision of hospital care and medicine, the unexamined teaching of curriculum, the policing of the streets, and the welfare safety net - are simply insufficient if we are to deal with these broader issues. They are particularly inadequate if we are serious about creating a better way of life generally and for all, no matter what their background or circumstances.

No wonder then that joined-up government, early intervention strategies, public-community partnerships, place and case management and concepts of co-production, personal responsibility, and community policing have all emerged 
as major influences on public sector policy and management and the education and training programs associated with them.

\section{Global warming and terrorism}

In the second place we have seen the new issues of global warming and terrorism having a significant impact on government priorities and their delivery.

Global warming is an issue that requires strategic planning not just within nations but between nations. It is a truly global matter. Not only that, but it requires integration across the traditional boundaries that have separated environmental and economic considerations. It also means integrating longer-term concerns into policy-making today. It challenges not just our mainstream technologies but our culture of consumption.

Because of its importance it has become the policy province for political leaders with central agency involvement in priority setting, policy-making and co-ordination across government.

Strategic planning is also required to deal with the reality and potentiality of natural disasters associated with global warming. Coordination across all government agencies with an interest in crisis management has become a necessity - and is recognised as a contemporary budget and administrative priority.

The same goes for counter-terrorism initiatives within government. Like global warming terrorism has helped facilitate a comeback by state power and government initiative. Attention can be drawn to a number of themes.

Firstly, with respect to the co-ordination of government agencies on everything from surveillance through to incident management, there are not many parts of government that have not been mobilised in the planning process and all levels of government have been affected - local, state and federal.

Secondly, legislation restricting rights and freedoms and extending police powers 'in the public interest' has become commonplace.

Thirdly, matters relating to religion and political difference have become more controversial as governments look to define the contours of citizenship and better integrate minorities into the mainstream. From being a regulator and a facilitator the State is also drifting into the role of 'educator'.

In many ways the terminology of a 'War on Terror' tells us a good deal about the increased role of the state as the important separations of political and military and politics and policing are blurred. Governments say that they must plan to avoid terrorism and deal with the eventuality should it occur. Laissez-faire is no longer an option. 


\section{The re-birth of the state}

Planning, then, is on the march as governments define their objectives on the basis of the triple bottom line and the new threats posed by global warming and terrorism. In working to achieve these objectives a renewed emphasis on the role of the state, increased co-ordination across government and partnerships with the community have become part and parcel of public management.

The belief that public concerns could be contracted out or left to the market for resolution by way of 'the cunning of reason' has experienced a significant defeat at the hands of democratic logic and the needs produced by contemporary history. Governments are simply not in a position to deflect responsibility when it comes to matters of life and death and matters about which the public wants real rather than rhetorical solutions.

There are, of course, different versions of strategic government depending upon the political colours of the parties involved. For conservatives, planning with respect to the new terrorism is given priority. For centre-left governments, planning to cover the field of economic, social and environmental concerns is given equal weight. For left-liberals, the planning involved in countering terrorism is seen as counter-productive and authoritarian beyond the limits of acceptability. It is the case, however, that all have moved beyond the era of New Public Management. The State is no longer being hollowed out. It is being given a new sense of purpose and a new content with the wider planning, co-ordinating and facilitating roles being developed.

It is not, however, like the State of old. At the very heart of the politics of Strategic Government is a recognition of complexity, the inevitable clash of values, and the importance of civil society. There is an understanding that not all knowledge lies within government and that engaging the public is not an optional extra but an essential ingredient of good government.

The overarching theme is one of government alongside the community working with it to solve problems. This means more collaboration between levels of government, within governments themselves and between governments and their communities. An enormous range of relationships are formed, within which there are complicated patterns of accountability.

\section{Accountability and strategic government}

The fact that the different levels and functions of government are now overlapping raises important questions for our democracy.

What does it mean for democratic accountability?

What does it mean for ministerial responsibility?

What does it mean for public service practice? 
One of the essential features of a good system of democracy is proper balance between the centre and the regions and the regions and the localities. As governments join forces to solve problems there is a risk of too much centralisation and standardisation. This can undermine more localised accountabilities, reduce meaningful choice in elections, and stifle innovation in policy and practice.

In Australia the link that is often drawn between national development, nationalism and Commonwealth power makes this an ever present threat to good government.

In order to respond to this potential threat to institutional autonomy, we would do well to incorporate into our debates and ultimately into our system the principle of subsidiarity. This aims to ensure that decisions are taken as closely as possible to the citizen and that serious questions should be asked as to whether action at higher levels is justified in light of the possibilities available at lower levels of government. ${ }^{8}$

The same principle applies when considering relations between the government and the non-government sectors. Sometimes the pressure of incorporation may come at a price that is too high, as various welfare agencies have determined in relation to the Federal Government's welfare-to-work policies.

When it comes to ministerial responsibility Strategic Government has brought with it a degree of inevitable confusion. In this case I believe it is a good thing because of the simplicities and impracticalities associated with both the Westminster doctrine and the New Public Management revision of that doctrine.

Whilst it was clear that the Westminster doctrine of ministerial responsibility was clearly deficient in the real world of public management, its reverse, most commonly described as 'Let The Managers Manage', had a corresponding political deficiency.

Firstly, its radical separation of ministerial power and public sector management was not feasible in a world of marginal seats, targeted lobbying and media aggression. To put it another way, there is often a tension between policy rationality and the inevitable messiness of democratic politics.

Secondly, its tendency to shift blame from politicians to public servants took some of the sting out of democratic accountability. Indeed there was something implausible about reducing ministerial responsibility to effective communication of government policy and the setting of performance targets for which public servants were held accountable.

The changes that have come with Strategic Government see ministers back into the managerial equation. Indeed in some of the jurisdictions which have developed plans, lead ministers have been created to chair collaborative initiatives and given strategy-setting, negotiating, and monitoring roles. However, public 
servants are still very much in the seat of policy delivery and human resource management, for which there will be clear accountabilities but now we see more balance in the relationship itself and in our understanding of responsibility.

This takes me to my third question about public service practice. It is no longer a case of delivering a particular service. It involves a set of relationships and situations of complexity and even ambiguity. New skills related to public engagement and consultation, project management, managing in a society of diversity, working in teams, developing a multi-disciplinary knowledge-base and planning for the future have all become indispensable even though awkwardly placed alongside our current systems of performance management and public accountability.

The bigger question is whether or not the patterns of accountability and public sector capabilities that are developing in this new era of Strategic Government will be enough. Not only is there a risk of too much centralisation in the system of government there is the related risk of too much power going to government generally. New Public Management required governments to perform fewer functions but to be strong in the way it carried out those functions - what Andrew Gamble called in his book with the same title: The Free Economy and the Strong State. ${ }^{9}$

Strategic Government, on the other hand, is requiring governments to do more and in different ways - facilitating, co-ordinating, partnering and enabling. That being said it is still the State we are talking about and you cannot have states without governments and politicians. Note also the new powers being taken on by the State to 'protect' and to 'educate'. These are powers that can be abused in a society of diversity and robust debate. As a community we need to ask whether we have an adequate system of checks and balances to combat abuse?

In the A.C.T. and Victoria they have asked this question and answered it with new human rights protections in their laws. ${ }^{10}$ This is a sensible course of action in a world where the power and authority of the State is bound to expand.

\section{ENDNOTES}

\footnotetext{
l See http://www.strategy.gov.uk.

2 John Maynard Keynes, The General Theory of Employment, Interest and Money (1935), ch.24 'Concluding Notes'.

3 John Alford and Deirdre O'Neill, The Contract State: Public Management and the Kennett Government (1994).

4 Francis Fukuyama, The End of History and the Last Man (1992).

5 In the Preface to his Philosophy of Right (1820) Hegel wrote: 'One more word about giving instruction as to what the world ought to be. Philosophy in any case always comes on the scene too late to give it ... When philosophy paints its gray in gray, then has a shape of life grown old. By philosophy's gray in gray it cannot be rejuvenated but only understood. The owl of Minerva spreads its wings only with the falling of the dusk.'
} 
6 See http://www.tasmaniatogether.tas.gov.au. See also Government of Western Australia, A Voice for All: Strengthening Democracy Western Australian Citizenship Strategy 2004-2009 (2004).

7 See John Wanna and Paul Williams (eds.), Yes, Premier: Labor Leadership in Australia's State and Territories (2005).

8 Subsidiarity was established in EU law by the Treaty of Maastricht, signed on 7 February 1992 and entered into force on 1 November 1993. The present formulation is contained in Article 5 of the Treaty Establishing the European Community (consolidated version following the Treaty of Nice, which entered into force on 1 February 2003): 'The Community shall act within the limits of the powers conferred upon it by this Treaty and of the objectives assigned to it therein. In areas which do not fall within its exclusive competence, the Community shall take action, in accordance with the principle of subsidiarity, only if and in so far as the objectives of the proposed action cannot be sufficiently achieved by the Member States and can therefore, by reason of the scale or effects of the proposed action, be better achieved by the Community. Any action by the Community shall not go beyond what is necessary to achieve the objectives of this Treaty.' See http://en.wikipedia.org/wiki/Subsidiarity.

9 Andrew Gamble, The Free Economy and the Strong State (1988, Second Edition 1994).

10 See ACT, Human Rights Act 2004 and Victoria, Charter of Human Rights and Responsibilities Act 2006. 



\title{
Chapter 8 - Recognising Public Value: The Challenge of Measuring Performance In Government
}

\author{
Professor Mark Moore, Director, Hauser Center for Nonprofit \\ Organizations, John F. Kennedy School of Government, \\ Harvard University
}

Lecture presented 9 November 2006

\section{Introduction}

When I wrote Creating Public Value, my intention was to offer a challenge and a source of inspiration for people who wanted to provide leadership in the public sector. At the time, there was, quite rightly, some criticism along the lines of: 'Well, fine. One can readily talk about a concept of public value at a very high level of abstraction. But can we define the concept more concretely so that we can recognise objectively and empirically whether we are producing it?' This seemed like an important challenge to address.

\section{The Concept of Recognising Public Value}

To respond to this criticism, I began to talk about the challenge of 'recognising public value' as well as imagining it and working to produce it. The word recognising seemed particularly suitable in talking about the challenge of measuring public value because it carried two different connotations - one intuitive, and one more technical.

The intuitive idea behind recognising public value is that we can collectively recognise a particular event or result as publicly valuable because we share a common intuitive notion of what we mean by public value. This is the meaning of 'recognition' suggested by United States Supreme Court Justice, Potter Stewart, who, when asked to define pornography, said, 'I know it when I see it'. So, one idea of recognising public value suggests some emergent, communal social process through which a community comes to understand (perhaps through some kind of continuing dialogue with an organisation) what valuable effects an organisation produces. Where such a common view exists, an organisation can take advantage of the shared understanding of the public value it delivers and simply point to those effects, as in: 'Look at that! We reduced crime in your neighbourhood,' or, 'See? The garbage has been removed from the curb'. 
The second idea of recognising public value is far more technical. It derives from the field of financial accounting. The most basic requirement for financial accounting is the development of an administrative system that allows the organisation's managers to recognise expenditures of the organisation's assets and the receipt of financial assets by the organisation). These technical, administrative systems are constructed to render objective and consistent the movement of material and financial assets across the boundaries of an organisation and enable the use of those assets in productive activity. While standard financial accounting systems can capture financial flows through an organisation together with the costs expended by an organisation in producing particular products and services, it should be clear that if we want to measure the public value an organisation produces, we will have to construct some other technical system that can allow us to record when public value is being produced. Generally speaking, that requires us to develop some conceptual and operational basis for defining what constitutes the public value the organisation produces.

I will begin, then, by introducing the concept of 'recognising public value,' in both its abstract sense and its concrete manifestations.

\section{The Example of COMPSTAT}

One frequently cited example of the importance of developing the systems through which a community and an organisation can come to recognise public value comes from the New York City Police Department (NYPD). In January, 1994 Mayor Rudolph Giuliani announced the appointment of William Bratton as head of the NYPD. ${ }^{l}$ Bratton came to the job saying he wanted to bring bottom-line management techniques to the NYPD. Correspondingly, like the CEO of a firm seeking to attract investment, he declared, first to the mayor and then to the public, that he was going to reduce crime by 10 per cent in New York City over the course of the next year. Somewhat surprisingly, this was a kind of promise that no police commissioner had ever made before.

Having promised this reduction, he exposed himself and his organisation to a substantial risk of failure. Necessarily, then, he began looking around for ways to engage other people in sharing the burden. He found a way to distribute responsibility for reducing crime throughout the NYPD by delegating responsibility for reducing crime to each of the NYPD's 72 precinct commanders. He and his deputy commissioners then called those managers to account for their crime reducing performance in public meetings in which precinct commanders were castigated for their failures to perform and challenged to come up with new approaches, or praised for strong performance with respect to the goal of reducing crime. They measured crime control effectiveness by looking at trends in reported crime statistics disaggregated by precinct and crime type. Essentially, Bratton followed the basic principles of 'Management 101': define your operational goals, delegate responsibility for achieving them, set up a system 
for monitoring the performance of managers in achieving the desired results, and sanction the managers on the basis of their performance.

Amazingly, after establishing this system and laying out some new guidelines for patrol officers, reported crime rates fell substantially in the city. In fact, during the two-year tenure of Bratton and his management team, the murder rate in New York City dropped 50 per cent and the overall crime rate dropped 39 per cent. So, there was a rather astonishing moment when it looked as though we might be able to get significantly improved performance from police departments, or maybe even public sector organisations more generally, just by being sufficiently tough-minded and straightforward about measuring the performance of organisations with respect to their core mission. And thanks in part to this, the use of performance measurement as part of a performance management system in public sector organisations is now fundamental to the mainstream teaching of public administration.

\section{Three Questions about Performance Measurement in the Public Sector}

Despite the apparent success of this initiative, and despite the widespread commitment to these simple uses of performance measurement, I want to move the discussion of performance measurement up a level or two, because I do not think the simple lessons of this case are the right ones to draw. I am quite confident that the way that Bratton chose to measure the public value created by a police department is wrong, and wrong in ways that will apply to many more public agencies than police departments. And I am also reasonably confident that the method he chose for using performance measurement to animate and guide his organisation is not necessarily the best. But it is hard to argue with success - particularly when I am basically in agreement that we need more and better ways to measure the performance of public agencies. What I propose to do, then, is to back up a few steps from these simple lessons and ask three harder questions about performance measurement in the public sector.

The first is: Why should a public manager measure performance? Perhaps another way to put the question is, 'Why should public managers load a gun that others will use to shoot them?' I regard this basic motivational question as very important for two simple reasons. On one hand, building a strong performance measurement system requires a huge investment. On the other, having such a system inevitably exposes a manager and his organisation to the risk of a clearly documented failure. Given these facts, any moderately self-protective manager might reasonably ask, 'Why should I make this big effort when all it does is carry risk for me and for my organisation?' Even if all the rest of us citizens thought public managers ought to measure performance as part of their general accountability to us, it would help if we could find a compelling reason for managers to commit themselves to doing rather than resisting it. 
The second question is: Where, along what I call the 'value chain,' is it best to measure performance? More particularly, the question might be, 'Should we measure inputs, processes, outputs or outcomes?'

The third question is: Should we measure customer satisfaction as an important dimension of public value creation, and, if so, who are the customers and what do they want?

\section{Two Academic Traditions in Performance Measurement}

I make these remarks against the backdrop of two substantial academic literatures that offer guidance about the recognition of public value on one hand, and the use of performance measures to animate and guide organisational performance on the other. The first is the academic literature that focuses on 'program evaluation' and 'benefit/cost analysis.' The second is the professional literature developed in business schools about the best ways to measure organisational performance.

\section{Benefit/Cost Analysis and Program Evaluation}

When I began my academic career over 30 years ago at the Kennedy School of Government, I was attracted, in part, because I thought that by going to the Kennedy School, I would learn a set of techniques that would allow me to undertake a relatively objective evaluation of the performance of government organisations. I thought that the development of those techniques was essential to improving both the design and evaluation of public policy initiatives. While I understood that there would inevitably be problems in achieving this goal, I certainly thought that by this time, almost thirty years later, we would have 'cracked' the issue of how to measure performance in the public sector.

At the Kennedy School, I was taught two basic ideas to use in recognising the public value of public policy initiatives and the performance of government organisations. The first of these was the theory and practice of 'benefit/cost analysis.' Benefit/cost analysis had a strong theoretical basis in welfare economics. The core idea was that individuals in a society were the only ones who could decide whether public policy results were valuable or not, and that the only way to discover what things were valuable was to ask individuals how they felt about them. The only way to find out the overall value of a given public policy was to sum up those individual valuations. If, for any given policy, there was enough value created for the beneficiaries of the policy to compensate those who suffered losses from it, then, arguably, some public value would be created by the proposed policy.

Although benefit/cost analysis had a strong theoretical basis, it was often applied in a less rarefied and more practical form. In that form, a benefit was defined as 'any effect that we consider good,' and a cost as 'any effect that we consider 
bad.' Thus, benefit/cost analysis was sometimes bowdlerised and used simply to identify the good things that were expected to come from a public policy (the benefits - whether individually experienced and evaluated or not), and the bad things that could happen (the costs - whether individually experienced or not.

The cruder form of benefit/cost analysis was closely related to a second method I was taught to recognise public value production. The second idea was called 'program evaluation.' Whereas benefit/cost analysis was grounded mainly in the discipline of economics, program evaluation came mostly from the field of statistics. The techniques of program evaluation required an analyst to develop a conception of public value creation by imagining what policymakers were trying to achieve through particular policies and programs. It was the hopes and aspirations of policy-makers to achieve particular social results that was the proper basis for defining value - not necessarily those of individuals who experienced the results (though we might have hoped that the policy-makers were guided by their best guesses about the views of individuals affected by public policies.) Once an analyst understood the initial aims and objectives of the policy or program, it would be possible to capture objective statistics to discern whether the characteristics of the world policy-makers were trying to influence did, in fact, change in the desired directions. One could then make a series of efforts to attribute observed changes to the activities carried out by the organisation. If the program evaluation demonstrated that the desired results had been achieved (at a low cost, with few unexpected bad consequences) then we could conclude that public value had been created. If the program evaluation showed that the desired results had not been achieved, or that the costs or unexpected adverse consequences had been larger than anticipated, then we could conclude that public value had been lost. This was how, as a student in public policy, I was taught to measure the performance of organisations. I subsequently discovered that this was a difficult, somewhat clumsy, and very expensive approach.

\section{Performance Measurement in the Private Sector}

I also learned that in the private sector, businesses did not think about performance measurement in this way at all. Rather, managers in the private sector used their organisation's information systems to track whether the organisation was creating value in the form of revenues over costs, or whether they were managing to maintain a satisfactory relationship with their customers. They were also, surprisingly, making much use of something that looked very similar to the traditional methods we were using in the public sector, which was essentially the measurement of concrete processes and activities. These kinds of measures helped organisations in both sectors make sure they were getting the benefit of technological systems. 
Case studies of the McDonald's and Burger King restaurant chains published by the Harvard Business School revealed a surprising fact. I naturally assumed that McDonald's and Burger King would analyse the performance of their restaurants in financial terms. Much to my astonishment, I learned that that they paid little attention to the financial performance of each individual restaurant. Instead, McDonald's was evaluating the performance of every restaurant on 12 distinct characteristics of the experience of being in the restaurant, including whether it was clean; whether the lines were short; whether the rest rooms were clean; whether there was a place to sit down; whether the food was fresh; and whether the cashier smiled at you when she took your money.

These concrete aspects of the experience of being in the restaurant, rather than hamburgers and fries, was McDonald's theory of what they were producing. What they wanted from each of their restaurants was a guarantee that each of the 12 attributes of the experience was being produced with a high degree of consistency. Their theory was that if they produced consistently good performance along the 12 dimensions of customer experience, they would make money. That theory was tested quarterly, and annually, against the financial performance of the organisation as a whole. But that theory didn't have to be tested for each individual restaurant. For the most part, all the individual restaurants needed to do was manage themselves to produce the particular set of 12 product/service attributes.

What was really eye-opening, however, was how often they measured the performance of each restaurant: about once every month. Over the period of a year, each restaurant would have been evaluated 12 times on each of these criteria. If we were to suggest some similar kind of performance measurement regime to a public sector executive, the response would likely be, 'Oh my God, that is an incredibly expensive and intrusive information system!' Bear in mind that McDonald's is collecting this information even when they have at hand a steady flow of financial information on the performance of the organisation.

One possible lesson for public sector executives is that if a firm like McDonald's is making this many extra measurements even when they have financial data available, then it might make sense for them to spend at least that much on measurement when they don't have good financial information. A second possible lesson is that measurement carried out this frequently might allow top managers to detect relatively small changes in organisational performance - changes that managers could conceivably influence. The fact that small changes in performance can actually be detected gives this performance measurement system more behavioural power to shape the performance of midlevel managers and staff than a less rigorous system would have.

An interesting question arises about which of these two different ways of thinking about these issues - the program evaluation/benefit-cost perspective 
or the business management perspective - offers a more viable approach to measuring performance in the public sector.

\section{Question 1: Why Measure Performance? Strategic Uses of Performance Measurement}

At this point, I will introduce some additional complications. In a narrow sense, there is a standard set of ideas about the managerial uses of performance measures. They are:

1. to meet demands for external accountability;

2. to establish a clear, significant mission and goal for the organisation; and

3. to foster a strong sense of internal accountability.

This last use of performance measurement could mean simply making everybody feel accountable for working harder to meet target numbers by setting and enforcing rigorous performance standards, but, if we capture information about both what we are doing and the results we get, could also allow for a softer kind of accountability admits the possibility of failure and allows more room for learning and innovation.

\section{The Strategic Triangle}

As many of you know, in Creating Public Value I developed a framework for thinking about strategic management in government that could be reduced to and represented by a 'strategic triangle.' (Figure 1)

Figure 1 - The Strategic Triangle

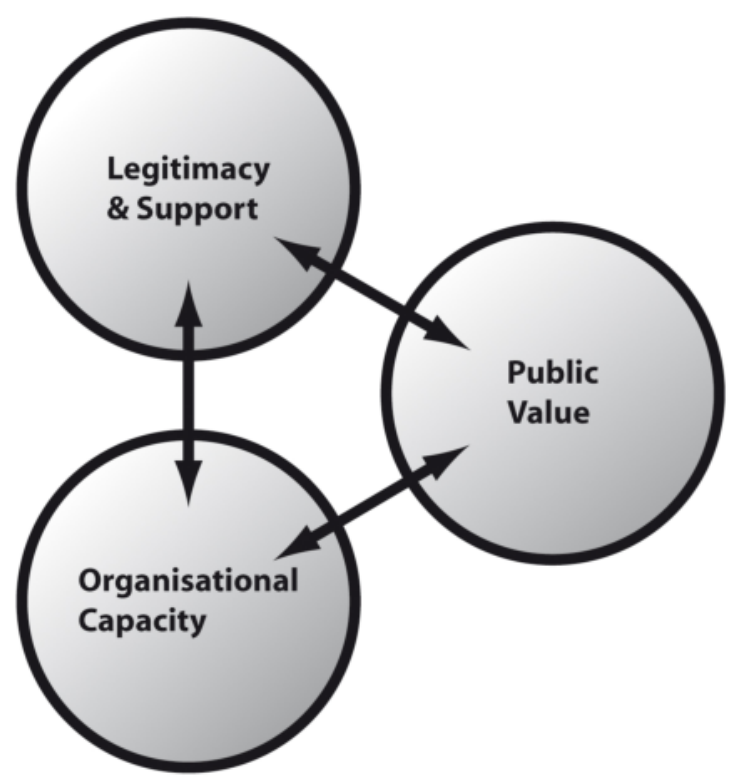


I argued that it was the important goal of public sector executives to find a 'fit' between a conception of the 'public value' their organisation sought to produce, and ensuring a continuing flow of resources to the organisation by building 'legitimacy and support' in what I call the 'authorising environment.' In addition, for any particular conception of public value to be strategically viable, managers would have to be able to build sufficient operational and organisational capabilities to achieve results. What was strategic about this was the idea that we were trying to fit a public sector organisation - led by an executive with control over a bundle of assets and a bundle of capabilities - into a dynamic environment. This environment is, on the one hand, a 'task environment' in which we try to orchestrate a portfolio of programs, policies, and procedures to produce public value and, on the other hand, an 'authorising environment,' consisting of the citizens, legislators, interest groups, and other parties that tell the manager what particular pieces of the world that executive is authorised and expected to attend to.

When I thought about the standard arguments for performance measurement in the public sector against the backdrop of the strategic triangle, I realised that performance measurement - the process of defining and recognising public value production - fits rather neatly into the strategic triangle and can be used as a highly effective, even essential, tool for strategic management. Take each point in order.

First, at the legitimacy and support point of the triangle, it is, I think, easy to see that one of the best ways to guarantee our legitimacy - to invite support is to embrace accountability for defining and recognising public value. Indeed, we have a professional and ethical obligation to be accountable for our performance to those who have the power to call us to account and expect us to perform, and this means developing concrete methods of measuring specific aspects of performance.

Second, at the public value point of the triangle, the effort to develop and use performance measures forces us to be much more concrete and explicit about the nature of the public value we are trying to create on behalf of our authorisers. If we cannot make it concrete, we cannot measure it.

Third, at the operational capacity point of the triangle, it is essential that we develop the administrative wherewithal to get the most capacity out of our organisations. This makes it necessary to foster a strong sense of internal accountability, and to give those who work in the organisation guidance so that they can focus on finding the means of improving performance through organisational learning and reflection. These responsibilities depend on the capacity to measure the performance of the organisation concretely and reliably.

So, for a manager standing in the middle of the strategic triangle, it is not hard to see that performance measurement would play an absolutely critical role with 
respect to handling each corner of this triangle: the definition of public purpose, the mobilisation of support, and the exploitation of operational capacities by driving performance inside the organisation (whether through a rigid structure of accountability or through a softer accountability that emphasises learning).

\section{Negotiating the Terms of Accountability}

Performance measurement also plays a key role in bringing the different points of the strategic triangle into alignment. Indeed, managers can use performance measurement to shape their mandate for action. They do this by trying to negotiate the terms of accountability with their overseers in the authorising environment. Given the importance of having a steady and coherent mandate for action in managing their organisations, it might well be worth a public manager's time and effort to use the challenge of developing performance measures for his or her organisation as a key part of developing their overall strategy.

If we, in our roles as citizen authorisers in democratic countries, were consistent in our expectations of public sector managers, and managers could expect the authorising environment to make sustained and serious efforts to demand performance, then measuring performance would be a very important feature of their task environment. Public managers might feel the need to invest significant effort in negotiations with the political authorising environment to reach some kind of agreement about what they are expected to produce. If public managers were trying to make an agreement with politicians about what they ought to produce and measure, it would be important to them that the politicians not be permitted to change the rules suddenly. If one could get an agreement to stick for a period of time, one would have, in effect, created a policy mandate and, if the authorising environment remained stable in its expectations and demands, managers would at least have some reasonable chance of accomplishing their agreed-upon goals.

Unfortunately, while the political system often says that it wants accountability, and occasionally demands it, it is usually reluctant to negotiate a stable deal about what constitutes public value. There is too much political advantage in retaining the right to change the rules when they want and finding the organisation suddenly accountable for some value that had not previously been treated as important. The reality is that the political system will not allow itself to be negotiated into a binding, long-term agreement. It will reserve the right to change the rules whenever it wants. If we cannot negotiate with the political authorising environment to achieve an agreement about performance measurement, then negotiating in advance will not help us manage organisational performance. 


\section{Doing 'The Right Thing'}

Perhaps, the right thing to do, then, is to appeal to shared virtues of executive responsibility and commitment. To be perfectly candid, I think this is an important part of the duty of a public official and, frankly, I cannot imagine any conscientious public official feeling fully accountable and fully responsible in his job without taking some responsibility for defining whatever it is that he or she is trying to accomplish and making some effort to measure successes and failures. I do not think people can manage public organisations without having a conception of public value that can be measured reliably. Performance measurement is fundamental to the ability to manage organisations. If you do not have such a tool, then I would argue that you are merely presiding over the organisation's activities. You are not really managing it and you are not creating conditions under which the organisation's performance could be expected to improve in any reliable way over a period of time. And the reason I think this is so important is that, left to their own devices, organisations tend to accumulate slack, and the only way to move that slack around and get it performing is to embrace a strong form of external accountability in order to animate and drive performance within the organisation.

This is exactly what Bill Bratton did in New York City. When Bratton said, 'I am going to reduce crime by 10 per cent over the next year,' he embraced external accountability, set a high standard, and exposed himself and his organisation to the risk of failure. This approach produces a certain amount of energy inside an organisation.

Now, as it turns out, this approach could also be unhelpful in the sense that it might not be a constructive challenge, or in the sense that it might drive the organisation in the wrong direction. However, it is also the case that, if we start running a little bit of voltage through the organisation - not too little, not too much - something begins to happen inside the organisation. The reason I think one should measure performance is that I do not believe one can manage or lead an organisation without some kind of accountability - that is to say, without concrete performance measurement.

\section{Question 2: Where Should We Measure Performance Along the Value Chain?}

A second key question in designing performance measurement systems focuses on the best place to measure performance in the complex system that transforms inputs granted to the organisation into the production of desired results through a particular set of policies, programs, and activities. One useful way to think about this production process is to describe it as a value chain that consists of several distinct stages of the production of public value. (See Figure 2 below) 
Figure 2 - The 'Value Chain'

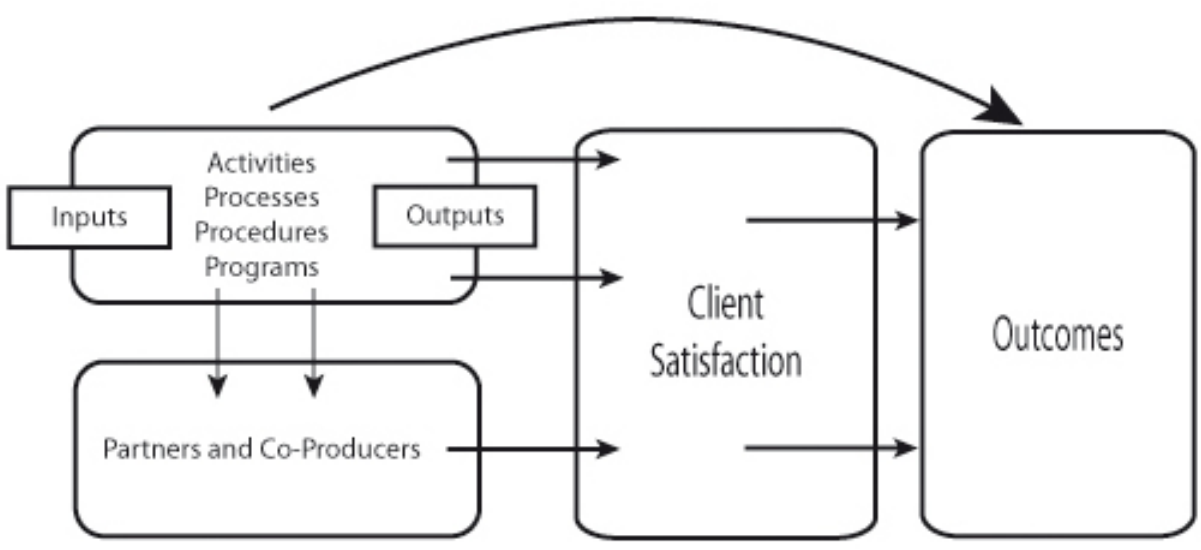

Obviously, the concept of a value chain is not rocket science. The value chain describes an organisation that is receiving inputs (in the case of a public organisation, money and authority from the state), which are deployed in particular processes, procedures, and programs which produce outputs. Many of those outputs involve an important engagement with people, or clients - and by clients I mean people who make individual transactions or have individual encounters or relationships with the organisation. One of the important consequences, or products, of those client transactions or encounters or relationships, is some form of social outcome. So the value chain gives us a general picture of organisational production.

But the value chain, as it is drawn above, also reminds us to focus on the actions of partners and co-producers who can be instrumental in the production of client satisfaction and social outcomes. Contributions from partners and co-producers could emerge spontaneously without any encouragement or guidance from the organisation. Or, they could emerge as a consequence of deliberate efforts made by the organisation to mobilise co-production activities. The organisation can write contracts with partners or it can seek to use moral persuasion of various kinds to motivate private individuals and organisations to contribute to public goals. It can even use the authority of the state to require others to contribute to socially desired outcomes.

In principle, we could take measurements and demand accountability for performance at any step along the value chain or the chain of partners and co-producers. We could focus on inputs to make sure that our managers have firm control over the equipment and inventory, that they are doing a good job of cash management, and so on. We could focus our attention on activities, processes, procedures and programs through a 'compliance audit,' where 
independent evaluators would go into government organisations and see whether people were following the policy and procedures that were laid down for them.

\section{Measuring Activities, Processes, and Programs}

We can all see the limits of a compliance audit: it does not tell us very much about the quantity or quality of outputs we are producing, or whether the outputs are judged to be valuable in the sense of satisfying clients or producing desired social outcomes. However, if we had already embedded in our policies and procedures the best available technology for accomplishing results, then a compliance audit would be tantamount to an audit of efficiency and effectiveness. If our procedures were known to be efficient and effective in producing desired results, then all we would have to do is monitor and demand performance with respect to following policy and procedures and, arguably, we would have achieved our purpose. If the policies and procedures are based upon 'best practices,' we can effectively guarantee operational performance by adhering to these policies and procedures rather than by guaranteeing results. (This is similar to the approach that McDonald's takes in trying to ensure that each restaurant produces the desired products and services. The judgment about whether this particular product and service can be delivered in a profitable way is made elsewhere.)

But there is another reason to adhere to strict policy and procedural regimes: namely, to assure not efficiency and effectiveness, but consistency. This is a desirable characteristic of government operations quite apart from questions of efficiency and effectiveness. One of the characteristics we want in a government organisation is a guarantee that like cases will be treated alike. This is part of what we mean by fairness, and it constitutes a virtue independent of how effective a particular government process turns out to be.

So, our options are: (1) concentrate on managing performance measurement at the level of activity, processes and procedures; or (2) monitor outputs, workload measures, and measures of productivity. Increasingly, however, government organisations are being pushed to measure performance even further down the value chain in the direction of either client satisfaction or outcomes. I think the reasons for that are pretty clear. But, as you know, the great debate goes on about whether we should measure outcomes or outputs in the public sector.

\section{Measuring Social Outcomes}

My observation is that the current debate is shifting heavily in the direction of measuring outcomes. The reason for this is that an outcome is a direct measure of the public value that we are trying to produce. If we need to be able to demonstrate that we are producing something of public value, then we would have to be able to measure outcomes. Once we devise a way to measure the outcome we are trying to achieve, we can find out whether the technical means 
that we are relying on represent the best technology for accomplishing that purpose, or whether there is a better alternative we can use to test the value proposition offered by the organisation, so that when we say, 'Well, we are going to produce public value by engaging in the following activities,' we can track whether our theory is correct.

If it is so clear that outcome measurement is valuable, why do we so rarely do it? Why do we not measure outcomes? Well, it turns out there are a lot of reasons why measuring outcomes is a difficult device for managing organisations. One reason is that measuring outcomes is incredibly expensive.

In a private sector firm, revenue is earned by the sale of products and services. Revenues earned by the sale of products and services to willing customers are easy pieces of information to collect. They are a terrific thing to use in measuring performance because they represent a reasonably objective, direct measure of value. What makes them a direct measure of value? Individuals' choices to spend their own money on a given product or service: people plunk their money down to buy the product or service. In doing so, they give objective information that they value whatever good or service the firm is producing.

The second attractive property of revenue earned through the sale of products and services (as an outcome measurement) is that the information is collected right at the boundary of the organisation at the moment of transaction. We don't have to go beyond this transaction to measure something that takes place at a relatively remote place and time. Nor do we have to wait for the result to occur. We get the judgment of value right at the point of delivery.

A third property of revenues earned through sales is that one can compare apples and oranges. Individuals show us how much they value these distinct products by paying for them in a given currency.

So, earning a revenue from the sale of products and services turns out to be a really wonderful way to measure the value of organisational output. If we have such a measurement, managers (and others) are in a good position to judge the value of what has been produced. If we do not have revenues earned from the sale of products and services to voluntary customers, we are in big trouble.

To see the significance of the loss of this kind of revenue measure, consider this problem: if I were the manager of General Motors and somebody said to me: 'You can have all the information you want about the cost of producing automobiles, but you cannot have any information on how much you have earned by selling them,' what would I do? How would I know whether I was creating something valuable?

I think there are only a limited number of answers. One of them would be to survey your customers to see whether they liked the vehicle. Another possibility: you might observe the outcome and see how often people drive and how well 
the car stands up to use. A third possibility: you might try to get engineers to tell you whether they think the car that you designed is a good car - is it better than previous or comparable models?

These would be all the same methods we would use in the public sector to try to ascertain whether we are producing something of value. We survey our customers; we evaluate outcomes; we check on the physical characteristics of our product. While such measures might do some managerial work for us in helping us determine whether we are producing valuable results, none of these measures of value would stack up well against the information we would receive from measuring the revenue that we earned from the sales of products and services.

So, one of the difficulties with relying on the measurement of outcomes is that outcomes are very expensive to measure: we have to go out into the world to find the information and, often, information comes in late.

In the case of a welfare-to-work program, for example, we are interested in trying to spend public dollars to cause clients who use the program to move from a dependent life on welfare to an independent status of job-holding and an active life in the community. An interesting question is: When do we decide that we have accomplished that outcome? And the answer to this question is: We never have achieved the outcome - at least not for a large group of people. What we are trying to do is to maintain a certain level of functioning for a group of people who, ideally, rely less and less on public support in the form of both dollar benefits and social services. The benefit of public support comes from the fact that people improve in their independence and social functioning continuously over a long period of time. So, when do we decide that we have accomplished the goal?

Perhaps the best way to think about it is that, each month, we have kept $\mathrm{X}$ number of people at a higher level of functioning than they would have been without intervention. That number represents the value but, in order to get it, you have to have continuous monitoring of the whole target population over a long period of time - a very difficult and expensive process.

Further complicating things, because the information about outcomes comes in late and public value production happens far down a causal chain, the effect is often hard to attribute to public managers or public organisations. Crime statistics may have gone down under Bill Bratton's watch, but we actually do not know whether or to what degree that was the consequence of any given action that Bratton took.

While we talk a great deal about the ultimate importance of focusing on outcomes in the public sector, and while the challenge to think about and measure the ultimate outcomes is certainly valuable, the reality is that we are not only 
interested in the social outcomes produced by government organisations. We are also interested in the processes and procedures we use to achieve the outcomes. We want to make sure they have certain characteristics - including fairness and economic and technical efficiency - and that means that we will want to measure some characteristics of activities and outputs as well as outcomes. So, while I understand and support the argument for measuring outcomes, there are real problems with relying exclusively on outcome measures.

\section{Measuring Outputs}

So then, what about measuring outputs? Measuring outputs is cheaper and easier than measuring outcomes. In addition, measuring outputs can contribute to improving the performance of midlevel managers because, unlike outcomes, outputs are mostly within managers' direct control. We can make interesting calculations about productivity and - without necessarily making claims about value or effectiveness - we can at least see whether we are driving down the cost per unit of output. This helps to focus the manager's attention. We get improved consistency in operations, and, if we have an idea about what kinds of practices constitute value, we can make sure that those best practices are being used widely throughout our organisation.

These observations add up to some important reasons to measure outputs rather than outcomes. So much so that it might be tempting to rely only on the measurement of outputs. The problem with that solution, however, is that organisational outputs are not quite the same as the production of something of public value - not even in terms of producing client satisfaction, let alone in terms of the achievement of desired social outcomes.

If both outcomes and outputs are important and useful to measure, and each has limitations, it seems to me that the right conclusion is that one ought to measure both.

This conclusion is reinforced by the observation that private sector organisations are increasingly managing according to 12 or 13 or 14 different measures of performance. They do not limit themselves to one 'bottom line.' They exist in a 'data rich environment' where they can make judgments about the degree to which their current strategies are succeeding and, at the same time, search for clues about how they might improve their performance.

The bad news about measuring multiple dimensions of performance is that it makes it harder for managers to focus. The more things you are trying to manage, the more complicated the job becomes. Another way to think about it, however, is that if we are managing 12 different dimensions of performance, then we have an opportunity to engage the organisation in a conversation about what it is being produced. A conversation about how to get all of those different dimensions of performance moving in the right direction would be more interesting for 
those inside the organisation than a simple thumbs up or thumbs down test of how well the organisation and the individuals in it are performing. The organisation might actually be able to learn and feel motivated to find better ways of achieving difficult results, rather than simply censuring people for failing to meet more or less arbitrary standards.

\section{Question 3: Should We Measure Customer Satisfaction? Who are the Customers and What Do They Want?}

The last question about performance measurement is the degree to which we should measure customer or client satisfaction, and who, exactly, is the customer? I have been struggling for a long time with this idea of a customer-oriented government. Personally, I do not favour the concept of a customer-oriented government because I do not actually think the government has 'customers.' Rather, I think the government has clients on one hand, and citizens on the other.

The characteristic of a customer in the private sector is that the person engages in an individual financial transaction with the private sector organisation. Customers are practically important to private sector firms because they provide financial support to the organisation through the voluntary purchase of goods and services. Insofar as a private sector firm can produce products and services that appeal to customers, the private firm can stay in business and continue to accumulate wealth for its shareholders.

But customers are normatively important to private sector firms as well. It is the customers' individual, voluntary decisions to purchase goods and services that provide the basic moral and social justification for the enterprise. They are, in essence, the arbiters of the value created by the enterprise. If customers can be satisfied (without deception or coercion), then one can make the argument that society as a whole ought to be satisfied with the output of the private firms.

Now, I am a public sector guy and proud of it. But every now and then, my strong public sector orientation causes me to say something really stupid. I get on my high horse, and I say something like, 'Why does the private sector produce junk like lemon-scented furniture polish and hula-hoops? With all the problems we have in the world, why on earth are we spending any managerial time, any labour, any resources on things like lemon-scented furniture polish and hula-hoops?' I feel really good when I say that. The problem is that the private sector has a really good answer: 'People buy this junk. The fact that they are buying it tells us that they value it. The fact that they value these products at a price that more than covers the cost of production means not only that businesses can stay alive and profitable, but also that they are creating something of value - as long as we think it is individuals' judgments of value, revealed in decisions to spend their own money, that defines at least one kind of value.' 
This is why customers are really important, both practically and ethically, in the private sector.

\section{Customers as Clients: Beneficiaries vs. 'Obligatees'}

So, who are the customers in the public sector? If we focus on the question of the relationship between the person and the organisation, we might imagine that the customer in the public sector would be the client of the organisation: the person who engages in a transaction at the business end of the organisation, rather than the reporting end. We might think this is a particularly apt definition in the case of clients who are beneficiaries of the organisation. Thus, it is easy to imagine that welfare recipients, or schoolchildren, or people who call the police for service - all of whom are transacting with the organisation at the individual level and getting something beneficial - might be thought of as customers of public sector organisations.

Notice, however, that there are some clients of government organisations who do not receive beneficial services from government. These clients include criminals who are arrested by the police, taxpayers who are asked to fork over their hard-earned money to the government, and companies who are required to stop dumping toxic wastes in the air and water. Instead of receiving beneficial services from government organisations, these particular clients of the organisation receive an obligation. I call those clients 'obligatees'.

This term amounts to a kind of linguistic crime. I know this is true because whenever I type 'obligatees' on my computer, a squiggly little red line shows up: this clearly is not a word in the English language. However, I am going to persist in using the word because I think we need it to understand how to manage government organisations. It conveys the essence of an important relationship between the government and individuals in society.

Government is in the business of obliging individual clients to contribute to public purposes as well as providing services to clients. Consequently, we have to think about what these kinds of clients would value in what I would call an 'obligation encounter' as well as a service encounter. The interesting question becomes: What are the socially and individually desired properties of obligation encounters?

I would go so far as to say that most, maybe even all, individual transactions between government organisations and individual clients involve both a service component and an obligation component. When we give money to welfare recipients, or teach students in public schools, we are not simply providing a service whose value will be judged by the clients themselves. In both cases, we are delivering a service that comes with certain social expectations and aspirations, and the quality of that service will be judged not only by the 
recipients, but also by the citizens and taxpayers whose aspirations to achieve some socially valued condition are contained in these transactions.

If we (tentatively) accept the claim that many clients of public services are indeed 'obligatees', then it becomes apparent, I think, that the goal of these transactions could not be simply to satisfy these clients and make them happy. Given a free choice, I expect most obligatees would say, 'If you really wanted to make me happy, you could excuse me from the obligation you are about to impose'. If we accept the claim that the sole objective of an obligation encounter cannot be to make an obligatee happy, then government must be producing these obligation encounters for some other purpose. That purpose might lie further down the value chain as a social outcome associated with the results of an obligatee coming into compliance with the duty imposed upon him or her.

\section{Customers as Citizen Authorisers}

An alternative idea about the 'customers' of government services is that they are not the clients who meet organisations in individual transactions at the service end of the organisation, but rather that they are the citizens of the democracy who authorise and pay for the organisations and hope that the organisations will realise through their operations the aggregate social results that citizens want to achieve. They are bystanders and witnesses of governmental organisations, rather than the objects of the organisations' attention. Their aspirations about what the government organisation ought to do in general become the guide and arbiter of the value produced by the organisation. It is citizens - acting collectively and deciding that some particular purpose (a social outcome) is worth taxing and regulating themselves to accomplish - who provide the practical and normative basis for a government organisation to proceed.

The first thing I notice, if we define the customers of government as citizens rather than clients, however, is that they do not look very much like customers. If we insist on using private sector analogies, they look more like shareholders - whose interests are reflected in the judgments of a board of directors - than customers.

In a sense, these citizen overseers and authorisers are more fundamentally the organisation's 'customers' than the people who interact with the organisation through individual transactions. After all, it is the citizens who provide the financial support to the organisation. It is also the citizens' collective decisions to support this or that public enterprise that constitute the normative justification for the organisation to continue its operations. In the public sector, the arbiter of public value is not just the individuals who transact with the organisation, it is the collective acting as a whole to achieve collectively defined social goals. The difficulty, of course, is that citizens are a collective customer - not simply a bundle of individual customers. Consequently, they have to learn how to speak 
with a clear voice through the mechanisms of representative government about what exactly they would like to have produced to meet their collective needs or aspirations.

So, let us compare and contrast customers in the private sector with clients and citizens in the public sector. In the private sector, customers meet businesses in individual transactions and encounters. In this sense, they resemble clients of public sector organisations. In the private sector, customers pay a price that covers the full cost of producing the goods and services. In the public sector clients do not - even when they are receiving a service from government. In addition, many clients in the public sector get obligations as well as services.

In the private sector, customer satisfaction is an important business goal. In the public sector, client satisfaction may be an important goal, but it is not necessarily the most important goal. In the private sector, customers' individual decisions to purchase a good or service for their own use generally provides both the practical and normative basis for the private sector firm to continue. In the public sector, clients' decisions about whether or not they like the service they receive does not play this important role. Instead, the resources available to a public organisation come from a collective decision made by citizens and their representatives that the purposes to be pursued by a given public organisation are valuable enough to tax and regulate themselves to accomplish. In the public sector, it is citizens - not customers - who provide the resources an organisation needs to carry on, and who act as the final arbiter of the value produced by the organisation.

\section{Reasons to Measure Client Satisfaction}

Of course, there are still some reasons why individual client satisfaction in encounters with government agencies could play an important role in a public enterprise. Public sector clients have rights that need to be protected in the delivery of services. To the extent that the individuals confronted by government organisations enjoy having their rights protected, we would want to make a commitment to satisfying individual clients along this particular dimension of performance. We, as citizens, could also decide and declare that an important role of the public organisation is to make clients happy and to treat them with dignity. If we, acting collectively as citizens rather than as individual clients, made this declaration, then the organisation would have to treat the satisfaction of individual clients as an important goal (among others, such as the achievement of social outcomes at a low cost). Or, if making clients happy helped to achieve something that citizens have declared a socially valuable result, then that, too, would be a reason to want to keep clients happy.

But the point is that when it comes to evaluating the performance of government organisations, we cannot assume that the goal is to make clients happy. We have 
to explore the relationship between client satisfaction and the social goals that citizens, acting through the representative processes of government, have set for the organisation.

I draw the conclusion, then, that customer satisfaction in both service encounters and obligation encounters in the public sector should be designed not only to protect rights and ensure some level of client satisfaction but also to produce any changes necessary to achieve desired outcomes. This makes it necessary to distinguish between those outcomes desired by the collective client 'WE' and those desired by the individual client ' $\mathrm{I}$ '. In other words, as citizens acting through collective political processes, we might articulate desired outcomes for individual clients, and, ideally, we are also collectively trying to help those individual clients help us achieve shared purposes.

\section{Giving Citizens What They Want}

As I have noted, the authorisation and tax revenues provided by citizens keep public sector organisations alive. But another important question for public managers to ask is: What do citizens, acting in their role as arbiters of value, want in exchange for their tax dollars and their liberty? Let us consider the possibilities. The simplest idea of what citizens might want from public organisations might be social outcomes. A slightly more complicated idea might be social outcomes at a relatively low cost in terms of the use of money and authority. You might add client satisfaction. There are various possibilities.

The point is that the organisation should be oriented to the citizen authorisers and their aspirations rather than to individual clients and their level of satisfaction. Presumably, citizens acting collectively might want various attributes of performance from public organisations. In policing, for example, citizens might want reduced crime, reduced fear, a certain kind of justice associated with calling offenders to account for their crimes, another kind of justice associated with the protection of individual rights, or still another kind of justice associated with a fair distribution of police services across a population - all at the lowest possible cost. Indeed, it is often true that citizens demand attributes of performance that seem inconsistent with one another, or unreasonable.

The important question then becomes: How do we cope with this incoherent mandate? One answer is simply to do the best we can to give those in the authorising environment whatever seem to want from us. The answer could be that we provide to each constituency, shareholder, or authoriser a report that speaks to their concerns. Furthermore, we ought to define value creation in the organisation in terms of movements in desired directions along as many attributes of performance as there are ideas about the value created. The idea here is that we should think of the performance of an organisation not in terms of a single measure of performance, but instead as a bundle of performance attributes, each 
of which is an object of concern to some kind of citizen, or some group that is participating in the process of democratic oversight.

An initial objection to such an approach would be to claim that it would be impossible for an organisation to improve its performance in all dimensions simultaneously. Surely, we cannot have less crime and reduced costs of policing! Surely we can't have greater reliability in both calling offenders to account and protecting civil rights! We need guidance about how to make trade-offs among competing values, not simply instruction about which of many dimensions of performance have value.

\section{Public Sector Organisations and the Production Possibility Frontier}

It is worth remembering, however, that an organisation will be forced to make trade-offs among competing performance goals only if it is now operating on what economists would call the production possibility frontier - the point at which an organisation can be said to be making the best possible use of an its assets to produce socially valuable results. ${ }^{2}$ It is only when we have exhausted all possible technical improvements in our efforts to produce social output that we necessarily face trade-offs. If we are not at the production possibility frontier, then, in principle, it is possible for organisations to discover technical means that will allow them to improve performance on some attributes of performance without sacrificing performance on other (apparently inconsistent) attributes of performance. In short, there may be different methods or technologies of policing that would allow us to have less crime and lower costs; or to catch more offenders without violating citizens' rights.

If trade-offs among competing values are necessary only when organisations are at their production possibility frontier, an important question is: What is the likelihood that public sector organisations are operating at the production possibility frontier? My answer is that it is very unlikely that most public sector organisations are even close to their theoretically possible production possibility frontiers. The reason is simply that public organisations face fewer pressures and have fewer opportunities to search for their production possibility frontiers than private sector firms. And even with all the pressures and opportunities that push private sector firms face to the production possibility frontier, many private sector firms still never get there.

Indeed, the fact that many private sector organisations are not on the production possibility frontier was revealed several decades ago when American automobile manufacturers faced a stiff competitive challenge from Japanese automakers. The Japanese were exporting cars to the United States that were better than American cars in all dimensions of quality. Further, they were $\$ 2,000$ cheaper than anything produced in the US. Faced with this competitive challenge, 
American car manufacturers thought they were stuck. They thought they could not increase quality without increasing costs, and that they were beaten on both dimensions. In short, they thought they were on their production possibility frontier. It turned out that they were wrong. Once they began looking at their production processes in search of technical improvements, they found many were possible. With investments in new operating technologies, they found they could simultaneously improve quality and reduce costs.

The lesson for the public sector might be that we should not assume at the outset that our public organisations are already operating at their production possibility frontier. In fact, we ought to make the opposite assumption; that it might be possible to improve along all dimensions of performance. We should not shift to the assumption that we face trade-offs until the evidence generated by performance measurement systems that capture all relevant dimensions of performance tell us we are now facing important trade-offs among values. In short, it might be wise to try to improve performance on all dimensions of performance simultaneously. That would help us discover how close we were to production possibility frontiers as we try to make good on our commitments to produce the things that our authorisers value.

\section{Improving Along Multiple Dimensions of Value: An Example from Policing}

One of the most important things in management is simply to know whether we are improving, not whether we have found the optimal solution. It is improvement that we are after. The optimal solution is going to change tomorrow when conditions and aspirations change. So, in the short run, the important thing to do is to focus on improvement, and improvement can best be guided by a comprehensive list of the attributes of performance that citizens and their representatives deem valuable in public sector operations.

Going back to my friend Bill Bratton, he formulated the proposition that the 'profit' the NYPD earned for New York City's citizens was reduced crime. Now Bratton was a very good manager, but a miserable accountant. When you think about it, the idea that reduced crime actually equals profit is not quite right. In any standard accounting system, profit equals revenues minus costs. When trying to estimate the profit earned by the police, then, we would have to take into account the costs (in both dollars and sacrifices of personal liberty) of producing reductions in crime. In addition, we might have to recognise that reduced crime is not the only thing that citizens value in a police department. There might be a large number of valuable effects other than crime control that the police manage to produce.

Over the years, I have spent a great deal of time thinking about how to measure public value creation in policing. I came to the conclusion that crime reduction 
was better seen as the equivalent of the 'gross revenue' earned by the NYPD for the citizens of New York City, not the profit. The profit (or net public value) earned by the NYPD would be the value citizens attached to reduced crime minus the costs to citizens of producing that result.

Policing relies on inputs of both public funds and public authority. Precisely because the police use authority as well as money (and are engaged in obligation as well as service encounters), police operations have to be evaluated in two quite distinct normative frameworks: a utilitarian framework to assess the effectiveness of inputs of labour and resources on one hand, and a justice framework to assess the degree to which the police helped to produce justice and behaved justly and fairly in the pursuit of both the practical goals of reducing crime and the principled goal of assuring justice. In the utilitarian framework, the end is to reduce crime and the means are to spend resources on materials to produce that result. In the justice framework, the end is to produce justice, and the means include using the force and authority of the state. A comprehensive evaluation would have to focus on whether both money and authority were used efficiently, justly, and fairly in efforts to achieve the results.

After a great deal of reflection and discussion, I hypothesised that we could actually understand most of the public value we citizens want the police to produce in terms of just seven different dimensions of performance. These were as follows:

1. Reducing crime and victimisation;

2. Producing the kind of justice associated with practical redress and calling offenders to account;

3. Reducing fear and creating a sense of personal security;

4. Ensuring stability in public spaces and creating ordered liberty;

5. Using force and authority fairly, efficiently, and effectively;

6. Using financial resources fairly, efficiently, and effectively; and

7. Trying to make people who call for services happy with the service they receive.

To test the adequacy of this conception, it seemed important to follow the idea that a good performance measurement system was one that spoke to the real concerns of citizens and other authorisers. Consequently, my colleagues and I carried out empirical investigations in two cities to determine what citizens and authorisers wanted from their police departments. This required us to identify both those who were actively overseeing police operations and the particular dimensions of performance that were the focus of their concern.

The important authorisers included four broad categories:

1. Formal overseers exercising continuous monitoring of organisational performance; 
2. Specially commissioned oversight agencies;

3. Informal organisations that appointed themselves to oversee the police; and

4. Partners in the criminal justice system.

These are the people who oversee, judge, mandate and monitor the value of police performance.

We then looked to see what attributes of performance interested them. Figure 3 presents the results obtained for New York City. Figure 3 sets out the particular dimensions of police performance particular 'authorisers' in NYC were paying attention to, and indicates the level and consistency of attention each authoriser is giving to a particular dimension of performance.

\section{Figure 3 - What Authorisers of Police Care About}

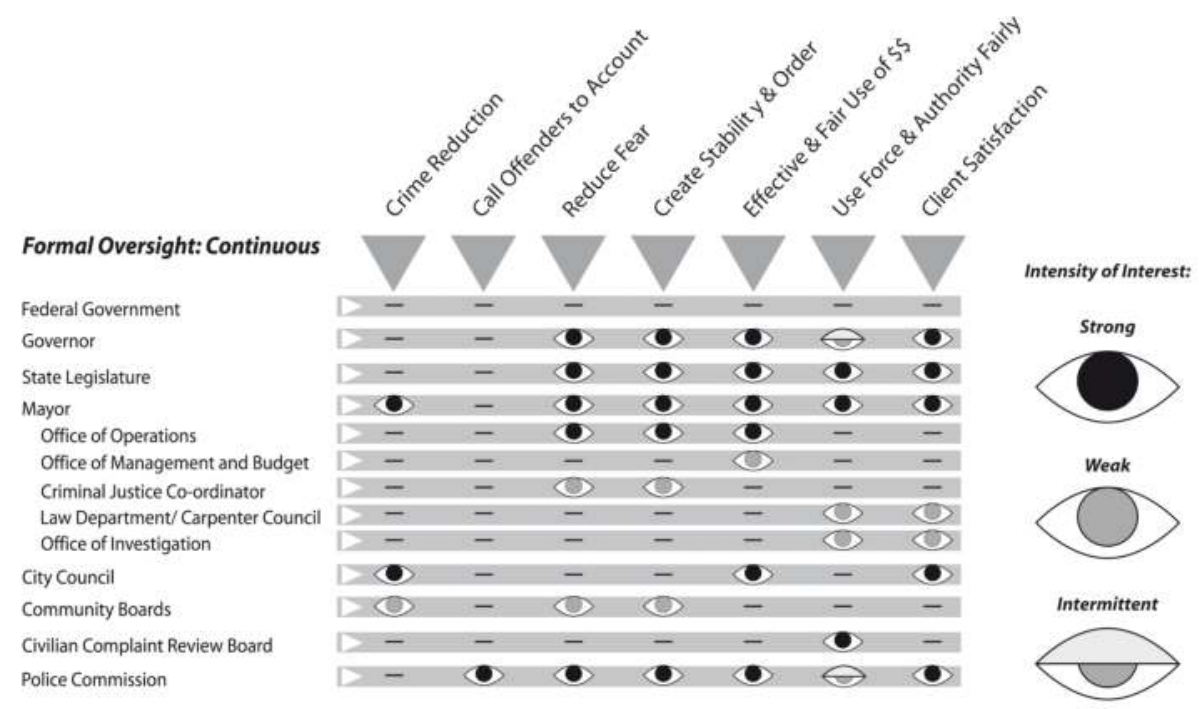

The results presented in this figure suggest, surprisingly, that relatively few people turned out to be worried about 'reducing crime.' An awful lot of attention seems to be focused on increasing a sense of security at the lowest possible cost. This gives both citizens and police managers a different basis on which to consider the social goals of policing, particularly when we understand both that fear is not always highly correlated with real criminal victimisation, and that some citizens are at least as afraid of the police as they are of muggers.

It is always possible that managers of public sector organisations might hold views about which of their organisation's activities create public value that are fundamentally different from those of authorisers and/or clients. This raises a strategic question for managers about how best to develop an external constituency that shares their conception of the public value they are trying to get their organisation to produce. One way for managers to search for such a 
constituency would be to construct a measurement system to monitor a particular activity or feature of performance they think is valuable to see who, if anybody, pays attention to it. This measurement system could become a tool for managing the organisation as well as a tool for delivering the activity in question.

\section{Conclusion}

In conclusion, performance measurement plays an essential role in creating public value through effective strategic management. The work of developing and improving performance measurement systems involves philosophical and normative as well as scientific and cognitive issues. Every time I make a claim that something is valuable, and therefore worth measuring, I make a philosophical/normative claim, not just an empirical/positive claim. Performance measurement is about value. Necessarily, then, performance measurement has important political dimensions beyond its obvious administrative and technical dimensions. This has to be the case because the only place a manager can go to get guidance about public value is the political authorising environment.

The obvious way for a manager to initiate and carry on a dialogue with the political world is to ask those in the political authorising environment what they think is valuable. If managers can engage their political overseers in serious, sustained discussions about the definition of public value, or the publicly valued dimensions of performance for their organisations, then they might be able to come to some conclusions about the definition of public value. Engaging in such a discussion, however, might well expose the manager and his organisation to criticism, and to the risk of a real, objective failure to produce what the public wants.

There are only two things that might motivate a manager to begin working in this risky and murky terrain - to take up the challenge of defining and recognising the creation of public value with the input and oversight of the political authorising environment. The first is that by doing so, one might emerge with a stronger, clearer, more consistent definition of the public value one is being asked to produce. The second is that one might call into existence the conditions under which one can successfully manage and lead one's organisation.

What finally compels managers to construct the systems that will allow them to recognise public value is that it is impossible to live up to the duties of their offices if they do not know what they are trying to produce in sufficiently concrete terms to know whether they are succeeding or not, and if they do not have the measurement tools that allow them to drive performance and seek out the technical means for continuing improvement. Only the strategic use of performance measurement makes such things possible. However, engaging in the task of constructing performance measures always means confronting unresolved conflicts. In the end, it means exposing ourselves and our 
organisations to potential failure. In the face of that, we might fall back in alarm. The only thing that moves us forward is the knowledge that we cannot run organisations without really understanding what constitutes public value and how we contribute to its creation.

\title{
Bibliography and Notes
}

\author{
Mark H. Moore (1995), Creating Public Value: Strategic Management in \\ Government, Harvard University Press.
}

\section{ENDNOTES}

${ }^{1}$ In 1994, William Bratton was appointed the 38th Commissioner of the New York City Police Department by Mayor Rudolph Giuliani. He introduced the CompStat system of tracking crimes, which proved successful in reducing crime in New York City and is still used to this day, but left the job in 1996 after alleged personal conflicts with Giuliani. In 1996, Bratton was featured in a business case prepared by James L. Heskett and published by Harvard Business School. Bratton's efforts to effectively turn around the New York City Police Department is used by many business schools, including Kenan-Flagler Business School, as a tool for teaching organisational design and change. (Source: http:// en.wikipedia.org/wiki/William_J._Bratton)

2 The production possibility frontier (PPF) represents the point at which an economy is most efficiently producing its goods and services and, therefore, allocating its resources in the best way possible. If the economy is not producing the quantities indicated by the PPF, resources are being managed inefficiently and the production of society will dwindle. The production possibility frontier shows there are limits to production, so an economy, to achieve efficiency, must decide what combination of goods and services can be produced. (Source: http://www.investopedia.com/university/economics/economics2.asp) 